\title{
Evaluating Transport and Attenuation of Inorganic Contaminants in the Vadose Zone for Aqueous Waste Disposal Sites
}

\section{September 2015}

MJ Truex

M Oostrom

GD Tartakovsky 


\title{
DISCLAIMER
}

This report was prepared as an account of work sponsored by an agency of the United States Government. Neither the United States Government nor any agency thereof, nor Battelle Memorial Institute, nor any of their employees, makes any warranty, express or implied, or assumes any legal liability or responsibility for the accuracy, completeness, or usefulness of any information, apparatus, product, or process disclosed, or represents that its use would not infringe privately owned rights. Reference herein to any specific commercial product, process, or service by trade name, trademark, manufacturer, or otherwise does not necessarily constitute or imply its endorsement, recommendation, or favoring by the United States Government or any agency thereof, or Battelle Memorial Institute. The views and opinions of authors expressed herein do not necessarily state or reflect those of the United States Government or any agency thereof.

\author{
PACIFIC NORTHWEST NATIONAL LABORATORY \\ operated by \\ BATTELLE \\ for the \\ UNITED STATES DEPARTMENT OF ENERGY \\ under Contract DE-AC05-76RL01830
}

Printed in the United States of America
Available to DOE and DOE contractors from the Office of Scientific and Technical Information,
P.O. Box 62, Oak Ridge, TN 37831-0062;
ph: (865) 576-8401
fax: $(865)$ 576-5728
email: reports@adonis.osti.gov
Available to the public from the National Technical Information Service
5301 Shawnee Rd., Alexandria, VA 22312 ph: (800) 553-NTIS (6847)
email: orders@ntis.gov $<$ http://www.ntis.gov/about/form.aspx $>$
Online ordering: http://www.ntis.gov

This document was printed on recycled paper. 


\title{
Evaluating Transport and Attenuation of Inorganic Contaminants in the Vadose Zone for Aqueous Waste Disposal Sites
}

\author{
MJ Truex \\ M Oostrom \\ GD Tartakovsky
}

September 2015

Prepared for

the U.S. Department of Energy

under Contract DE-AC05-76RL01830 



\section{Summary}

In many cases, inorganic contaminants in aqueous waste solutions disposed of at the land surface must migrate through the vadose zone before entering groundwater. Because of contaminant transport through the vadose zone, the temporal profile of contaminant concentrations entering the groundwater is different than the temporal profile of the aqueous waste disposal. Vadose zone transport mechanisms tend to decrease contaminant concentrations and limit the rate of contaminant movement. In these ways, contaminant concentrations are attenuated during transport of the contaminants through the vadose zone. The temporal profile of contaminant discharge into underlying groundwater defines the contaminant source characteristics with respect to predicting the resulting groundwater plume. Quantifying contaminant attenuation and the resulting temporal profile of contaminant concentrations in underlying groundwater is important for assessing the need for, and type of, remediation in the vadose zone and groundwater. Contaminant transport through the vadose zone beneath aqueous waste disposal sites is affected by two types of attenuation processes: 1) attenuation caused by unsaturated flow and 2) attenuation caused by biogeochemical reactions and/or physical/chemical interaction with sediments. Mixing processes that occur at the interface between the vadose zone and the groundwater system are also important for estimating contaminant concentrations in groundwater resulting from vadose zone contaminant flux.

An approach was developed for evaluating vadose zone transport and attenuation of aqueous wastes containing inorganic (non-volatile) contaminants that were disposed of at the land surface (i.e., directly to the ground in cribs, trenches, tile fields, etc.) and their effect on the underlying groundwater. The approach provides a structured method for estimating transport of contaminants through the vadose zone and the resulting temporal profile of groundwater contaminant concentrations. The intent of the approach is also to provide a means for presenting and explaining the results of the transport analysis in the context of the site-specific waste disposal conditions and site properties, including heterogeneities and other complexities. The document includes considerations related to identifying appropriate monitoring to verify the estimated contaminant transport and associated predictions of groundwater contaminant concentrations. While primarily intended for evaluating contaminant transport under natural attenuation conditions, the approach can also be applied to identify types of, and targets for, mitigation approaches in the vadose zone that would reduce the temporal profile of contaminant concentrations in groundwater, if needed.

A series of simulations were conducted to investigate how different factors affect contaminant transport in the vadose zone and the conditions for which an individual factor is important. This analysis demonstrated that, while water flow and contaminant transport can be complex during and immediately following aqueous-waste disposal activities, these complexities tend to decrease over time after disposal ceases, and fewer factors will control the contaminant transport rate and resulting temporal profile of groundwater contaminant concentrations. Verification that these conditions have been reached can be provided using data describing the vertical profile of moisture content, the temporal profile of recharge at the site, and basic information about waste disposal and subsurface properties. Under these conditions, and with information about specific contaminant transport parameters (e.g., for partitioning), estimates for contaminant transport can be made and used to support remedy decisions.

Several aspects of this approach and associated technical foundations offer new perspectives for evaluation of vadose zone contamination. 
- Contaminant transport behavior can be categorized based on a set of site and waste disposal parameters, using groundwater plume data to corroborate the selection of a category. There are distinct characteristics of the temporal profile of groundwater contamination for each category.

- Some sites are characterized by contaminant discharge from the vadose zone to the groundwater resulting in a single peak of groundwater contamination that, in most cases, will occur in the future. Remedy decisions for these sites will need to consider whether the contaminant discharge from the vadose zone will cause a plume of concern and, if remediation is needed, whether a near-term vadose zone remedy or a later, longer-term groundwater remedy would be more effective.

- Other sites - those with large waste disposal volumes compared to the thickness of the vadose zone - are characterized by contaminant discharge from the vadose zone to the groundwater resulting in two peaks in groundwater contamination: one peak associated with an existing/nearterm plume, and one peak that will occur in the future. Remedy decisions for these sites must consider that, even though groundwater concentrations in the source area are diminishing in the near term (i.e., the decline of the first peak), the contaminant mass discharge from the vadose zone will not decline to zero and will rise again much later as part of the second peak. Thus, near-term remedy decisions must consider the nature and extent of the existing or near-term plume and how a combined vadose zone/groundwater remedy or a groundwater-only remedy can be applied to reach remedial action objectives (RAOs). In addition, remedy decisions for these sites will need to consider the continuing vadose zone source that will occur and, potentially, will be of a higher magnitude than the current source.

- For sites that are expected to exhibit a single peak in groundwater contamination, algebraic equations can be used to estimate the arrival time of the peak groundwater contaminant concentration beneath the vadose zone source and its concentration relative to the disposed concentration. Tabulated values for the duration of the contaminant mass discharge from the vadose zone to the groundwater (between the initial arrival and final elution of $1 \%$ of the peak concentration value) can be used to further estimate the characteristics of the vadose zone source area.

- While nuances in site properties and waste disposal details will affect contaminant transport in the vadose zone, the technical basis for the evaluation approach herein suggests that reasonable estimates of vadose zone transport can be made. That is, transport of contaminants in the vadose zone is predictable under most conditions that are relevant to predicting the future contaminant mass discharge into groundwater from an aqueous waste disposal. In addition, a relatively small set of site and waste disposal parameters are needed to make estimates that will represent the bulk behavior of contaminant mass discharge into the groundwater. 


\section{Acknowledgments}

This document was prepared by the Deep Vadose Zone-Applied Field Research Initiative at Pacific Northwest National Laboratory. Funding for this work was provided by the U.S. Department of Energy (DOE) Richland Operations Office. The Pacific Northwest National Laboratory is operated by Battelle Memorial Institute for the DOE under Contract DE-AC05-76RL01830. 



\section{Acronyms and Abbreviations}

$\begin{array}{ll}\mathrm{cm} & \text { centimeter(s) } \\ \mathrm{CM} & \text { center of mass } \\ \mathrm{d} & \text { day(s) } \\ \text { DOE } & \text { U.S. Department of Energy } \\ \text { EPA } & \text { U.S. Environmental Protection Agency } \\ \mathrm{g} & \text { gram(s) } \\ \mathrm{L} & \text { liter(s) } \\ \mathrm{m} & \text { meter(s) } \\ \mathrm{m}^{2} & \text { square meter(s) } \\ \mathrm{m}^{3} & \text { cubic meter(s) } \\ \mathrm{mm} & \text { millimeter(s) } \\ \mathrm{MNA} & \text { monitored natural attenuation } \\ \mathrm{Pa} & \text { pascal(s) } \\ \text { PNNL } & \text { Pacific Northwest National Laboratory } \\ \text { RAO } & \text { remedial action objective } \\ \text { yr } & \text { year(s) }\end{array}$





\section{Contents}

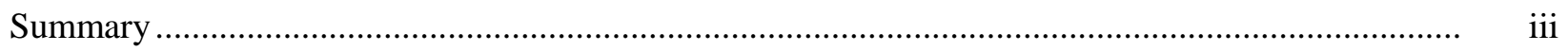

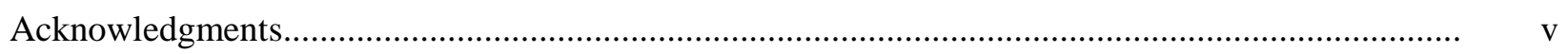

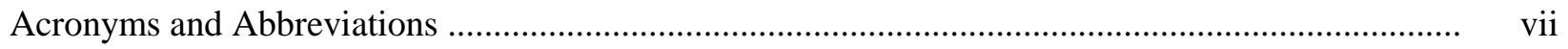

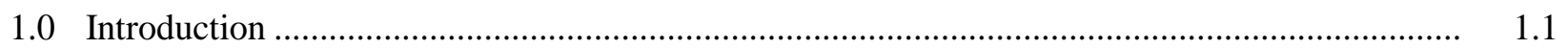

2.0 Flow and Transport of Disposed Aqueous Waste in the Vadose Zone ................................... 2.1

2.1 Vadose Zone Flow and Transport Description............................................................... 2.1

2.2 Groundwater Impact Categories............................................................................. 2.6

3.0 Conceptual Model and Numerical Simulations ........................................................... 3.1

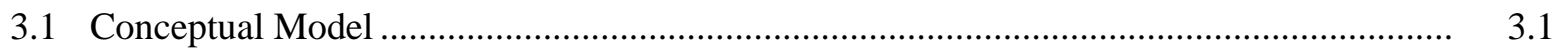

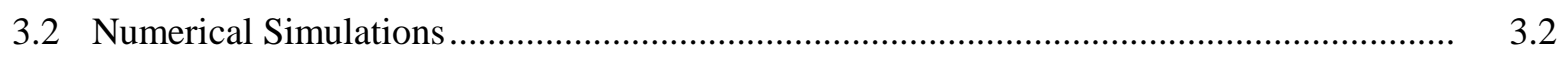

3.3 Computation of Groundwater Concentrations ............................................................ 3.3

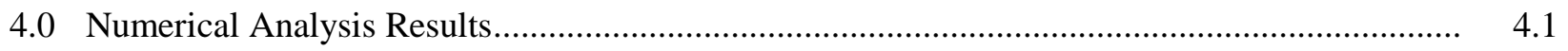

4.1 Vadose Zone Parameters .................................................................................... 4.1

4.1.1 Category I; Homogeneous Subsurface .......................................................... 4.1

4.1.2 Category I; Layered Subsurface ........................................................................ 4.15

4.1.3 Category I: Contaminant Mixing ….............................................................. 4.19

4.2 Waste Disposal Parameters ............................................................................... 4.22

4.2.1 Waste Disposal Volume ................................................................................ 4.22

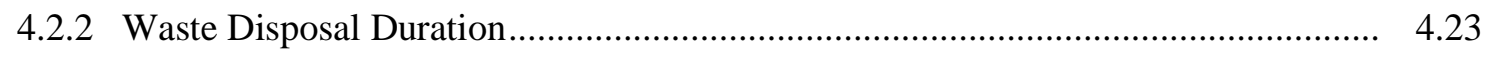

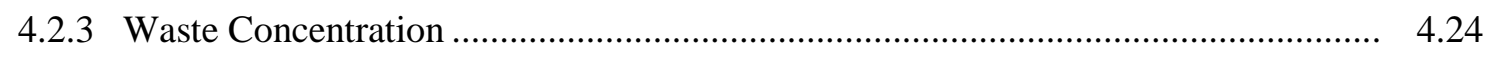

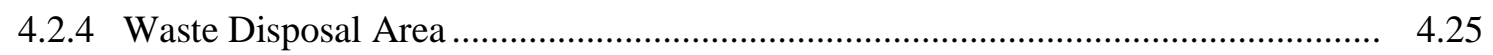

4.3 Transition from Category I to Category II ................................................................... 4.26

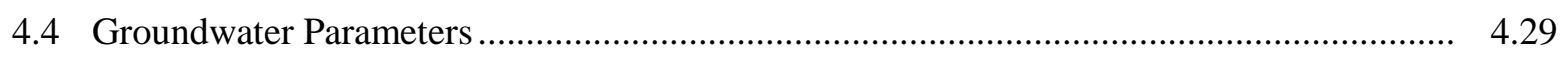

5.0 Evaluation Procedure ................................................................................................... 5.1

5.1 Parameter Value Estimation ................................................................................. 5.1

5.2 Contaminant Distribution Assessment …............................................................. 5.2

5.3 Groundwater Impact Assessment ............................................................................. 5.3

5.4 Travel Time Predictions .............................................................................................. 5.3

5.5 Prediction of Groundwater Concentrations .............................................................. 5.4

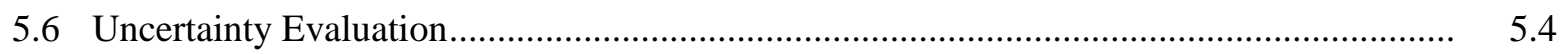

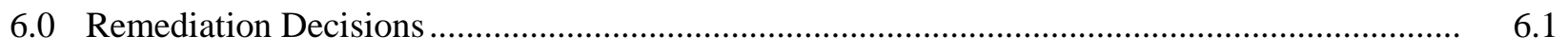

6.1 Context of the Site-Specific Heterogeneities and Other Complexities .............................. 6.1

6.1.1 Non-Uniform Disposal Conditions at a Single Site ........................................... 6.1

6.1.2 Clusters of Waste Disposal Sites with Different Type and Timing of
Disposal Fluids........................................................................................

6.1.3 Large Uncontaminated Water Discharges in the Vicinity of the Waste

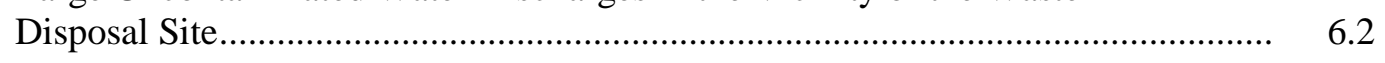


6.1.4 Large-Scale Layered Sequences of Sediments with Contrasting Hydraulic Properties.

6.1.5 Numerous Small-Scale Lenses of Sediments with Contrasting Hydraulic Properties

6.1.6 Tilted Layers or Lenses of Sediments that Promote Lateral Flow during Aqueous Disposal.....

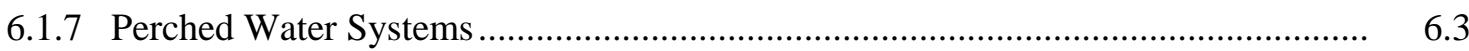

6.1.8 Presence of Features that Can Promote Localized Accelerated Vertical Transport (e.g., Clastic Dikes)

6.1.9 Acidic or Alkaline Waste Fluids

6.1.10 High Ionic Strength Waste Fluids

6.1.11 Dense or Viscous Waste Fluids

6.1.12 Nonaqueous-Phase Liquid Waste Fluids

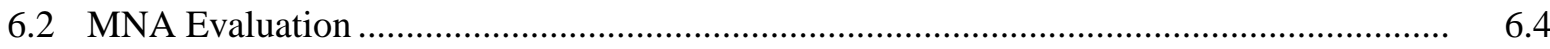

6.2.1 Tier I: Demonstrate that Conditions Are Suitable for Recharge to Be Considered a Primary Driving Force for Contaminant Transport.

Tier I Summary:

6.2.2 Tier II: Determine and Quantify the Factors Attenuating the Contaminant Transport Rate.

Tier II Summary:

6.2.3 Tier III: Determine Temporal Profile of Contaminant Mass Discharge to the Groundwater and Resulting Groundwater Contaminant Concentration Profile

Tier III Summary:

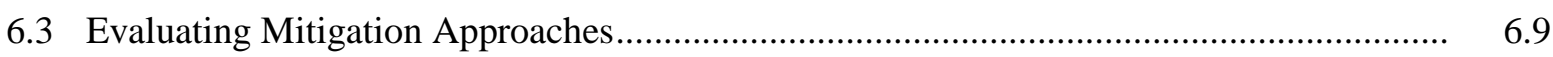

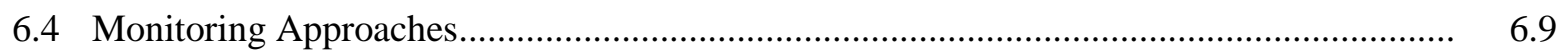

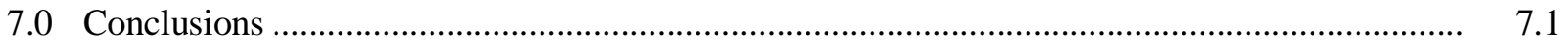

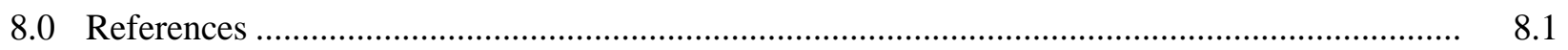

Appendix A - Detailed Simulation Matrices ................................................................................. A.1 


\section{Figures}

2.1. Water content - capillary pressure relationships for sand, sandy loam, and silt according to Eq. (2.5).

2.2. Water content - relative permeability relationships for sand, sandy loam, and silt according Eq. (2.4)

2.3. Contaminant distribution during disposal and at the time of the transport evaluation for Category I, where the disposed volume was not sufficient to cause short-term impact on the groundwater

2.4. Contaminant distribution during disposal and at the time of the transport evaluation for Category II contaminant discharge, where the disposed volume was sufficient to cause a short-term impact on the groundwater

2.5. Example of a transitional case where the waste disposal was sufficient to cause a small near-term contaminant mass discharge to the groundwater but the bulk of the contaminant discharge occurs in the future, similar to a Category I response.

2.6. Heterogeneities in the subsurface may cause skewed contaminant distributions in the subsurface during disposal for Category I and Category II sites

2.7. Multiple disposal events spaced in time (top left) or at adjacent disposal sites may add complexity to the contaminant distribution at the time of transport evaluation

2.8. Different contaminants may be disposed of at the same disposal site as shown in this example during disposal and at the time of transport evaluation.

2.9. Different contaminants may be disposed of at adjacent sites as shown in this example during disposal and at the time of transport evaluation ....

2.10. Layers (or lenses) of contrasting hydraulic properties (e.g., a silt layer within a sandy vadose zone as shown in the above example) can be incorporated into the transport evaluation during disposal and at the time of the transport evaluation.

3.1. Conceptual model for vadose zone flow transport simulations and aquifer direct mixing model

3.2. Side view and top view of mixing model to compute groundwater concentrations from solute discharge rates.

3.3. Groundwater recharge and mass discharge into groundwater over time for sandy loam simulations with $S A_{w d}=25 \mathrm{~m}^{2}, L_{v}=25 \mathrm{~m}, V_{w d}=25 \mathrm{~m}^{3}, D_{w d}=1$ day, $C_{w d}=$ $1 / \mathrm{L}, R=3.5 \mathrm{~mm} / \mathrm{yr}$, and $L_{a}=5 \mathrm{~m}$. The legend denotes years after the waste disposal.

3.4. Simulated mass discharge into groundwater and computed normalized groundwater concentration over time for three solutes with $K_{d}=0,0.1$, and $0.2 \mathrm{~mL} / \mathrm{g}$

4.1. Normalized groundwater concentration over time for $L_{v}=10,25,50$, and $100 \mathrm{~m}$

4.2. Normalized groundwater concentration vs. normalized time $\left(t R /\left(L_{v} \bar{\theta}_{v}\right)\right)$ for $L_{v}=$ $10,25,50$, and $100 \mathrm{~m}$.

4.3. Normalized groundwater concentration over time for $L_{v}=10,25,50$, and $100 \mathrm{~m}$. 
4.4. Normalized groundwater concentration vs. normalized time $\left(t R /\left(L_{v} \bar{\theta}_{v}\right)\right)$ for $L_{v}=$ $10,25,50$, and $100 \mathrm{~m}$

4.5. Relation between predicted and simulated peak arrival times of nonsorbing contaminants for $L_{v}=10,25,50$, and $100 \mathrm{~m}$

4.6. Normalized groundwater concentration over time for $R=3.5,8,25,50$, and 100 $\mathrm{mm} / \mathrm{yr}$.

4.7. Normalized groundwater concentration vs. dimensionless time $\left(t R /\left(L_{v} \bar{\theta}_{v}\right)\right)$ for $R=$ $3.5,8,25,50$, and $100 \mathrm{~mm} / \mathrm{yr}$.

4.8. Relation between predicted and simulated peak arrival times of nonsorbing contaminants for $R=3.5,8,25,50$, and $100 \mathrm{~mm} / \mathrm{yr}$

4.9. Normalized groundwater concentration over time for $n_{v}=0.1,0.2,0.3$, and 0.41

4.10. Normalized groundwater concentration vs. normalized time $\left(t R /\left(L_{v} \bar{\theta}_{v} R_{v c}\right)\right)$ for $n_{v}=0.1,0.2,0.3$, and 0.41

4.11. Relation between predicted and simulated peak arrival times of nonsorbing contaminants with $n_{v}=0.1,0.2,0.3$, and 0.41 for sandy loam and $n_{v}=0.1,0.2$, 0.3 , and 0.43 for sand

4.12. Normalized groundwater concentration over time for solutes with $K_{d}=0,0.1$, and $0.2\left(R_{c v}=1,2.42\right.$, and 3.86)

4.13. Normalized groundwater concentration vs. normalized time $\left(t R /\left(L_{v} \bar{\theta}_{v} R_{c v}\right)\right)$ for solutes with $K_{d}=0,0.1$, and $0.2\left(R_{v c}=1,2.42\right.$, and 3.86).

4.14. Relation between predicted and simulated peak arrival times for three solutes with $K_{d}=0.0,0.1$, and $0.2 \mathrm{~mL} / \mathrm{g}$

4.15. Normalized groundwater concentration over time for $R=3.5,8,25,50$, and 100 $\mathrm{mm} / \mathrm{yr}$ with the initial $C / C_{o}=1.0$ between $z=10$ and $15 \mathrm{~m}(C M$ is at $z=12.5 \mathrm{~m})$

4.16. Normalized groundwater concentration vs. normalized time $\left(t R /\left(L_{v} \bar{\theta}_{v} R_{c v}\right)\right)$ for $R$ $=3.5,8,25,50$, and $100 \mathrm{~mm} / \mathrm{yr}$ with the initial $C / C_{o}=1.0$ between $z=10$ and $15 \mathrm{~m}$ $(C M$ is at $z=12.5 \mathrm{~m})$.

4.17. Normalized groundwater concentration versus time for two $5 \mathrm{~m}$ thick contaminated zones where the initial $C / C_{o}=1.0$

4.18. Normalized groundwater concentration over time/CM for two $5 \mathrm{~m}$ thick contaminated zones where the initial $C / C_{o}=1.0$

4.19. Peak arrival travel time from a waste disposal site to depth $z(\mathrm{~m})$ under steady-state, recharge-dominated conditions with $R=50 \mathrm{~mm} /$ year $(0.05 \mathrm{~m} /$ year $)$

4.20. Normalized groundwater concentration over time for $L_{v}=10,25,50$, and $100 \mathrm{~m}$

4.21. Normalized groundwater concentration vs. dimensionless time $\left(t R /\left(L_{v} \bar{\theta}_{v} R_{c v}\right)\right)$ for $L_{v}=10,25,50$, and $100 \mathrm{~m}$. 
4.22. Relation between predicted and simulated peak arrival times of nonsorbing contaminants for $L_{v}=10,25,50$, and $100 \mathrm{~m}$

4.23. Normalized groundwater concentration over time for $R=3.5,8,25,50$, and 100 $\mathrm{mm} / \mathrm{yr}$

4.24. Normalized groundwater concentration vs. dimensionless time $\left(t R /\left(L_{v} \bar{\theta}_{v} R_{v c}\right)\right)$ for $R=3.5,8,25,50$, and $100 \mathrm{~mm} / \mathrm{yr}$.

4.25. Relation between predicted and simulated peak arrival times of nonsorbing contaminants for $R=3.5,8,25,50$, and $100 \mathrm{~mm} / \mathrm{yr}$

4.26. Normalized groundwater concentration over time for various diffusion coefficients $\left(D_{o}=2.5 \mathrm{e}-5 \mathrm{~cm}^{2} / \mathrm{s}\right.$

4.27. Normalized time $\left(t R /\left(L_{v} \bar{\theta}_{v} R_{v c}\right)\right)$ versus $L_{v}$ for contaminant arrival, peak, and elution times

4.28. Normalized groundwater concentration over time for $V_{w d}=1,2,5$, and $10 \mathrm{~m}^{3}$.

4.29. Normalized groundwater concentration over time/ $V_{w d}$ for $V_{w d}=1,2,5$, and $10 \mathrm{~m}^{3}$

4.30. Normalized groundwater concentration over time for $D_{w d}=1,2,5$, and 10 days

4.31. Normalized groundwater concentration over time for $C_{w d}=1,2,5$, and $101 / \mathrm{L}$

4.32. Normalized groundwater concentration over time for $S A_{w d}=1,10,25$ and $100 \mathrm{~m}^{2}$.

4.33. Normalized groundwater concentration over time for different waste disposal volumes with the same mass. The numbers in the legend denote $V_{w d}\left(\mathrm{~m}^{3}\right)$ and $C_{w d}(1 / \mathrm{L})$

4.34. Comparison of Category I and II normalized groundwater concentrations over time for different waste scenarios with the same mass

4.35. Normalized groundwater concentration over time for different waste disposal times with the same mass. The numbers in the legend denote the disposal time

4.36. Peak contaminant arrival time as a function of $V_{w d}\left(\mathrm{~m}^{3}\right)$ for $L_{v}=10,25,50$, and $100 \mathrm{~m}$.

4.37. Normalized groundwater concentration over time for $q_{a}=0.3,0.6,1.5$ and 3.0 $\mathrm{m} / \mathrm{d}$

4.38. Normalized groundwater concentration over time for $L_{a}=5,10$, and $20 \mathrm{~m}$

4.39. Normalized groundwater concentration over time for $n_{v}=0.1,0.2,0.3$, and 0.41

4.40. Normalized groundwater concentration over time for $K_{d}=0,0.1$, and $0.2\left(R_{a c}\right.$ $=1,1.38$, and 1.76)

6.1. Attenuation mechanisms for inorganic contaminants in the vadose zone and factors that can impact attenuation. 


\section{Tables}

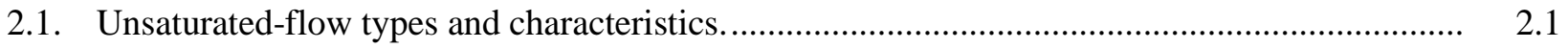

3.1. Primary data needs for the evaluation method. .................................................................. 3.2

3.2. Hydraulic properties of the sediments used in the STOMP simulations................................. 3.3

3.3. Input values for vadose zone and waste disposal parameters ................................................ 3.3

4.1. Simulated ranges in $T_{c a}: T_{c p}$ and $T_{c e}: T_{c p}$ ratios for Category I disposal events....................... 4.21

6.1. Summary of the EPA Protocol tiered MNA assessment for groundwater plumes.................... 6.5

6.2. Summary of the tiered transport and attenuation assessment for inorganic contaminants in the vadose zone. 


\subsection{Introduction}

In many cases, inorganic contaminants in aqueous waste solutions disposed of at the land surface must migrate through the vadose zone before entering groundwater. Because of contaminant transport through the vadose zone, the temporal profile of contaminant concentrations entering the groundwater is different than the temporal profile for aqueous waste disposal. Vadose zone transport mechanisms tend to decrease contaminant concentrations and limit the rate of contaminant movement. In these ways, contaminant concentrations are attenuated during transport of the contaminants through the vadose zone. The temporal profile of contaminant discharge into underlying groundwater defines the contaminant source characteristics with respect to predicting the resulting groundwater plume. At sites where inorganic contaminants in aqueous waste solutions have been disposed of at the land surface and a groundwater plume is still evolving or has not yet emerged, methods to evaluate vadose zone contaminant transport are needed to estimate the future temporal profile of contaminant discharge to the groundwater. This estimate can be used to support remedy decisions for the vadose zone and groundwater.

This document provides an approach for evaluating vadose zone transport and attenuation of aqueous wastes containing inorganic (non-volatile) contaminants that were disposed of at the land surface (i.e., directly to the ground in cribs, trenches, tile fields, etc.) and the resultant effect on underlying groundwater. The approach provides a structured method for estimating transport of contaminants through the vadose zone and the temporal profile of groundwater contaminant concentrations in the resulting source area. The intent of the approach is also to provide a means for presenting and explaining the results of the transport analysis in the context of the site-specific waste disposal conditions and site properties, including heterogeneities and other complexities. This document includes considerations related to identifying appropriate monitoring to verify the estimated contaminant transport and associated predictions of groundwater contaminant concentrations. While primarily intended for evaluating contaminant transport under natural attenuation conditions, the approach can also be applied to identify types of, and targets for, mitigation approaches in the vadose zone that would reduce the temporal profile of contaminant concentrations in groundwater, if needed. The evaluation approach herein builds on concepts presented by Truex and Carroll (2013) by providing a quantitative analysis useful to estimate future contaminant mass discharge from the vadose zone to the groundwater. Multi-dimensional simulation results were interpreted to provide insight into vadose zone transport behavior and define appropriate transport analysis approaches.

In Section 2, vadose zone transport processes are described as a foundation for the evaluation method. Multiple scenarios for waste disposal are considered and grouped into groundwater impact categories as a means to help structure the evaluation approach. A series of simulations was applied to investigate how different factors affect contaminant transport in the vadose zone and the conditions for which an individual factor is important. Sections 3 and 4 describe the simulations and the factors that were found to be important in estimating transport of contaminants through the vadose zone. This information supports the steps in the evaluation approach described in Section 5. Section 6 provides information associated with using the vadose zone evaluation in support of remedy decisions. This information includes considerations for interpreting and implementing the results of the evaluation. Conclusions are presented in Section 7. 



\subsection{Flow and Transport of Disposed Aqueous Waste in the Vadose Zone}

This section provides background for the pertinent vadose zone flow and transport behavior and related equations (Section 2.1). Section 2.2 describes the categories of disposed contaminant behavior in terms of the characteristics of how contaminants are transported through the vadose zone and into groundwater.

\subsection{Vadose Zone Flow and Transport Description}

The vadose zone, sometimes called the unsaturated zone or zone of aeration (Nimmo 2005), is a buffer zone between the land surface and underlying aquifers and often acts as a controlling agent in the transport of contaminants and aquifer recharging water. Unsaturated-flow phenomena have different levels of complexity, depending on the flow type. Not considering highly complex preferential flow within the vadose zone, the three main types of unsaturated flow are static (no flow), steady-state flow, and unsteady (diffuse) flow. The main characteristics of these three flow types are presented in Table 2.1.

Table 2.1. Unsaturated-flow types and characteristics.

\begin{tabular}{|c|c|c|c|}
\hline Flow Type & Phenomena & $\begin{array}{l}\text { Mathematical } \\
\text { Description }\end{array}$ & $\begin{array}{l}\text { Relevant } \\
\text { Features and } \\
\text { Properties }\end{array}$ \\
\hline Static & All forces balance (no flow) & Hydrostatic equation & Water retention \\
\hline Steady-state & $\begin{array}{l}\text { Flow driven by unchanging } \\
\text { fluid pressures }\end{array}$ & Darcy's Law (Eq. 2.2) & $\begin{array}{l}\text { Water retention and } \\
\text { hydraulic conductivity }\end{array}$ \\
\hline Unsteady (diffuse) & Dynamic force fields & Continuity Equation (Eq. 2.1) & $\begin{array}{l}\text { Water retention and } \\
\text { hydraulic conductivity }\end{array}$ \\
\hline
\end{tabular}

For most subsurface conditions, the unsteady flow type is applicable. However, when long-term boundary conditions, such as surface recharge and water table locations, are relatively constant, steadystate flow may be appropriate. The time it takes for steady-state conditions to develop depends to a large degree on the vadose zone thickness and the change in recharge rate. Truex et al. (2015) demonstrated that for a $100 \mathrm{~m}$ thick vadose zone, it takes less than 50 years to obtain steady-state conditions throughout the vadose zone for a recharge rate change from $3.5 \mathrm{~mm} / \mathrm{yr}$ (shrub-steppe vegetation) to $92 \mathrm{~mm} / \mathrm{yr}$ (gravel backfill surface).

Unsteady flow is described with the continuity equation

$$
\frac{\partial \theta_{w}}{\partial t}=-\nabla q_{w}
$$

where $\theta_{w}(-)$ is the water moisture content, $t(\mathrm{~T})$ is time, and $q_{w}\left(\mathrm{LT}^{-1}\right)$ is the Darcy velocity. For steadystate conditions, $\theta_{w}$ does not change over time and the Darcy velocity is a constant. Darcy's Law can be written as 


$$
q_{w}=-\frac{k k_{r}}{\mu_{w}}\left[\nabla P_{w}+\rho_{w} g z\right]
$$

where

$$
\begin{aligned}
\mathrm{k}(\mathrm{L} 2) & =\text { the permeability, } \\
k_{r} & =\text { the relative permeability, } \\
\mu \mathrm{w} & =\text { the water viscosity (MT-1L-1), } \\
P_{w} & =\text { the water pressure (MT-2L-1), } \\
\rho_{w} & =\text { the density (ML-3), } \\
\mathrm{g} & =\text { the gravitational acceleration (LT-2), and } \\
\mathrm{z}(\mathrm{L}) & =\text { the vertical direction. }
\end{aligned}
$$

For vertical flow during recharge-dominated conditions, Eq. (2.2) can be written as

$$
q_{w}=-\frac{k k_{r}}{\mu_{w}}\left[\frac{d P_{w}}{d z}+\rho_{w} g\right]
$$

The application of Darcy's Law for unsaturated conditions (Eqs. (2.2) and (2.3)) is far more complex than for saturated systems because of the nonlinear $\theta_{w}-P_{w}$ and $\theta_{w}-k_{r}$ relations. The $\theta_{w}$ in the vadose zone is a strong function of the capillary pressure, $P_{c}$, defined as the difference between the ambient air pressure and the water pressure, $P_{c}=P_{g}-P_{w}$, which is positive for unsaturated conditions. A widely used $\theta_{w}-P_{c}$ relation was introduced by van Genuchten (1980):

$$
\bar{\theta}_{w}=\left[1+\left(\alpha P_{c}\right)^{m_{1}}\right]^{-m_{2}}
$$

where $\bar{\theta}_{w}=\left(\theta_{w}-\theta_{r}\right) /\left(n-\theta_{r}\right), \alpha\left(\mathrm{MT}^{-2} \mathrm{~L}^{-1}\right)$ is roughly the inverse of the entry pressure, and $m_{1}$ and $m_{2}$ (where $m_{2}=1-1 / m_{1}$ ) are pore-geometry fitting parameters. $\theta_{r}$ is the residual water content, denoting the water content where $k_{r}$ approaches zero, and $n$ is the porosity. For constant air pressures, Eq. (2.4) defaults to a $\theta_{w}-P_{w}$ relation. The relation between water content and capillary pressure, such as Eq. 2.4, is often called a water retention curve and depends on the porous medium. A sediment with many large pores will decrease rapidly to low $\theta_{w}$ when $P_{c}$ increases. On the other hand, a sediment with a considerable amount of small pores will retain water even at large $P_{c}$ values. To illustrate nonlinear $\theta_{w}-P_{c}$ behavior, water retention curves were obtained for relations for sand, sandy loam, and silt using Eq. (2.4) (Figure 2.1). The curves show that the finer-grained silt retains more water than the coarsergrained sand and sandy loam at the same capillary pressure. The sand curve is relatively flat, indicating a rapid desaturation when $P_{c}$ increases. 


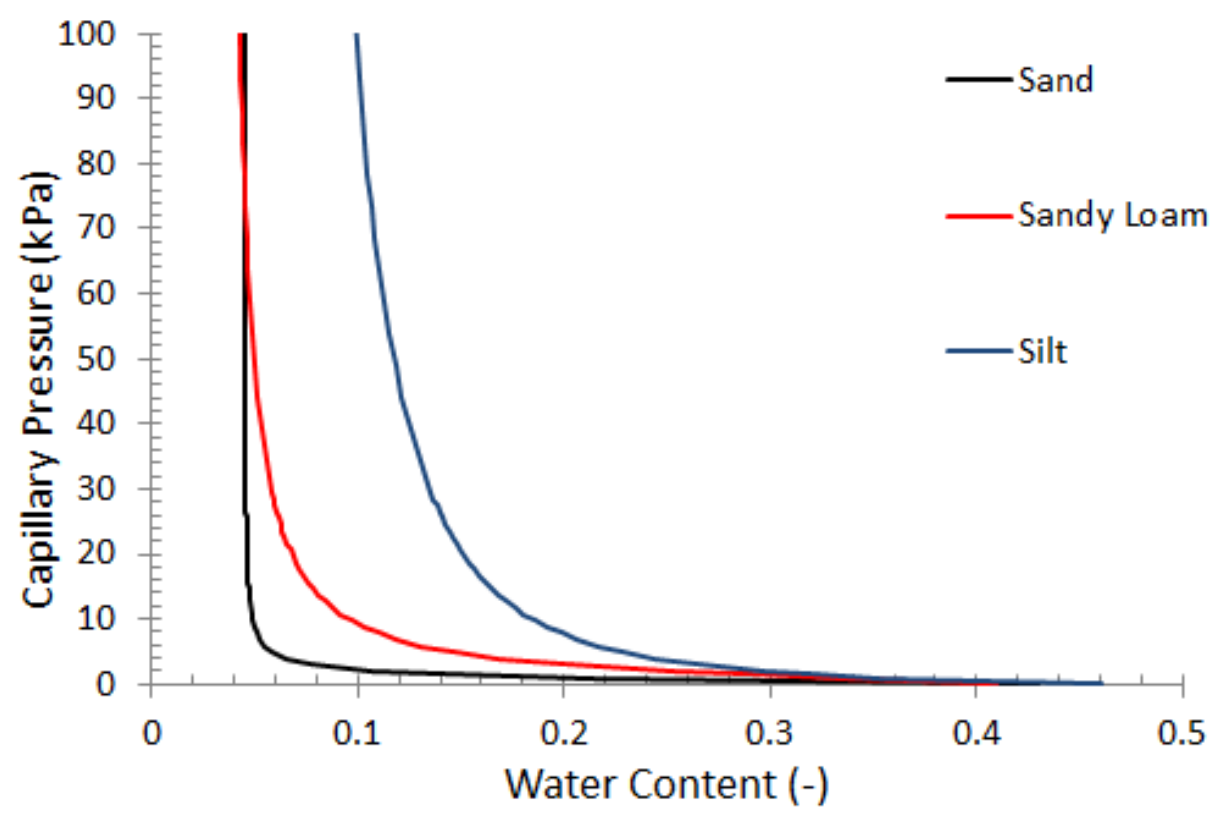

Figure 2.1. Water content - capillary pressure relationships for sand, sandy loam, and silt according to Eq. (2.5). The retention parameter values are obtained from Carsel and Parrish (1988).

In Darcy's Law (Eqs. (2.2) and (2.3)), the permeability $k$ is a porous medium property. The relative permeability, $k_{r}$, is a strong function of the water content, $\theta_{w}$. When $\theta_{w}$ decreases, the larger pores, which make by far the largest contribution to $k_{r}$, empty first. When water drainage continues, the affected pores are smaller and less conductive because there is more viscous friction. In addition, the flow path becomes more tortuous. Under relatively dry conditions, very few pores are filled with water and water flow mainly occurs through a poorly conducting film that adheres to the soil particles. These factors result in a decrease in $k_{r}$ by several factors as the soil goes from saturation to field conditions. In numerical models for vadose zone flow, the Mualem (1976) equation is often used:

$$
k_{r}=\left(\frac{\bar{\theta}_{w}}{n}\right)^{1 / 2}\left(1-\left[1-\left(\frac{\bar{\theta}_{w}}{n}\right)^{1 / m_{2}}\right]^{m_{2}}\right)^{2}
$$

where $n(-)$ is the porosity and $m_{2}$ is fitting parameter obtained from the capillary pressure relation (Eq. (2.4)). Mualem's equation (Eq. 2.5) was used to compute $k_{r}-\theta_{w}$ relations for sand, sandy loam, and silt (Figure 2.2). The figure shows that $k_{r}$ indeed decreases by several orders of magnitude during water drainage from full saturation to dry conditions. For a given water content, the silt $k_{r}$ is the smallest, followed by sandy loam and sand. This behavior is the result of the shape of the capillary pressure relation (Figure 2.1), which show a much more gradual desaturation of silt compared to the other two porous media. 


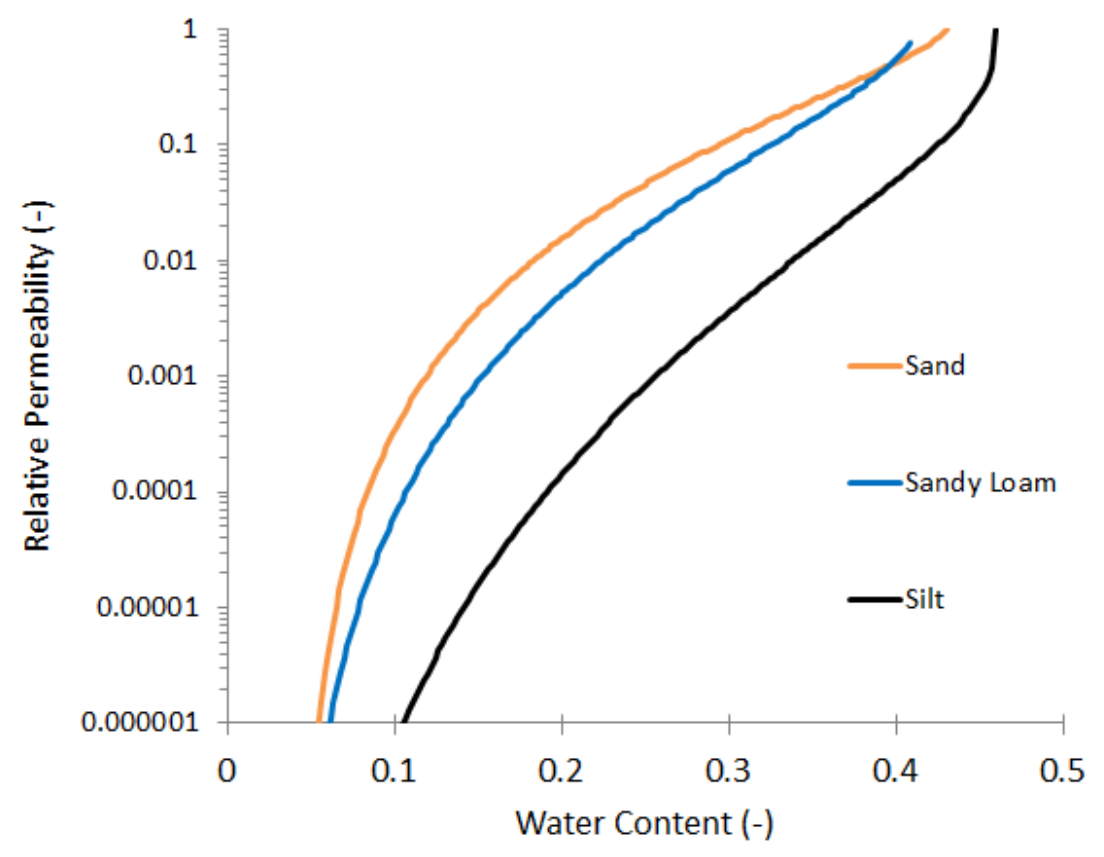

Figure 2.2. Water content - relative permeability relationships for sand, sandy loam, and silt according Eq. (2.4). The retention parameter values are obtained from Carsel and Parrish (1988).

Contaminant transport in the vadose zone is strongly related to flow. The two major transport processes are advection and hydrodynamic dispersion, including mechanical dispersion and molecular diffusion. Due to hydrodynamic dispersion, contaminant transport is typically non-steady and is represented by a continuity equation, such as

$$
\frac{\partial\left(R_{c} C_{w}\right)}{\partial t}=\nabla\left(q_{w} C_{w}\right)+\nabla\left[\left(\theta_{w} D_{m e}^{c}+\tau \theta_{w} D_{o}^{c}\right) \nabla C_{w}\right]-\dot{R}^{C} C_{w}
$$

where advective transport and hydrodynamic transport are represented by the first and second term on the right-hand side, respectively. In Eq. (2.6), $C_{w}$ is the contaminant concentration in water $\left(\mathrm{ML}^{-3}\right), R_{c}$ is the retardation coefficient, $D_{m e}^{c}$ is the mechanical dispersion coefficient $\left(\mathrm{L}^{2} \mathrm{~T}^{-1}\right), D_{o}^{c}$ is the molecular diffusion coefficient $\left(\mathrm{L}^{2} \mathrm{~T}^{-1}\right), \tau(-)$ is the tortuosity, and $\dot{R}^{C}\left(\mathrm{~T}^{-1}\right)$ is a reaction term to include biodegradation, hydrolysis, and (radioactive) decay. Assuming equilibrium sorption, $R_{c}$ can be expressed as a linear Freundlich relation:

$$
R_{c}=1+\frac{\rho_{s}(1-n) K_{d}}{\theta_{w}}
$$

where $\rho_{s}$ is the particle density $\left(\mathrm{ML}^{-3}\right)$, and $K_{d}\left(\mathrm{~L}^{3} \mathrm{M}^{-1}\right)$ is the partitioning coefficient. The tortuosity coefficient, $\tau$, is typically represented by a relation proposed by Millington and Quirk (1959):

$$
\tau=\theta_{w}{ }^{7 / 3} / n^{2}
$$


The relation between transport and flow is apparent for advective transport in Eq. (2.6). In addition, the mechanical dispersion coefficient, $D_{m e}^{c}$, is often related to Darcy Law as follows:

$$
D_{m e, L}^{c}=\alpha_{L} q_{w} / n ; D_{m e, T}^{c}=\alpha_{T} q_{w} / n
$$

where the subscripts $L$ and $T$ denote the longitudinal and transverse direction for dispersivities $\alpha(\mathrm{L})$.

The strong relationship between unsaturated flow and transport, as shown in Eq. (2.6), has important consequences. Even when flow is considered to be steady, as in recharge-dominated systems, transport is often unsteady due to hydrodynamic dispersion. However, when the flow direction in such systems is predominantly in a vertical downward direction, the peak arrival time of contaminants from relative small disposal volumes may be predicted using an expression with just a few basic parameter values:

$$
t_{p}=\frac{L_{v} \bar{\theta}_{w} R_{c}}{R}
$$

where $\quad \begin{aligned} t_{p} & =\text { the peak travel time }(\mathrm{T}), \\ L_{v} & =\text { the vadose zone thickness, } \\ \bar{\theta}_{w} & =\text { the average moisture content in the vadose zone, and } \\ \mathrm{R} & =\text { the surface recharge (LT-1). }\end{aligned}$

For a layered vadose zone, the contaminant peak travel times may be estimated by

$$
t_{p}=\sum_{l=1}^{n} \frac{L_{v j} \bar{\theta}_{w j} R_{c}}{R} \text { for } j=1, n
$$

where $L_{v j}(\mathrm{~L})$ is the layer thickness and $\bar{\theta}_{w j}$ is the average moisture content of layer $j$ in the vadose zone.

The actual peak travel times are expected to be slightly shorter than the predicted travel times using either Eq. (2.10) or (2.11) because of the discharge volumes and soil moisture in the capillary fringe. The concentration spreading around the peak arrival time is affected by hydrodynamic dispersion. The effects of diffusion coefficient, tortuosity term, and dispersivity values need to be investigated for such systems.

Another important feature of flow and transport in the vadose zone is the phenomenon that disposed water tends to migrate ahead of the contaminant it originally contained. In unsaturated systems, water occupies the smallest pores and air the largest. When water migrates downward or laterally after disposal, water enters the largest of the pores that are not occupied by water. During this time, the contaminant migrating with the water is assumed to be evenly distributed over all of the pores. As an example, consider a $1 \mathrm{~m}^{3}$ volume of unsaturated soil with a porosity of 0.4 and $\theta_{w}$ equal to 0.2 . This means that for this example, $200 \mathrm{~L}$ of water $\left(0.2 \mathrm{~m}^{3}\right)$ occupies $50 \%$ of the pore space. Next, assume that $50 \mathrm{~L}$ of water 
$\left(0.05 \mathrm{~m}^{3}\right)$, with a solute concentration of $1 \mathrm{~g} / \mathrm{L}$, is added to this volume. The addition results in a $\theta_{w}$ increase from 0.2 to 0.25 as the water volume increases from 200 to $250 \mathrm{~L}$. During this step, $50 \mathrm{~g}$ of solute is added with the $50 \mathrm{~L}$ of water. After the addition, the $50 \mathrm{~g}$ of solute is now residing in $250 \mathrm{~L}$ of water, reducing the concentration by a factor five from $10 \mathrm{~g} / \mathrm{L}$ to $0.2 \mathrm{~g} / \mathrm{L}$. If $50 \mathrm{~L}$ of this water migrates downwards, resulting in a similar $\theta_{w}$ change, the concentration will again decrease by a factor five from $0.2 \mathrm{~g} / \mathrm{L}$ to $0.04 \mathrm{~g} / \mathrm{L}$. This example shows that vadose zone dilution might be a relatively fast process, separating contamination from the water it was originally disposed in. The dilution effect is enhanced by retardation and is often encountered in unsaturated contaminant transport.

\subsection{Groundwater Impact Categories}

Mass discharge from vadose zone sources into groundwater may be the result of numerous disposal scenarios. A number of them are illustrated in this section. When relative small volumes are disposed of in the vadose zone, the disposed volume is not sufficient to cause short-term contaminant impact on the groundwater. The contaminant arrives later and the mass discharge is characterized by a nearly symmetric single-peak elution curve. Contaminant transport largely occurs through recharge, enabling the application of Eqs. (2.10) and (2.11). For a contaminant with this transport behavior, the disposal site is characterized as a Category I site. The disposal volumes associated with this category are relative to the vadose zone size and do not have to be small in absolute terms. For instance, Truex et al. (2015) identify Category I sites for disposal of several million liters of wastewater over a 2-3 month period in a $100 \mathrm{~m}$ thick vadose zone.

When the disposed volume is sufficient to cause short-term impacts on groundwater, part of the contaminant mass is discharged into the groundwater quickly after (or during) disposal. During this period some contaminant also migrates laterally in the vadose zone due to advection and hydrodynamic dispersion. This process results in some contaminant mass in the vadose zone that will be discharged into the groundwater after the main discharge subsides. Elution curves for this type of disposal are characterized by an initial peak, representing the immediate impact on groundwater, and a second peak representing the impact of contaminant not transported by the initial pulse. For a contaminant with this discharge behavior, the disposal site is characterized as a Category II site. Some sites may have contaminants with both Category I and Category II waste disposal characteristics. This situation might arise when multiple waste disposals occurred with different volumes. Another scenario when both categories are represented may be when a sorbing and a nonsorbing contaminant are in the same highvolume waste disposal; in such a case the sorbing contaminant leads to a Category I mass discharge, and the nonsorbing contaminant results in a Category II mass discharge. However, in some instances, the observed mass discharge behavior may be characterized by a nonsymmetric single-peak elution curve, indicating a condition in between Category I and II.

Figure 2.3 through Figure 2.10 depict several examples of both Category I and II conditions. These examples show conceptual diagrams and associated plots of solute discharge from the vadose zone to the groundwater. Details of how the solute discharge plots were developed are provided in Section 3. 

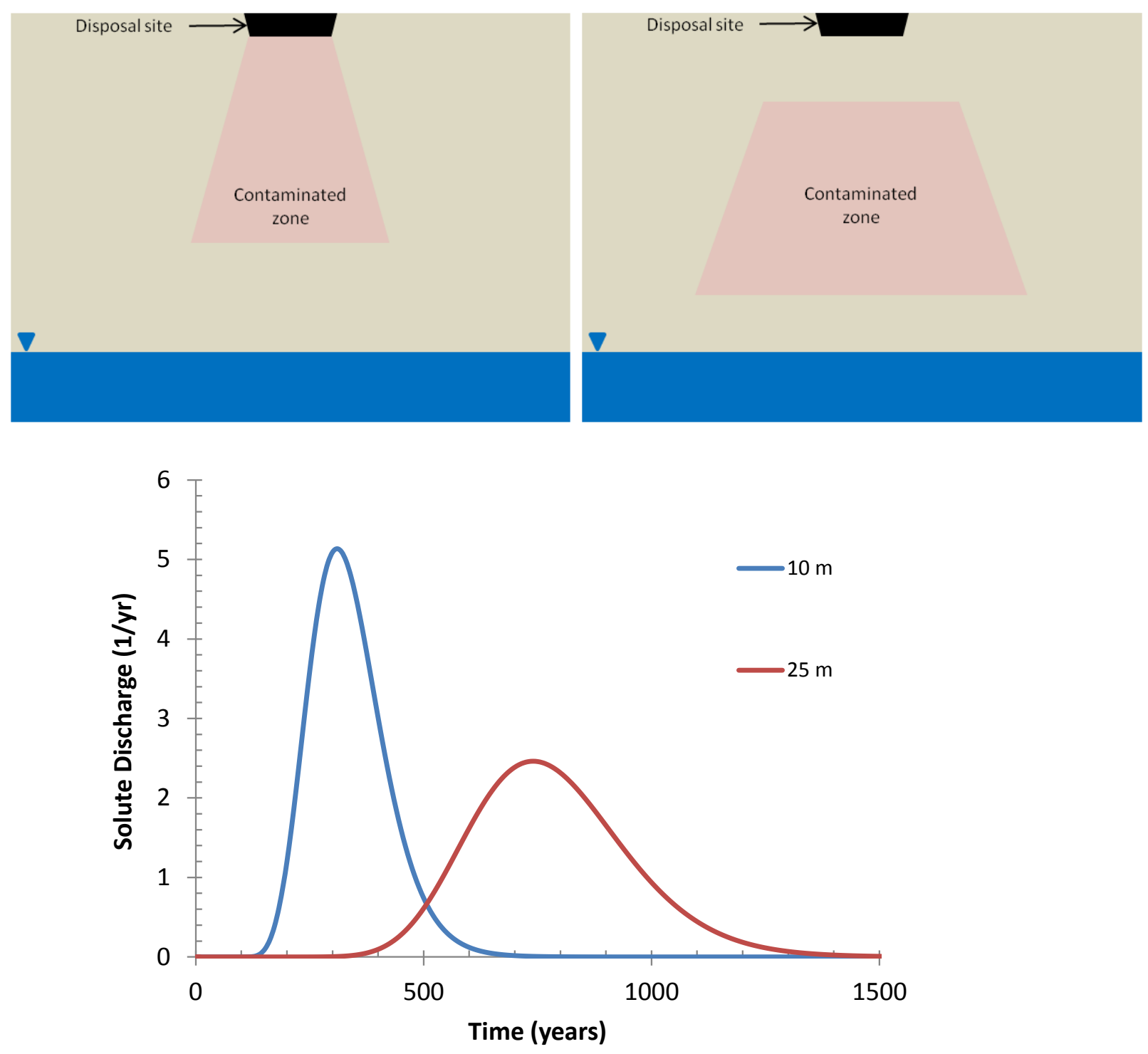

Figure 2.3. Contaminant distribution during disposal (top left) and at the time of the transport evaluation (top right) for Category I, where the disposed volume was not sufficient to cause short-term impact on the groundwater. In the bottom figure, typical example plots of solute discharge into groundwater for this scenario are shown for two vadose zone thicknesses. 

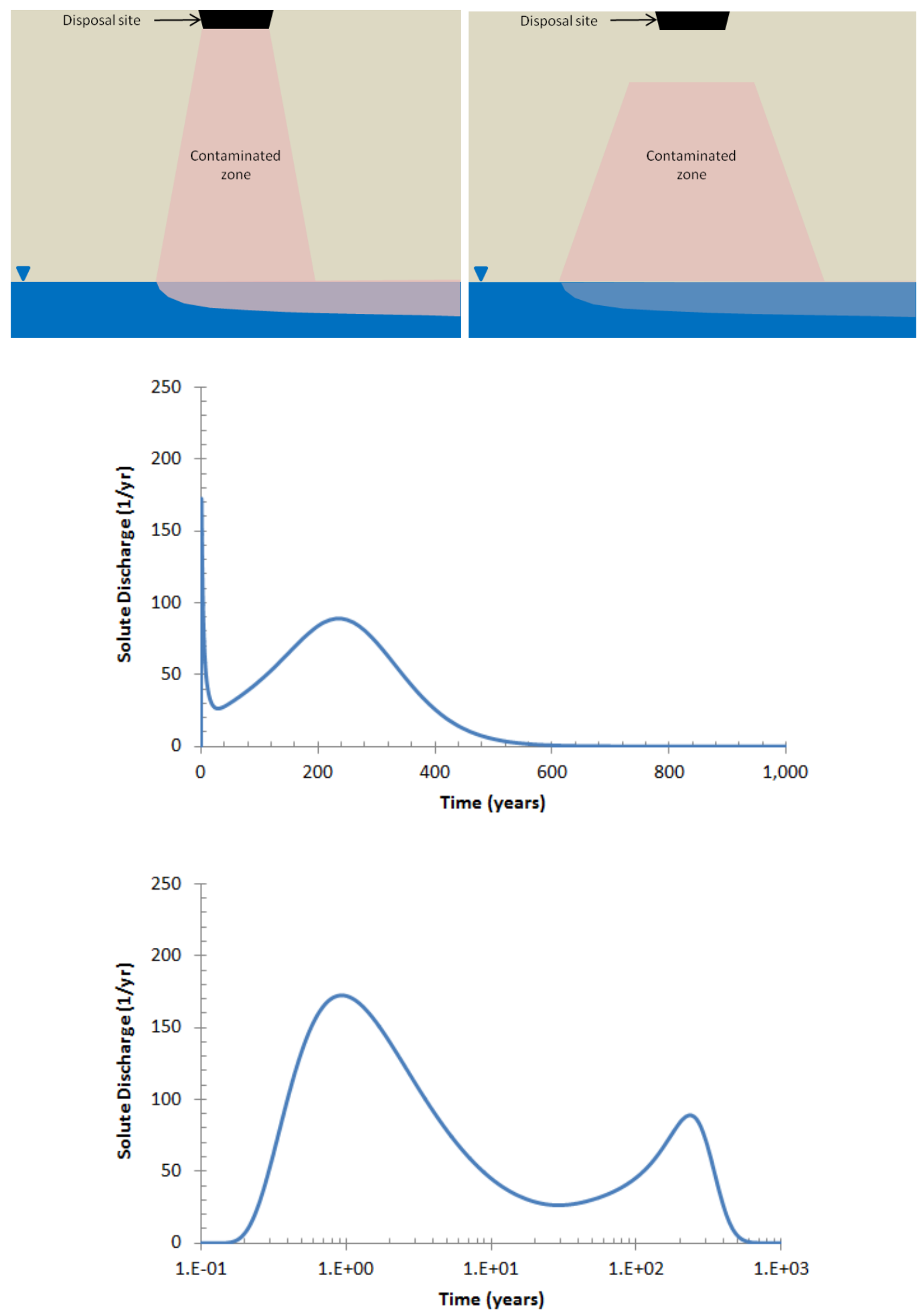

Figure 2.4. Contaminant distribution during disposal (top left) and at the time of the transport evaluation (top right) for Category II contaminant discharge, where the disposed volume was sufficient to cause a short-term impact on the groundwater. In the middle and bottom figures, a typical example plot of solute discharge into groundwater for this scenario is shown with linear and logarithmic time scales. 


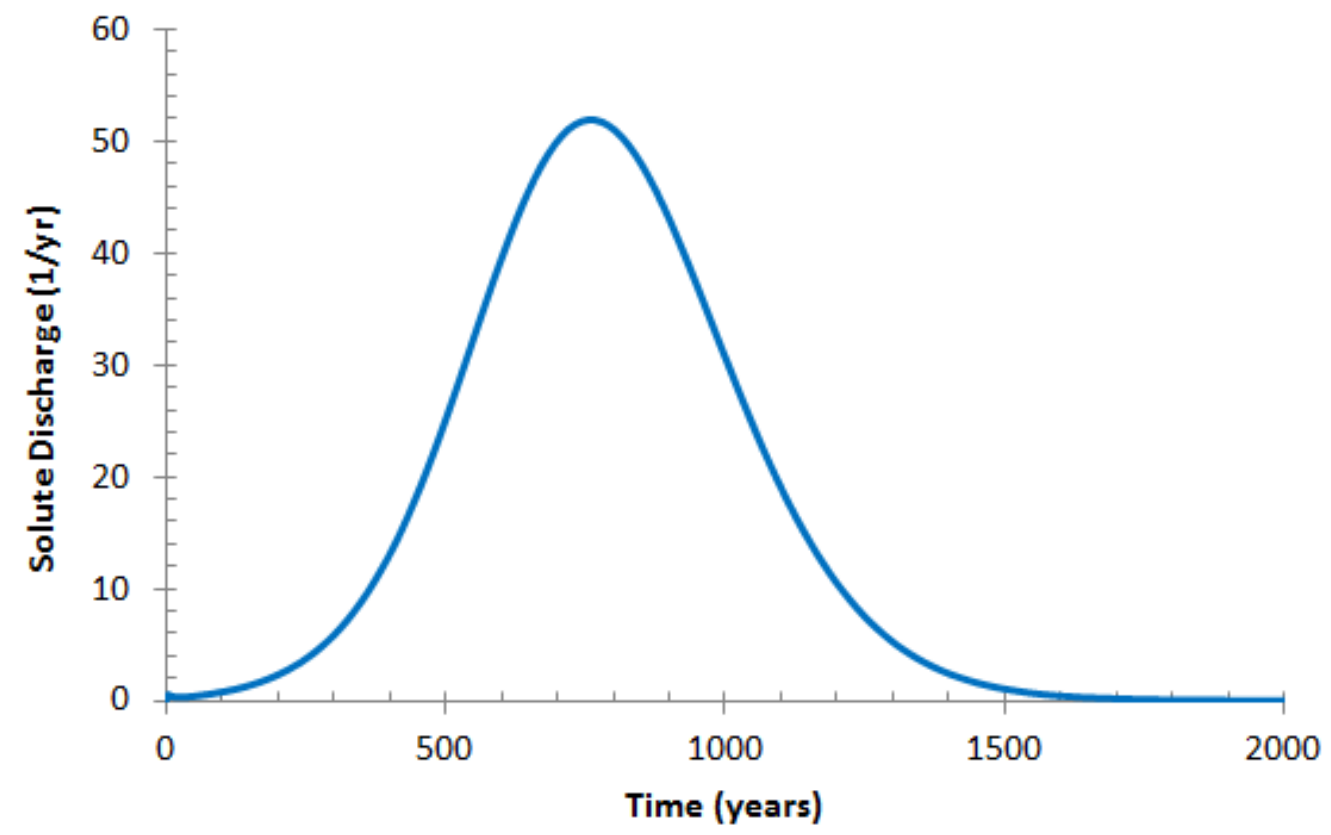

Figure 2.5. Example of a transitional case where the waste disposal was sufficient to cause a small near-term contaminant mass discharge to the groundwater (a low-magnitude Category II response) but the bulk of the contaminant discharge occurs in the future, similar to a Category I response. 

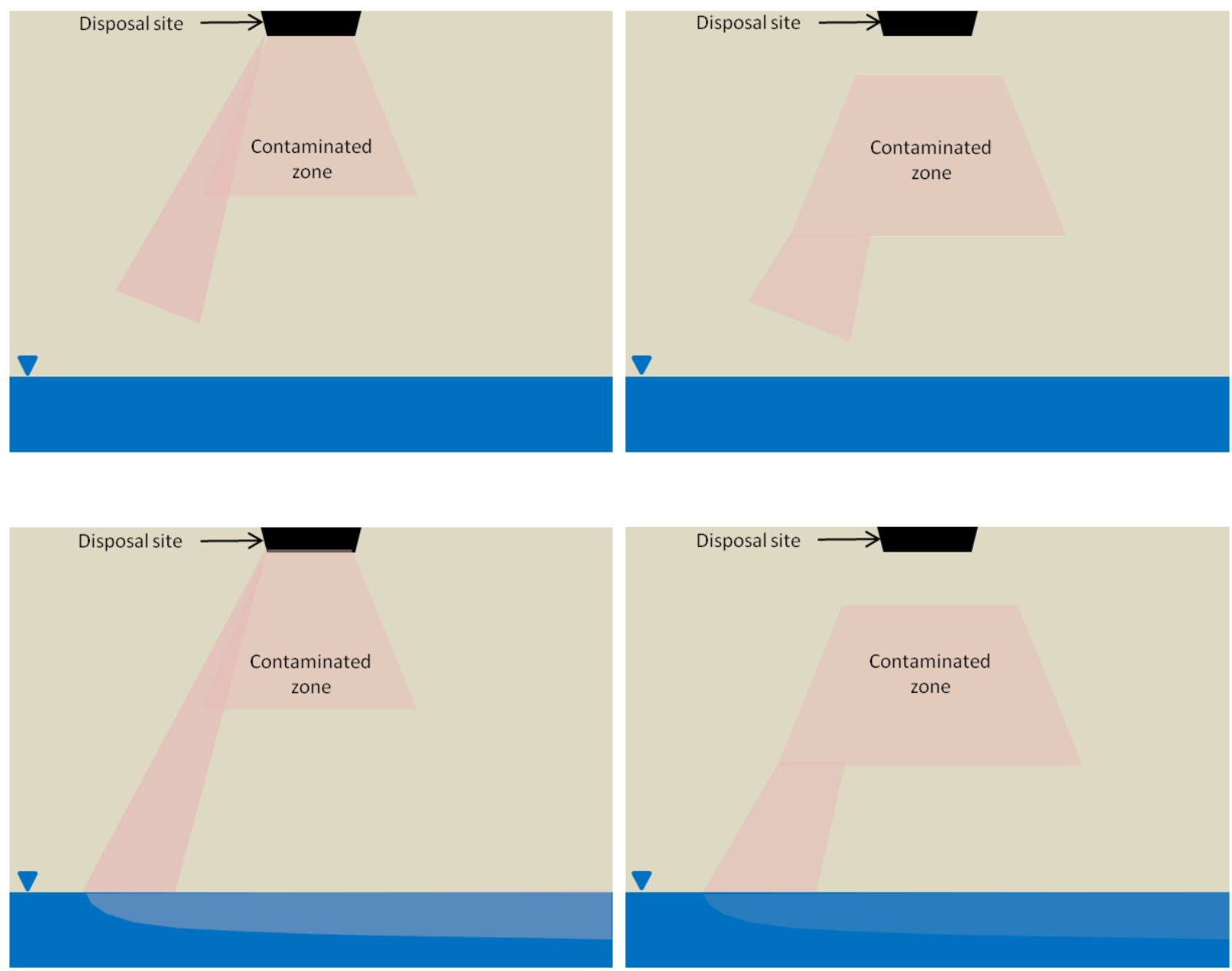

Figure 2.6. Heterogeneities in the subsurface may cause skewed contaminant distributions in the subsurface during disposal (left) for Category I (top) and Category II (bottom) sites. The resultant contaminant distribution at the time of the transport evaluation (figures at right) will need to be described in terms of the skewed distribution, but the effect of heterogeneities on transport diminishes over time after waste disposal ceases. For Category I (top) sites, contaminant discharge behavior will be similar to Figure 2.3, showing a single peak. Figure 2.4 includes typical contaminant discharge versus time curves for Category II (bottom) sites with two distinct peaks. 

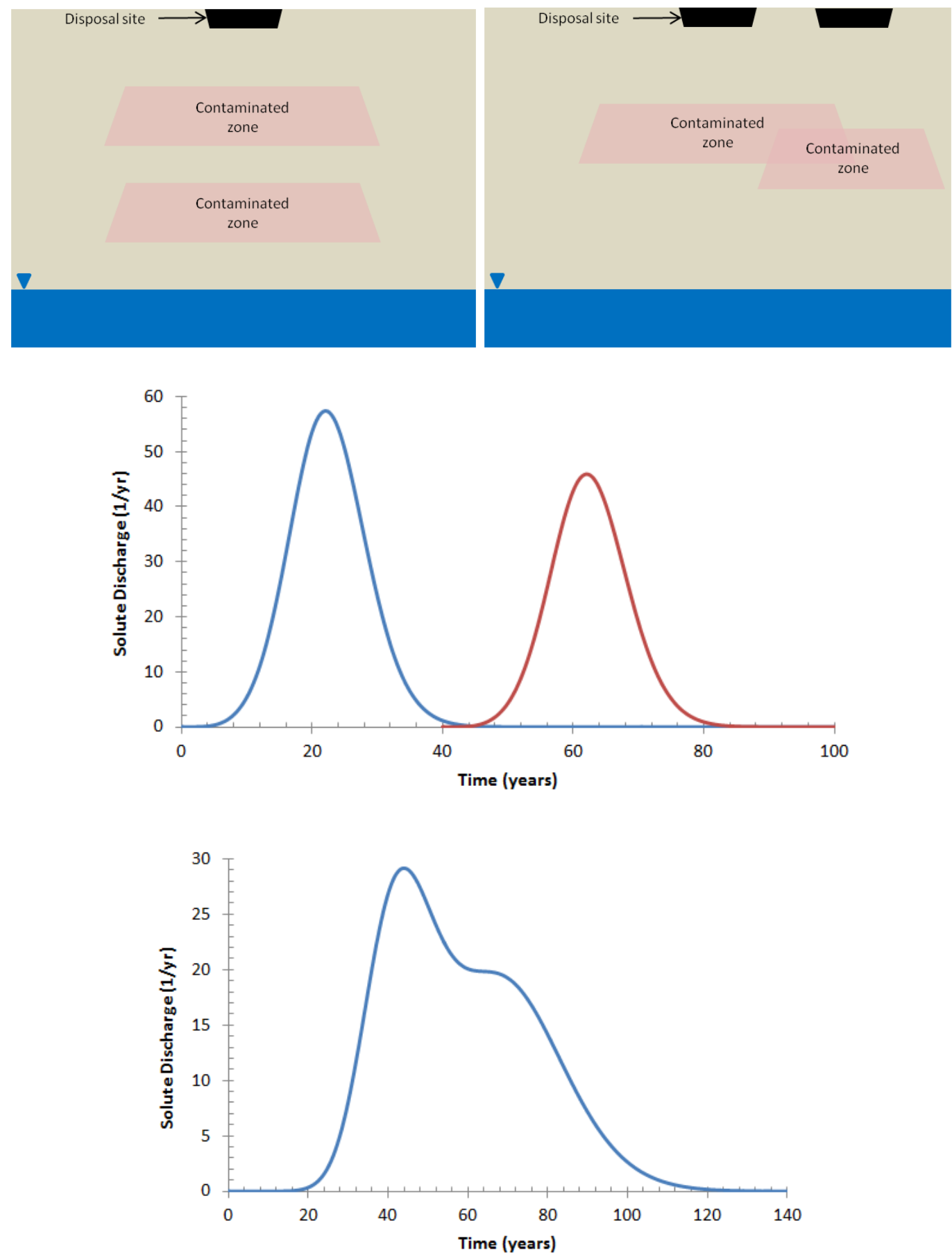

Figure 2.7. Multiple disposal events spaced in time (top left) or at adjacent disposal sites (top right) may add complexity to the contaminant distribution at the time of transport evaluation. In the middle figure, an example is shown for two waste disposal events spaced in time. In the bottom figure, an example of mass discharge of the same contaminant is shown for two adjacent disposal sites. Both waste disposal sites are classified as Category I sites. 

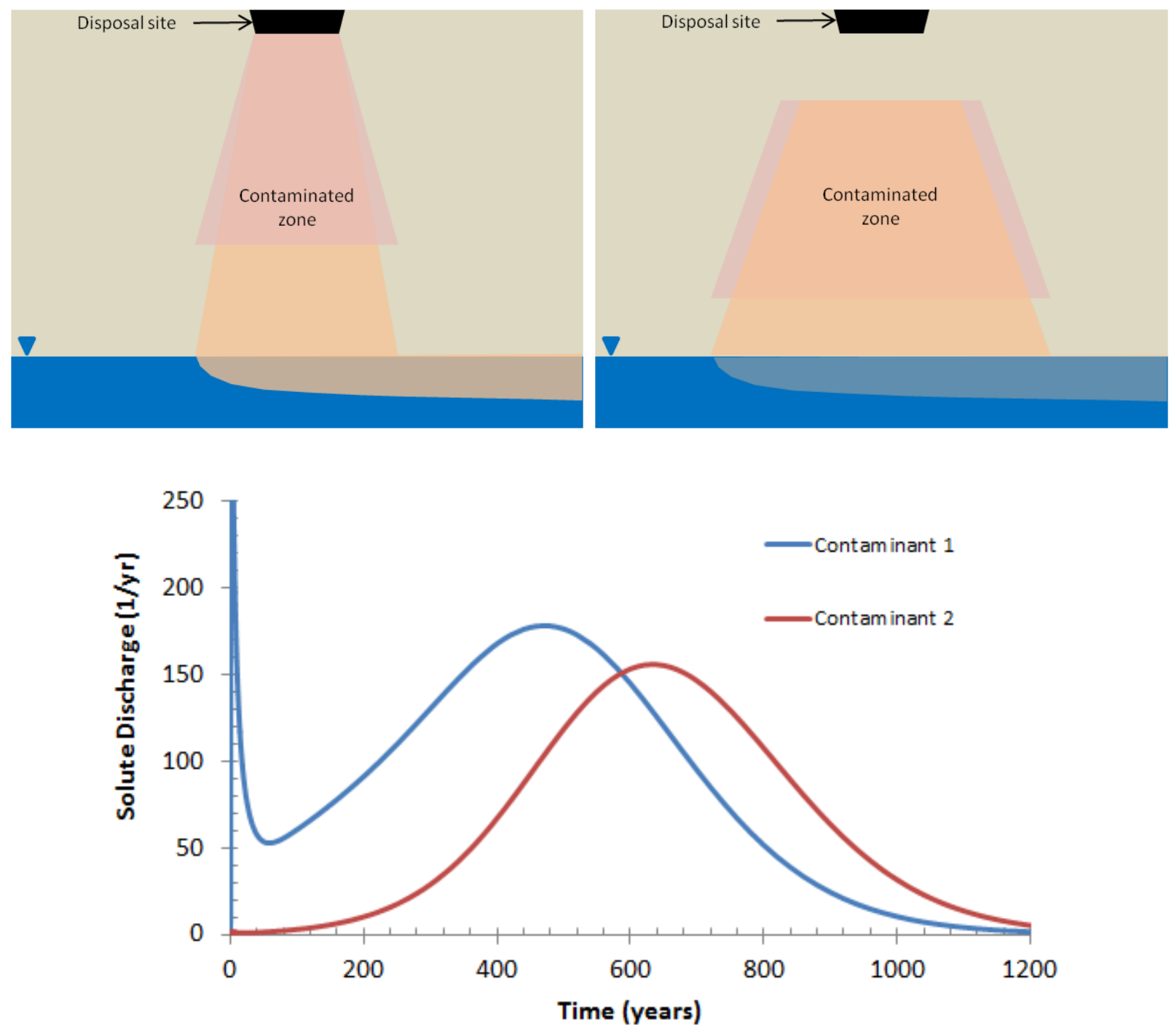

Figure 2.8. Different contaminants may be disposed of at the same disposal site as shown in this example during disposal (top left) and at the time of transport evaluation (top right). The effects of overlapping subsurface contaminant distributions may need to be considered in terms of the aqueous discharge volumes or waste chemistry effects on transport parameters. A typical groundwater mass discharge plot for this scenario is shown in the bottom figure. The discharge of Contaminant 1 (orange in upper figures) falls into Category II. The discharge behavior of Contaminant 2 (pink) falls in between Category I and II. Discharge starts almost immediately after disposal but the amount increases gradually and only a single peak is observed. 

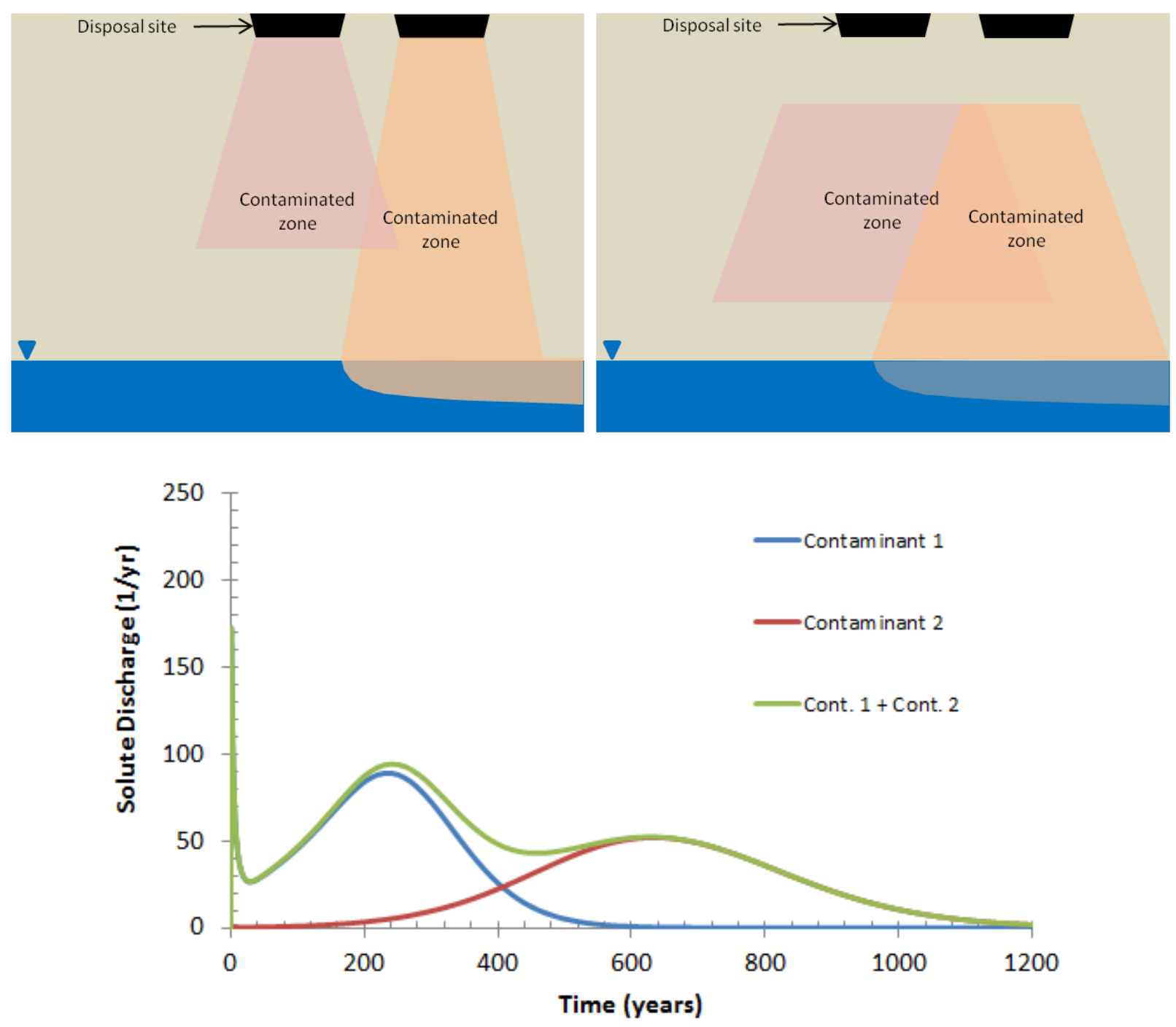

Figure 2.9. Different contaminants may be disposed of at adjacent sites (as shown in this example during disposal (top left) and at the time of transport evaluation (top right). The effect of overlapping subsurface contaminant distributions may need to be considered in terms of the aqueous discharge volumes or waste chemistry effects on transport parameters. A typical groundwater mass discharge example for this scenario is shown in the bottom figure with a Category I and a Category II discharge event. If site 1 and site 2 disposed the same contaminant, a discharge response with three peaks is observed (Cont. $1+$ Cont. 2 curve). 

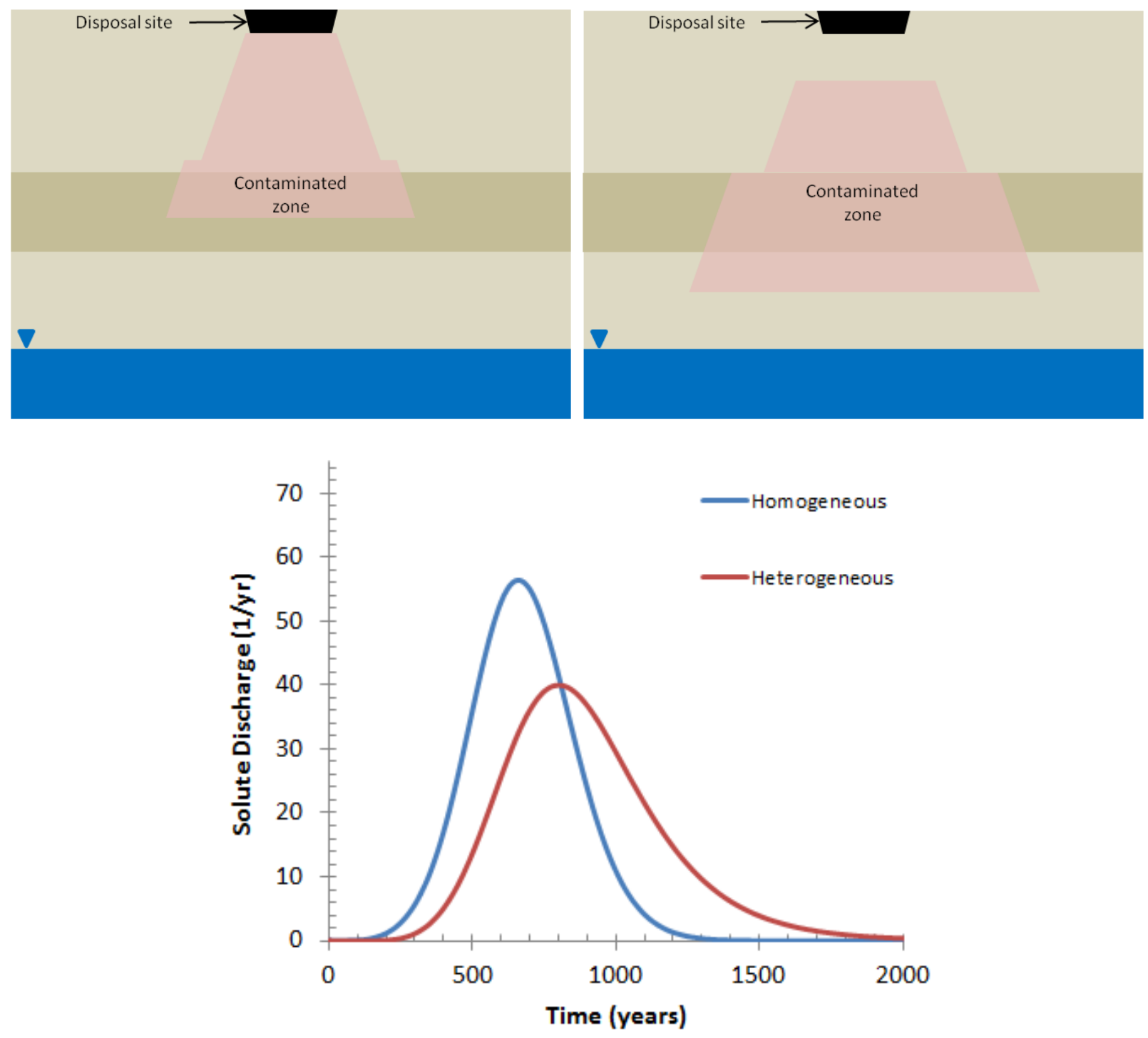

Figure 2.10. Layers (or lenses) of contrasting hydraulic properties (e.g., a silt layer within a sandy vadose zone as shown in the above example) can be incorporated into the transport evaluation during disposal (top left) and at the time of the transport evaluation (top right). A typical Category I groundwater mass discharge example for this scenario is shown in the bottom figure. 


\subsection{Conceptual Model and Numerical Simulations}

This section provides information about the configuration and calculations associated with the evaluation approach.

\subsection{Conceptual Model}

Contaminant transport through the vadose zone beneath aqueous waste disposal sites is affected by two types of attenuation processes: 1) attenuation caused by unsaturated flow and transport, and 2) attenuation caused by biogeochemical reactions and/or physical/chemical interaction with sediments. Mixing processes with the groundwater are also important for estimating contaminant concentrations in groundwater resulting from vadose zone contaminant flux. To investigate vadose zone attenuation and mass discharge to groundwater, flow and transport numerical simulations (Section 3.2) have been completed for the vadose zone using the conceptual model shown in Figure 3.1. The conceptual model includes a waste disposal site, a (layered) vadose zone, and an aquifer. A direct mixing model (Section 3.3) is used to convert mass discharge into aquifer (groundwater) concentrations.

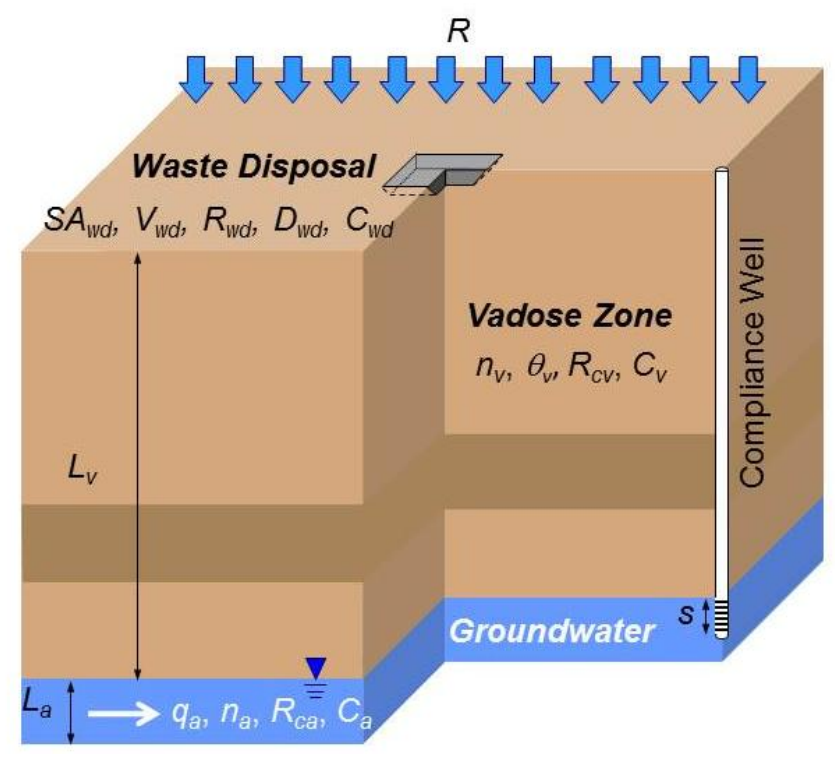

Figure 3.1. Conceptual model for vadose zone flow transport simulations and aquifer direct mixing model. The subscripts $w d, a$, and $v$ denote waste disposal, aquifer, and vadose zone, respectively. $R$ is the surface recharge. Regarding the disposal site, $S A_{w d}$ is the surface area, $V_{w d}$ is the volume, $R_{w d}$ is the rate, $D_{w d}$ is the duration, and $C_{w d}$ the concentration. In the vadose zone, $n_{v}$ is the porosity, $\theta_{v}$ is the volumetric water content, $R_{c v}$ is the contaminant retardation coefficient, and $C_{v}$ is the concentration. In the aquifer (groundwater), $q_{a}$ is the Darcy velocity, $n_{a}$ is the porosity, $R_{c a}$ is the contaminant retardation coefficient, and $C_{a}$ is the concentration. The vertical lengths of the vadose zone and the contaminant mixing thickness in the aquifer are indicated by $L_{v}$ and $L_{a}$, respectively. The compliance well screen length is indicated by $s$. The conceptual model is applicable to homogeneous and layered systems. 
The primary data needs to evaluate flow and transport regarding Category I and II sites are listed in Table 3.1. The table separates the data needs for vadose zone, waste disposal, and groundwater parameters. The numerical analysis presented in this work considers mass discharge behavior for reasonable ranges in most of the parameters listed in the table. Based on the results (Section 4), a site evaluation method was developed (Section 5).

Table 3.1. Primary data needs for the evaluation method.

\begin{tabular}{|c|c|c|}
\hline $\begin{array}{l}\text { Vadose Zone } \\
\text { Parameters }\end{array}$ & Waste Disposal Parameters & $\begin{array}{l}\text { Groundwater } \\
\text { Parameters }\end{array}$ \\
\hline Thickness $\left(L_{v}\right)$ & Aqueous volume $\left(V_{w d}\right)$ & $\begin{array}{l}\text { Groundwater Darcy } \\
\text { flux }\left(q_{a}\right)\end{array}$ \\
\hline $\begin{array}{l}\text { Recharge rate (historical, current, } \\
\text { and estimated future rates) }(R)\end{array}$ & Disposed mass $\left(M_{w d}\right)$ & $\begin{array}{l}\text { Contaminant mixing thickness } \\
\text { in aquifer }\left(L_{a}\right)\end{array}$ \\
\hline Porosity $\left(n_{v}\right)$ & Rate of waste disposal $\left(R_{w d}\right)$ & $\begin{array}{l}\text { Monitoring well screen length } \\
\text { for compliance }(s)\end{array}$ \\
\hline $\begin{array}{l}\text { Contaminant retardation } \\
\text { coefficient }\left(R_{c v}\right)\end{array}$ & Contaminant concentration $\left(C_{w d}\right)$ & Porosity $\left(n_{a}\right)$ \\
\hline $\begin{array}{l}\text { Current vertical distribution of } \\
\text { contamination }\end{array}$ & Surface area of aqueous disposal $\left(S A_{w d}\right)$ & $\begin{array}{l}\text { Contaminant retardation } \\
\text { coefficient }\left(R_{c a}\right)\end{array}$ \\
\hline \multirow[t]{2}{*}{ Moisture content profile $\left(\theta_{v}\right)$} & $\begin{array}{l}\text { Acidity or alkalinity of the waste } \\
\text { Ionic strength and co- } \\
\text { contaminants/species in the waste }\end{array}$ & \\
\hline & Timing of waste disposal & \\
\hline
\end{tabular}

\subsection{Numerical Simulations}

The water mode of the STOMP simulator (White and Oostrom 2006) was used to simulate vadose zone aqueous phase flow and contaminant transport. The fully implicit, integrated finite difference code has been used to simulate several laboratory and field contaminant transport systems (e.g., Oostrom et al. 2010, 2013; Carroll et al. 2012). The applicable governing equations are the component massconservation equation for water and the solute transport equation, which is solved using a total variation diminishing scheme. A cylindrical model was constructed for the vadose zone with the same discretization in the $\mathrm{x}$-direction, independent of the source size $\left(S A_{w d}\right)$. For all simulations, the upper and lower $5 \mathrm{~m}$ of the domain used the same grid discretization $(0.1 \mathrm{~m})$. In between these two zones, $0.25 \mathrm{~m}$ grid blocks were used. Several grid refinement iterations were conducted until no changes were observed in the water and contaminant fluxes across the water table. A total of three sediments were considered in the simulations: sand, sandy loam, and silt. The properties of the sediments were obtained from Carsel and Parrish (1980) and are shown in Table 3.2.

The simulations include waste disposal scenarios in homogeneous sand and sandy loam and systems with silt layers in sand and sandy loam. The details of the simulation matrix are shown in Appendix A. An overview of the ranges of values used for each considered variable is shown in Table 3.3. 
Table 3.2. Hydraulic properties of the sediments used in the STOMP simulations (from Carsel and Parrish 1988). The van Genuchten (1980) retention relation is shown in Eq. (2.4).

\begin{tabular}{|c|c|c|c|c|c|}
\hline Sediment & $\begin{array}{c}\text { van Genuchten } \\
\alpha(1 / \mathbf{P a})\end{array}$ & $\begin{array}{c}\text { van } \\
\text { Genuchten, } \\
m_{1}\end{array}$ & $\begin{array}{c}\text { Residual } \\
\text { Volumetric } \\
\text { Water Content, } \\
\theta_{r}\end{array}$ & $\begin{array}{c}\text { Hydraulic } \\
\text { Conductivity, } K_{\text {sat }} \\
(\mathbf{c m} / \mathbf{h r})\end{array}$ & $\begin{array}{c}\text { Porosity } \\
(-)\end{array}$ \\
\hline Sand & $1.45 \times 10^{-3}$ & 2.68 & 0.045 & 29.70 & 0.43 \\
\hline Sandy Loam & $7.50 \times 10^{-4}$ & 1.89 & 0.035 & 4.42 & 0.41 \\
\hline Silt & $1.60 \times 10^{-4}$ & 1.37 & 0.034 & 0.25 & 0.46 \\
\hline
\end{tabular}

Table 3.3. Input values for vadose zone and waste disposal parameters. Simulation details are provided in Appendix A.

\begin{tabular}{lcc}
\hline \multicolumn{1}{c}{ Parameter } & Units & Range \\
\hline Vadose Zone Thickness $\left(L_{v}\right)$ & $\mathrm{m}$ & $10-100$ \\
Recharge $(R)$ & $\mathrm{mm} / \mathrm{yr}$ & $3.5-100$ \\
Vadose Zone Porosity $\left(n_{v}\right)$ & - & $0.1-0.41$ (sandy loam) \\
& - & $0.1-0.43$ (sand) \\
Retardation Coefficient* $\left(R_{c v}\right)$ & & $1-3.84$ (sandy loam) \\
Waste Disposal Surface Area $\left(S A_{w d}\right)$ & $\mathrm{m}^{2}$ & $1-100$ \\
Waste Disposal Volume $\left(V_{w d}\right)$ & $\mathrm{m}^{3}$ & $1-8000$ \\
Waste Disposal Duration $\left(D_{w d}\right)$ & $\mathrm{days}$ & $1-1000$ \\
Waste Disposal Rate $\left(R_{w d}\right)$ & $\left(\mathrm{m}^{3} / \mathrm{d}\right)$ & $0.01-8000$ \\
Waste Concentration $\left(C_{w d}\right)$ & $1 / \mathrm{L}$ & $0.001-1$ \\
& & \\
*Range corresponded with input values & & \\
for $K_{d}$ between 0 and $0.2 \mathrm{~mL} / \mathrm{g}$ & & \\
\hline
\end{tabular}

\subsection{Computation of Groundwater Concentrations}

Groundwater (aquifer) concentrations $\left(C_{a}\right)$ are computed using a mixing model equivalent to the mass balance approach proposed by Summers et al. (1980):

$$
C_{a}=\frac{Q_{v-a} C_{v-a}}{Q_{a}+Q_{v-a}}
$$

where $Q_{v-a}$ is the volumetric flow rate $\left(\mathrm{m}^{3} / \mathrm{yr}\right)$ from the vadose zone into the groundwater, $Q_{a}$ is the volumetric flow rate $\left(\mathrm{m}^{3} / \mathrm{yr}\right)$ of groundwater through the aquifer underlying the contaminant plume in the vadose zone, and $C_{v-a}$ is the vadose zone contaminant concentration at the vadose zone-groundwater interface. The Darcy flow velocity in the aquifer is assumed to be constant and is denoted as $q_{a}$. The mixing method and associated terminology is shown in Figure 3.2 (following the equations below) and 
illustrated with an example in Figure 3.3 and Figure 3.4 (after the equations). First, for each time step, the total contaminant mass flux at the vadose zone-groundwater interface is computed. Assuming the vadose zone contaminant plume at the interface has a circular shape, the diameter $D_{v-a}$ is then computed representing the area over which $99 \%$ off the mass flux occurs. This area can be written as

$$
A_{v-a}=\pi D_{v-a}^{2} / 4
$$

To compute an average contaminant travel time of groundwater, moving with a velocity $v_{a}=q_{a} / n_{a}$, $A_{v-a}$ is converted to an equivalent rectangle with the same size:

$$
A_{v-a}^{*}=W_{v-a} D_{v-a}
$$

where $W_{v-a}$ is the average width in the direction of flow. Using Eq. (3.3), an expression relating $Q_{a}$ and $q_{a}$ is

$$
Q_{a}=q_{a} L_{a} D_{v-a}
$$

It follows from Eqs. (3.2) and (3.3) that

$$
W_{v-a}=\pi D_{v-a} / 4
$$

The average residence time of the contaminated groundwater, $t_{a r}$, is then calculated as

$$
t_{a r}=W_{v-a} / v_{a}
$$

The computed $t_{a r}$ value is subsequently used to compute the volumetric $\left(Q_{v-a} t_{a r}\right)$ and contaminant mass discharges $\left(Q_{v-a} C_{v-a} t_{a r}\right)$ into the volume $V_{a}=A_{v-a}^{*} L_{a}$ as follows:

$$
C_{a}=\frac{Q_{v-a} C_{v-a} t_{a r}}{V_{a}+Q_{v-a} t_{a r}}
$$


This expression is equivalent to the Summers et al. (1980) equation (Eq. (3.1)), because all terms have been multiplied by the average residence time. For sorbing contaminants, Eq. (3.6) is modified by the groundwater retardation coefficient $\left(R_{c a}\right)$ to recognize the reduction in contaminant concentration as part of the discharged mass is sorbed on the solid phase:

$$
C_{a}=\frac{Q_{v-a} C_{v-a} t_{a r}}{\left(V_{a}+Q_{v-a} t_{a r}\right) R_{c a}}
$$

Figure 3.3 and Figure 3.4 illustrate how the described approach is used for a waste disposal example with $S A_{w d}=25 \mathrm{~m}^{2}, L_{v}=25 \mathrm{~m}, V_{w d}=25 \mathrm{~m}^{3}, D_{w d}=1$ day, $C_{w d}=1 / \mathrm{L}, R=3.5 \mathrm{~mm} / \mathrm{yr}$, and $L_{a}=5 \mathrm{~m}$. Figure 3.3a shows that $Q_{v-a}$ only deviates from the imposed recharge rate $(3.5 \mathrm{~mm} / \mathrm{yr})$ over the first 50 years. During this time, however, $C_{v-a}$ is zero and no mass transport into the groundwater occurs (Figure $3.3 \mathrm{~b}$ and Figure 3.4a). Figure 3.3b shows that the contaminated zone at the vadose zone-groundwater interface slowly grows over time and that the maximum diameter is approximately $16 \mathrm{~m}$. For this example it means that the maximum contaminated vadose zone-groundwater interface is $\sim 200 \mathrm{~m}^{2}$, which is eight times the source area. This phenomenon was introduced in Section 2. Figure 3.4a shows an example of the mass discharge into groundwater over time for three solutes with different retardation coefficients. The computed groundwater concentrations using the described methodology are depicted in Figure $3.4 \mathrm{~b}$. These figures show that the method honors the shape of the mass discharge relations and the peak arrival times. 

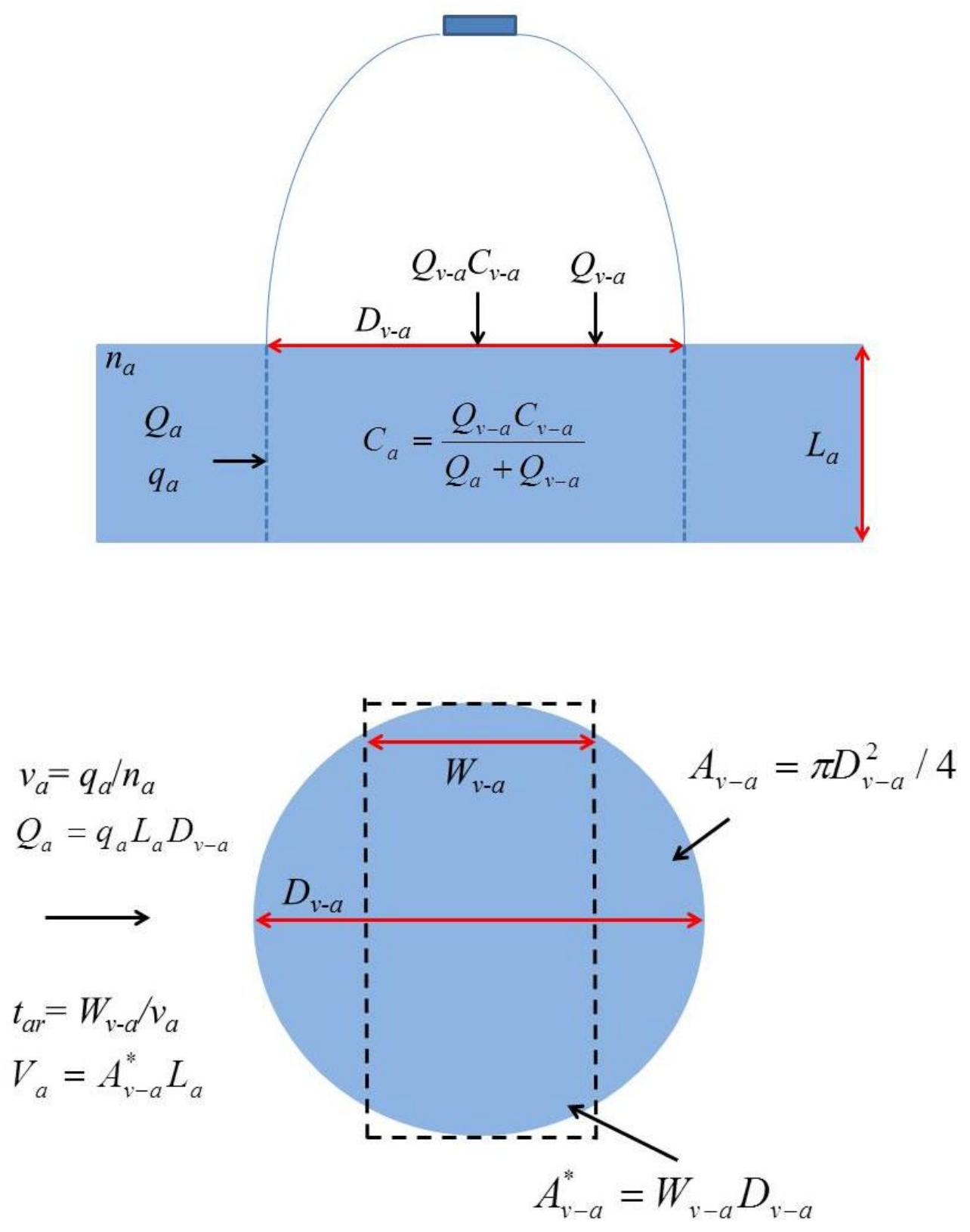

Figure 3.2. (a) Side view and (b) top view of mixing model to compute groundwater concentrations from solute discharge rates. 


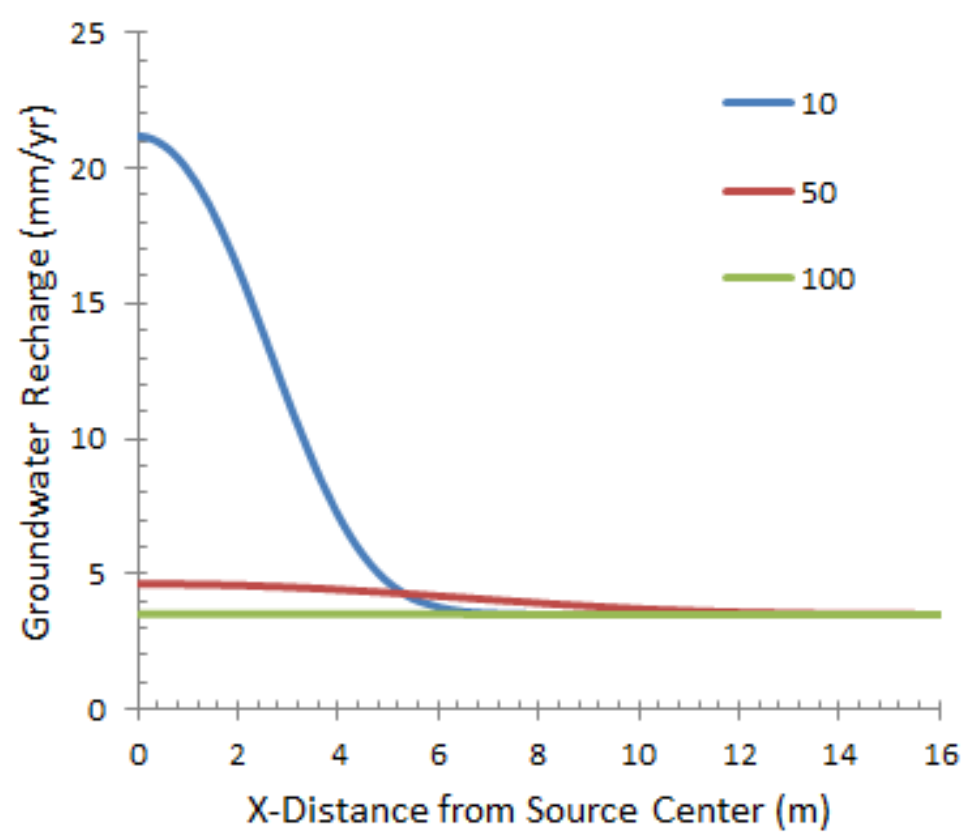

(a)

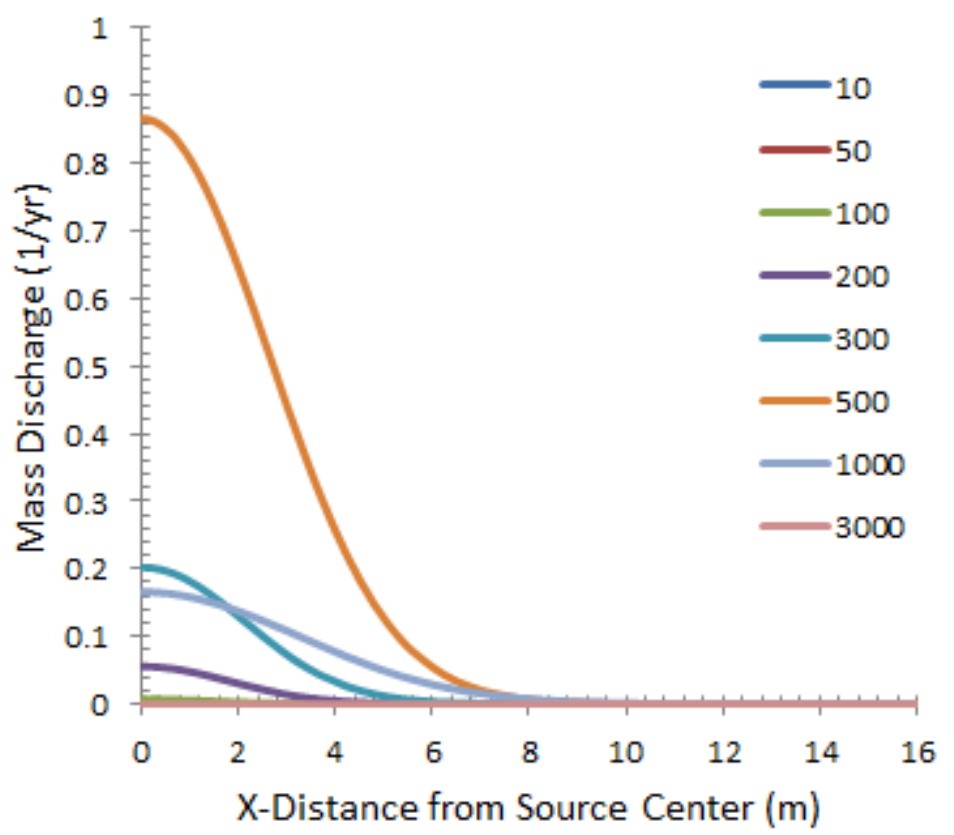

(b)

Figure 3.3. (a) Groundwater recharge and (b) mass discharge into groundwater over time for sandy loam simulations with $S A_{w d}=25 \mathrm{~m}^{2}, L_{v}=25 \mathrm{~m}, V_{w d}=25 \mathrm{~m}^{3}, D_{w d}=1$ day, $C_{w d}=1 / \mathrm{L}, R$ $=3.5 \mathrm{~mm} / \mathrm{yr}$, and $L_{a}=5 \mathrm{~m}$. The legend denotes years after the waste disposal. 


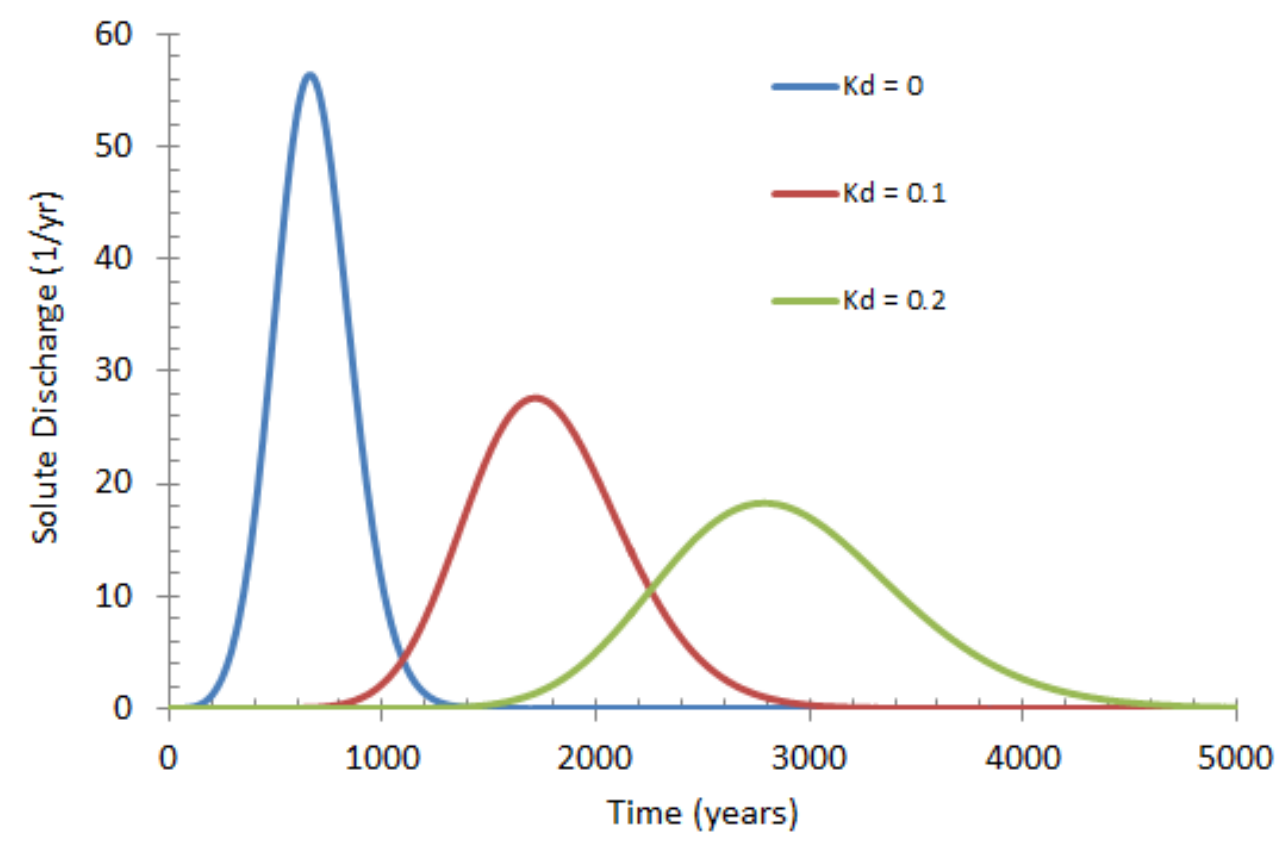

(a)

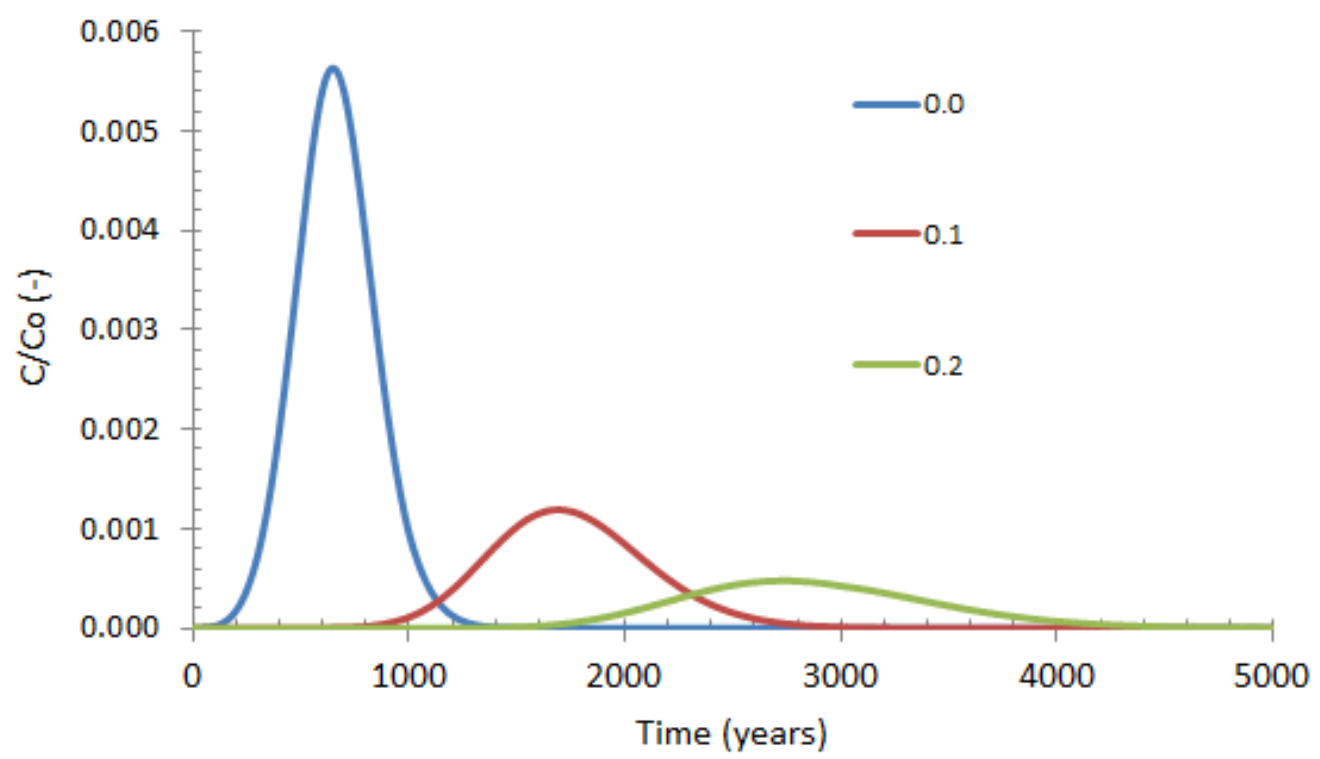

(b)

Figure 3.4. (a) Simulated mass discharge into groundwater and (b) computed normalized groundwater concentration over time for three solutes with $K_{d}=0,0.1$, and $0.2 \mathrm{~mL} / \mathrm{g}$. Simulations:

sandy loam with $S A_{w d}=25 \mathrm{~m}^{2}, L_{v}=25 \mathrm{~m}, V_{w d}=25 \mathrm{~m}^{3}, D_{w d}=1$ day, $C_{w d}=1 / \mathrm{L}, R=3.5$ $\mathrm{mm} / \mathrm{yr}$, and $L_{a}=5 \mathrm{~m}$. 


\subsection{Numerical Analysis Results}

In this section, the results of the flow and transport numerical simulations (Table 3.3; Appendix A) are presented. The effects of key vadose zone, waste disposal, and groundwater parameters (Table 3.1; Figure 3.1) on analysis results are discussed in Sections 4.1, 4.2, and 4.4, respectively. A discussion of the transition from Category I to Category II disposal sites as a result of vadose zone and waste disposal parameters is included in Section 4.3. Results from flow and transport simulations in homogenous and layered vadose zone configurations are presented.

\subsection{Vadose Zone Parameters}

In this section, the effects of key vadose zone parameters (Table 3.1) on analysis results are discussed for Category I sites. The parameters include thickness $\left(L_{v}\right)$, recharge rate $(R)$, porosity $\left(n_{v}\right)$, contaminant retardation $\left(R_{c v}\right)$, and the current vertical distribution of contamination. These parameters determine the water content $\left(\theta_{v}\right)$ profile in the vadose zone and therefore the travel time of disposed contaminants. In all examples, it was assumed that 1) the retardation coefficients and porosities were the same in the vadose zone and groundwater $\left(R_{c a}=R_{c v}\right.$ and $\left.\left.n_{a}=n_{v}\right), 2\right) L_{a}=5 \mathrm{~m}$, and 3) $C_{w d}=1 / \mathrm{L}$.

\subsubsection{Category I; Homogeneous Subsurface}

The effects of selected parameters on the analysis results are described in the following sections.

\subsubsection{Impact of Vadose Zone Thickness}

In Figure 4.1 (at the end of this section), examples of computed groundwater concentrations, $C_{a}$, resulting from the disposal of a nonsorbing contaminant in sandy loam, are shown for four $L_{v}$ values. The recharge rate, $R$, is $3.5 \mathrm{~mm} / \mathrm{yr}$, which is representative of long-term recharge at the Hanford Site for a shrub-steppe vegetation. Additional details of the simulations are provided in the figure caption. The $C_{a}$ plots indicate that even for $L_{v}=10 \mathrm{~m}$, the contaminant does not arrive in the aquifer for more than 100 years. For the largest considered $L_{v}(100 \mathrm{~m})$, the contaminant takes more than 2,000 years to migrate through the unsaturated zone. Because of the considerable travel times, the concentrations have been reduced by more than three orders of magnitude compared to the disposed concentration. For such systems, groundwater concentration peak arrival times can be estimated by

$$
t_{c p}=\frac{L_{v} \bar{\theta}_{v} R_{c v}}{R}
$$

Eq. (4.1) is equivalent to Eq. (2.10) but contains parameters consistent with the conceptual model shown in Figure 3.1. 
In Figure 4.2, the concentrations are plotted as a function of normalized time, $T_{c}$, defined as:

$$
T_{c}=\frac{t R}{L_{v} \bar{\theta}_{v} R_{c v}}
$$

where $\bar{\theta}_{v}$ is the average moisture content in the vadose zone and all other variables have been defined before. Eq. (4.1) follows directly from Eqs. (2.11) and (2.12) described in Section 2. For nonsorbing contaminants with $R_{c v}=1.0$, Eq. (4.2) defaults to

$$
T_{c}=\frac{t R}{L_{v} \bar{\theta}_{v}}
$$

Per square meter $\left(\mathrm{m}^{2}\right)$ of surface, the units of both the numerator and denominator are cubic meters, and therefore represent volumes. The term $t R$ (with $t$ in years and $R$ converted to $\mathrm{m} /$ year) is the volume of recharge that has migrated into the subsurface per square meter. The term $L_{v} \bar{\theta}_{v}$ is the volume per square meter of water that is occupying the pore space. The normalized arrival time of the contaminant peak, $T_{c p}$, disposed under Category I conditions, should therefore approximately occur when $t R=L_{v} \bar{\theta}_{v}$ and $T_{c p}=1$. To confirm this relationship, normalized groundwater concentrations were plotted against normalized time for the evaluated cases. Figure 4.2 shows that for all $L_{v}$ values, $T_{c p}$ is close to 1 , based on simulated $\bar{\theta}_{v}$ values of $0.116,0.109,0.108$, and 0.107 for $L_{v}=10,25,50$, and $100 \mathrm{~m}$, respectively. The deviation from $T_{c p}=1$ increases with a decrease in $L_{v}$ because the relative influence of the disposal volume is larger in a smaller vadose zone.

Results for similar waste disposal events in sand are shown in Figure 4.3 and Figure 4.4. These figures show that under similar conditions, the contaminant arrives in the aquifer much faster than in the sandy loam (Figure 4.1 and Figure 4.2) due to the lower water content in the sand. For sand, the simulated $\bar{\theta}_{v}$ values are $0.062,0.059,0.058$, and 0.057 for $L_{v}=10,25,50$, and $100 \mathrm{~m}$, respectively. As a result, the pore-water velocity, defined as $v_{v}=q_{v} / \theta_{v}$, is larger in sand and contaminants migrate faster in this sediment than in a sandy loam. It is noted that for Category I sites, all results for sand and sandy loam could be scaled with $\bar{\theta}_{v}$. For that reason, only sandy loam examples are shown in the remainder of this report.

A comparison of predicted peak arrival times $\left(t_{c p}\right)$ using Eq. (4.1) and STOMP simulated $t_{c p}$ is shown in Figure 4.5 for the sandy loam and sand examples shown in Figure 4.1-Figure 4.4. As already suggested in Figure 4.2 and Figure 4.4, the figure demonstrates that the use of the relatively simple predictive formula, using just a few parameter values, is reasonable to predict values in homogeneous formations with constant recharge. The predicted $T_{c p}$ values are always slightly larger than the simulated values due to the effect of the actual spill size on transport. 


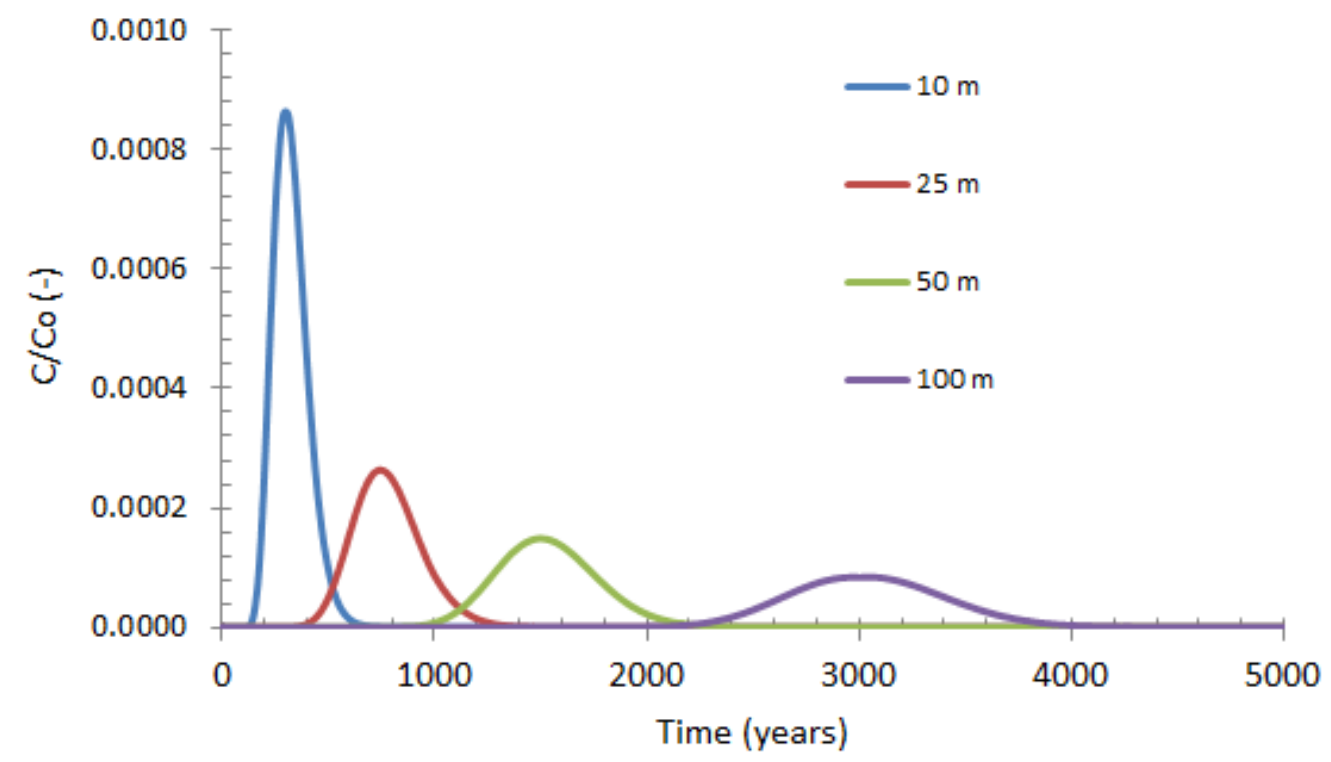

Figure 4.1. Normalized groundwater concentration over time for $L_{v}=10,25,50$, and $100 \mathrm{~m}$.

Simulations: sandy loam with $S A_{w d}=25 \mathrm{~m}^{2}, V_{w d}=1 \mathrm{~m}^{3}, D_{w d}=1$ day, and $R=3.5$ $\mathrm{mm} / \mathrm{yr}$.

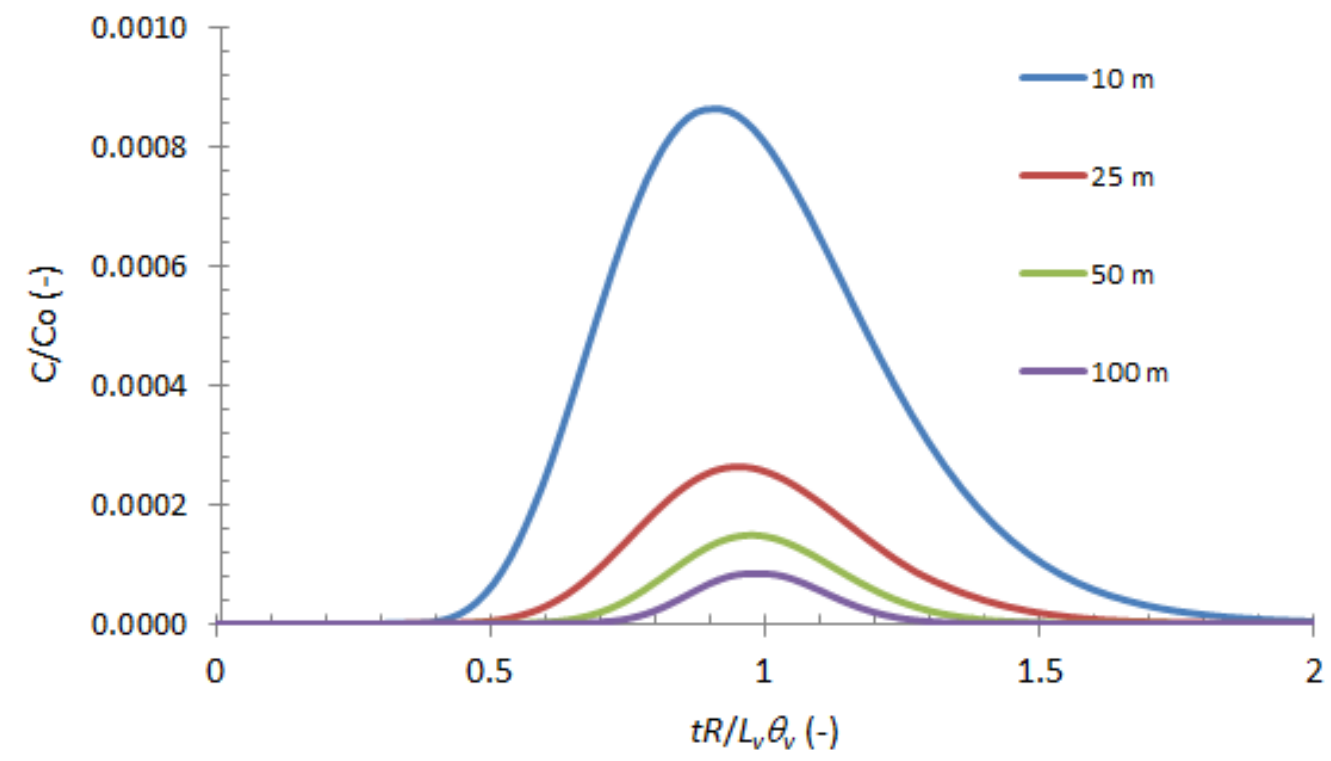

Figure 4.2. Normalized groundwater concentration vs. normalized time $\left(t R /\left(L_{v} \bar{\theta}_{v}\right)\right)$ for $L_{v}=10,25$, 50 , and $100 \mathrm{~m}$. Simulations: sandy loam with $S A_{w d}=25 \mathrm{~m}^{2}, V_{w d}=1 \mathrm{~m}^{3}, D_{w d}=1$ day, and $R=3.5 \mathrm{~mm} / \mathrm{yr}$. 


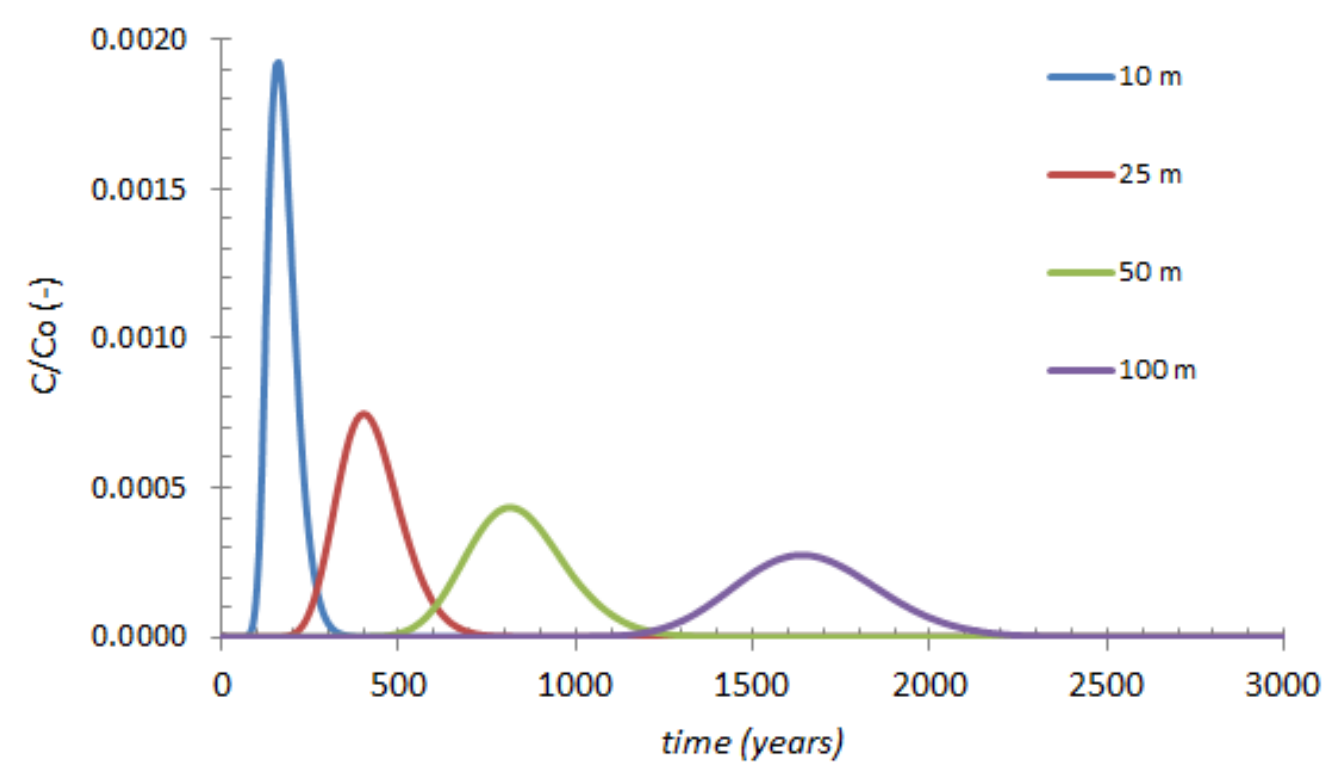

Figure 4.3. Normalized groundwater concentration over time for $L_{v}=10,25,50$, and $100 \mathrm{~m}$.

Simulations: sand with $S A_{w d}=25 \mathrm{~m}^{2}, V_{w d}=1 \mathrm{~m}^{3}, D_{w d}=1$ day, and $R=3.5 \mathrm{~mm} / \mathrm{yr}$.

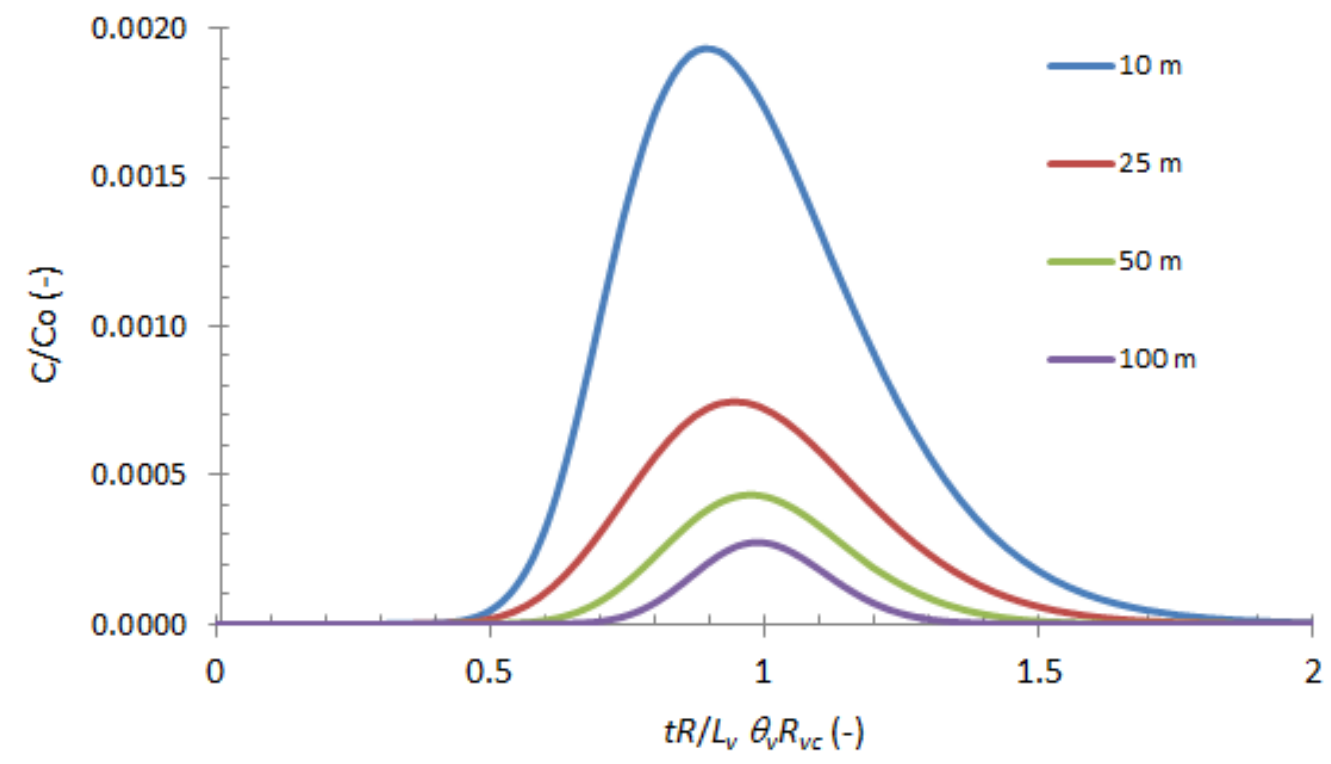

Figure 4.4. Normalized groundwater concentration vs. normalized time $\left(t R /\left(L_{v} \bar{\theta}_{v}\right)\right)$ for $L_{v}=10,25$, 50 , and $100 \mathrm{~m}$. Simulations: sand with $S A_{w d}=25 \mathrm{~m}^{2}, V_{w d}=1 \mathrm{~m}^{3}, D_{w d}=1$ day, and $R=$ $3.5 \mathrm{~mm} / \mathrm{yr}$. 


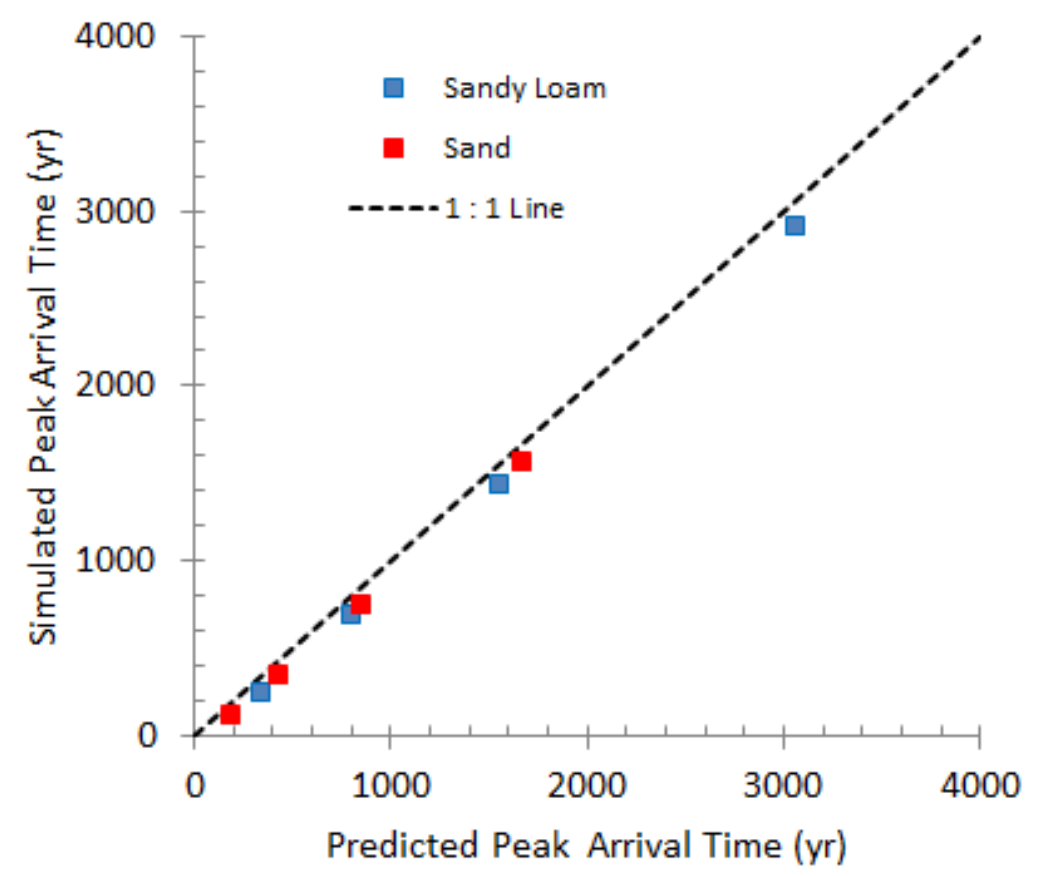

Figure 4.5. Relation between predicted and simulated peak arrival times of nonsorbing contaminants for $L_{v}=10,25,50$, and $100 \mathrm{~m}$. Simulations: sandy loam and sand with $S A_{w d}=25 \mathrm{~m}^{2}, V_{w d}$ $=1 \mathrm{~m}^{3}, D_{w d}=1$ day, and $R=3.5 \mathrm{~mm} / \mathrm{yr}$.

\subsubsection{Impact of Recharge}

In Figure 4.6, an example of computed groundwater concentrations, $C_{a}$, is shown for five $R$ values, ranging from $3.5 \mathrm{~mm} / \mathrm{yr}$ to $100 \mathrm{~mm} / \mathrm{yr}$. The maximum value is an estimate of recharge through surface backfill at the Hanford Site. Additional parameter values of the flow and transport simulations for the nonsorbing contaminant are presented in the figure caption. Note that for this example case, a larger nominal disposal volume is used than for the previous case assessing the effects of vadose zone thickness. The $C_{a}$ results indicate that the arrival times decrease and the concentrations increase with increasing $R$. The $C_{a}$ results versus normalized time (Figure 4.7) show $T_{c p}$ values close to one for all $R$ values, indicating that even for the largest $R$ value of $100 \mathrm{~mm} / \mathrm{yr}$, the contaminant mass discharge still falls in Category I. A comparison of predicted peak $t_{c p}$ values using Eq. (4.1) and simulated $t_{c p}$ values is shown in Figure 4.8 for the sandy loam and equivalent sand simulations. Similar to what was shown for the example in the previous section, the predicted and simulated values are close. Again, the predicted $t_{c p}$ values are always slightly larger than the simulated values due to the effect of the actual spill size on transport. 


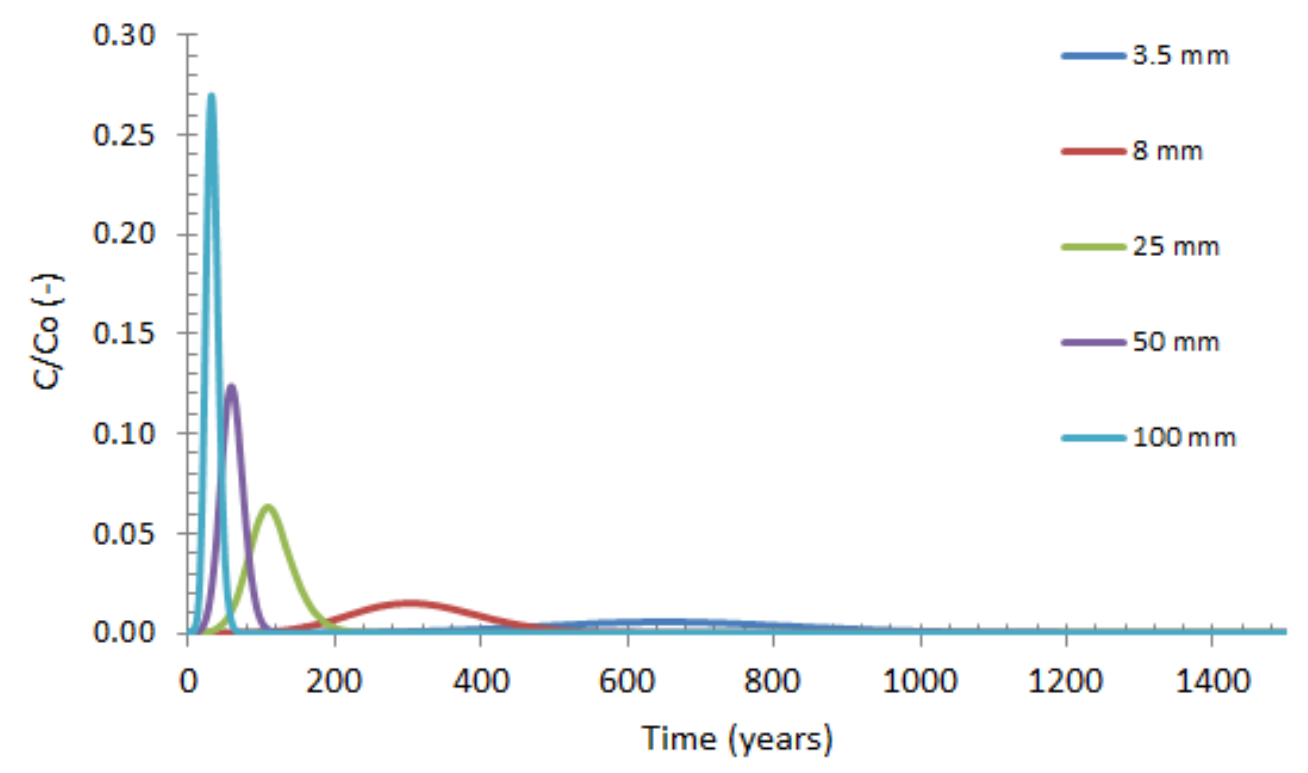

Figure 4.6. Normalized groundwater concentration over time for $R=3.5,8,25,50$, and $100 \mathrm{~mm} / \mathrm{yr}$. Simulations: sandy loam with $S A_{w d}=25 \mathrm{~m}^{2}, V_{w d}=25 \mathrm{~m}^{3}, D_{w d}=1$ day, and $L_{v}=25 \mathrm{~m}$.

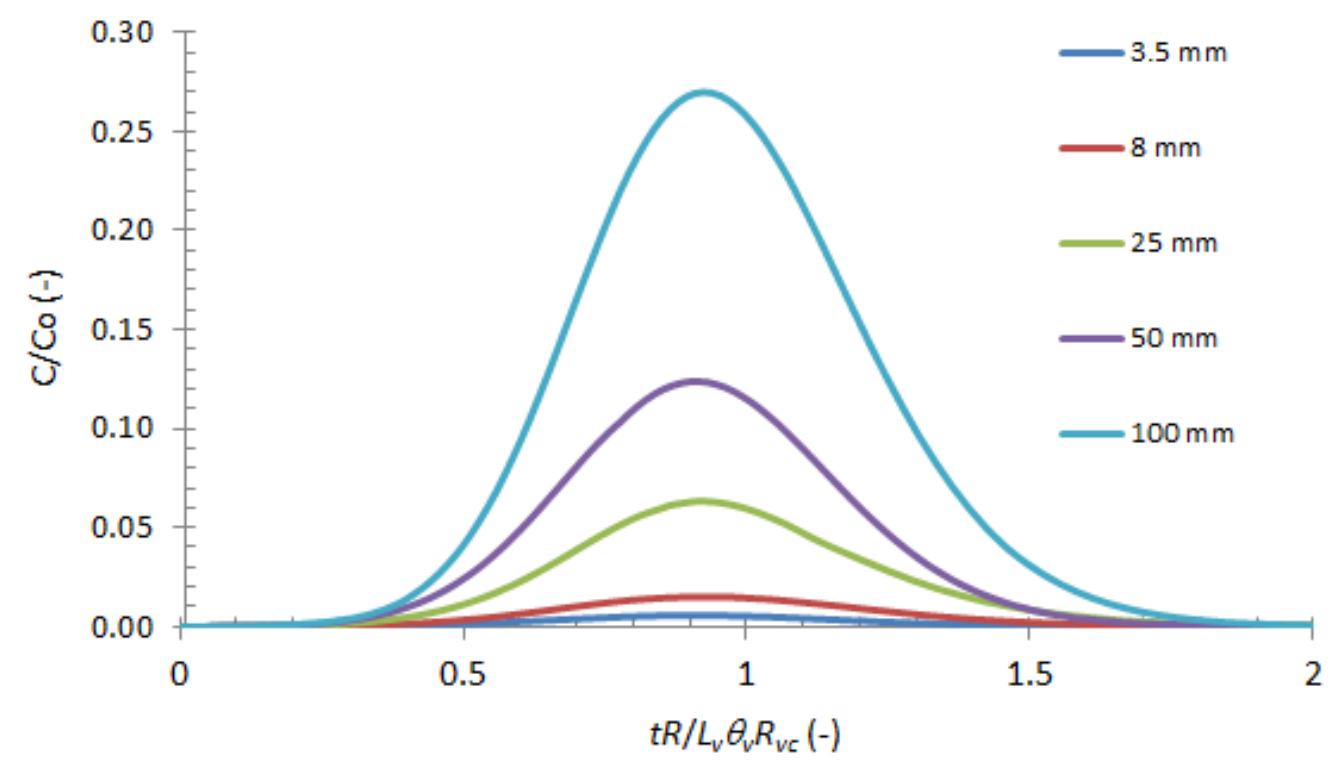

Figure 4.7. Normalized groundwater concentration vs. dimensionless time $\left(t R /\left(L_{v} \bar{\theta}_{v}\right)\right)$ for $R=3.5,8$, 25, 50, and $100 \mathrm{~mm} / \mathrm{yr}$. Simulations: sandy loam with $S A_{w d}=25 \mathrm{~m}^{2}, V_{w d}=25 \mathrm{~m}^{3}, D_{w d}=$ 1 day, and $L_{v}=25 \mathrm{~m}$. 


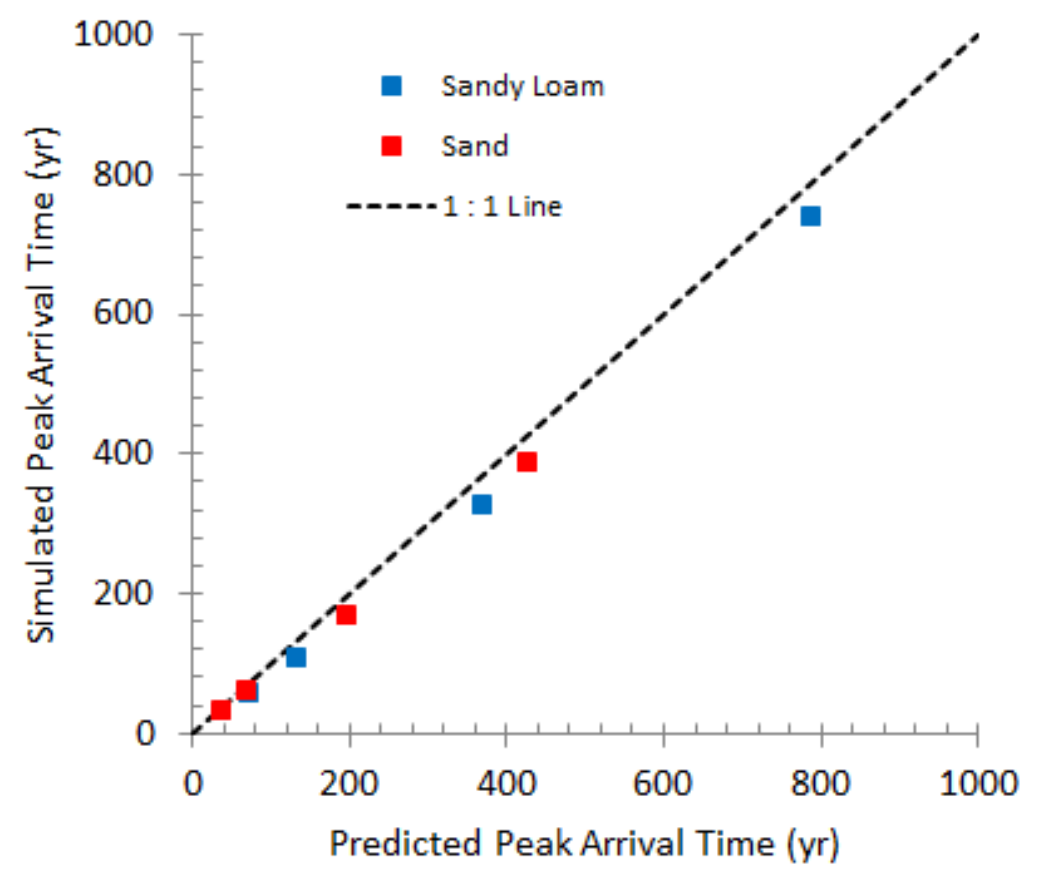

Figure 4.8. Relation between predicted and simulated peak arrival times of nonsorbing contaminants for $R=3.5,8,25,50$, and $100 \mathrm{~mm} / \mathrm{yr}$. Simulations: sandy loam and sand with $S A_{w d}=25 \mathrm{~m}^{2}$, $V_{w d}=25 \mathrm{~m}^{3}, D_{w d}=1$ day, and $L_{v}=25 \mathrm{~m}$.

\subsubsection{Impact of Porosity}

In Figure 4.9, an example of computed groundwater concentrations, $C_{a}$, is shown for four $n_{v}$ values, ranging from 0.1 to 0.41 . In the simulations, it was assumed that residual saturation, $S_{r}\left(=\theta_{r} / n_{v}\right)$, was the same for all four considered $n_{v}$ values. With this assumption, the application of the van Genuchten (1980) retention relation (Eq. (2.4)) results in $\bar{\theta}_{v}$ values directly proportional to the $n_{v}$ values. The $C_{a}$ results indicate that the arrival times increase and concentrations decrease with increasing $n_{v}$. The $C_{a}$ results versus normalized time (Figure 4.10) show $T_{c p}$ values close to one for all $n_{v}$ values, indicating that mass discharge behavior can be classified as Category I for all considered $n_{v}$ values. A comparison of predicted peak $t_{c p}$ values using Eq. (4.1) and simulated $t_{c p}$ values is shown in Figure 4.11 for the sandy loam and equivalent sand simulations. Similar to what was shown for variations in $L_{v}$ and $R$ in the previous sections, the predicted and simulated values are relatively close; the predicted $t_{c p}$ values are slightly larger than the simulated values. 


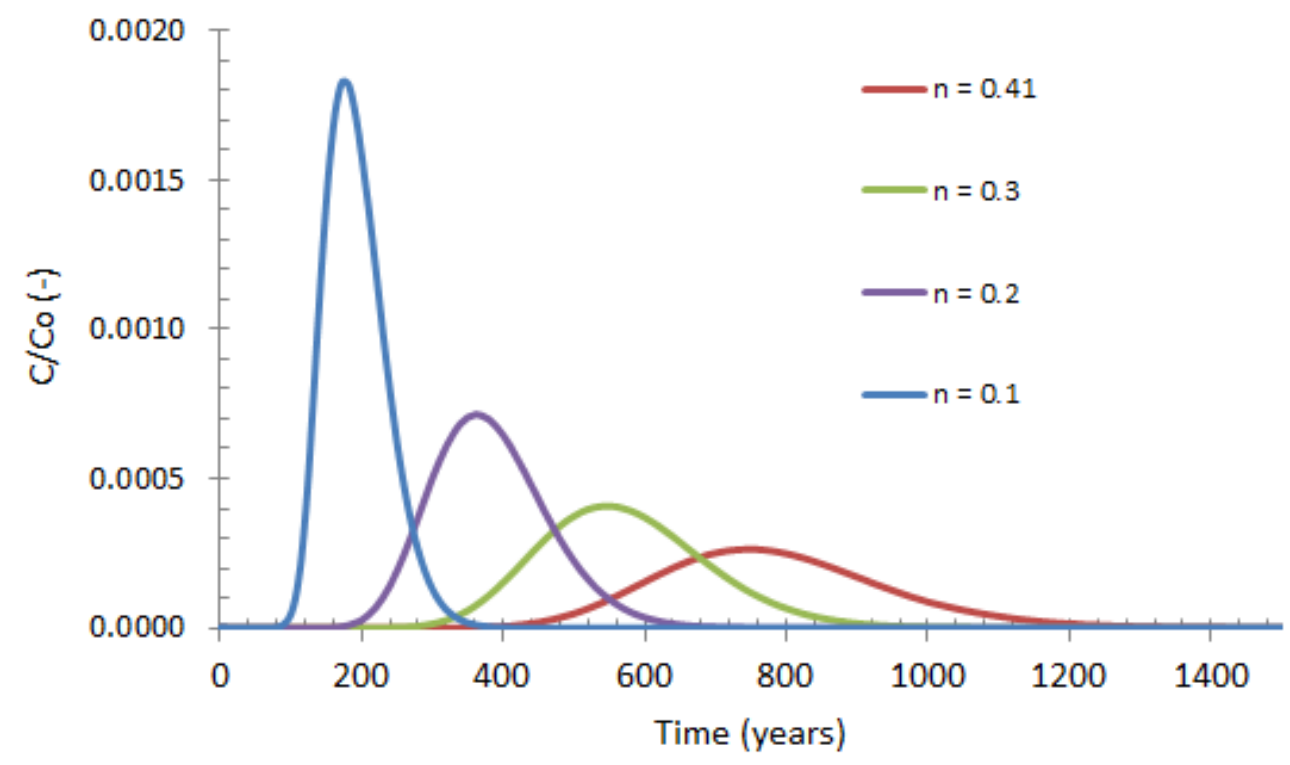

Figure 4.9. Normalized groundwater concentration over time for $n_{v}=0.1,0.2,0.3$, and 0.41 .

Simulations: sandy loam with $S A_{w d}=25 \mathrm{~m}^{2}, V_{w d}=1 \mathrm{~m}^{3}, D_{w d}=1$ day, and $L_{v}=25 \mathrm{~m}$.

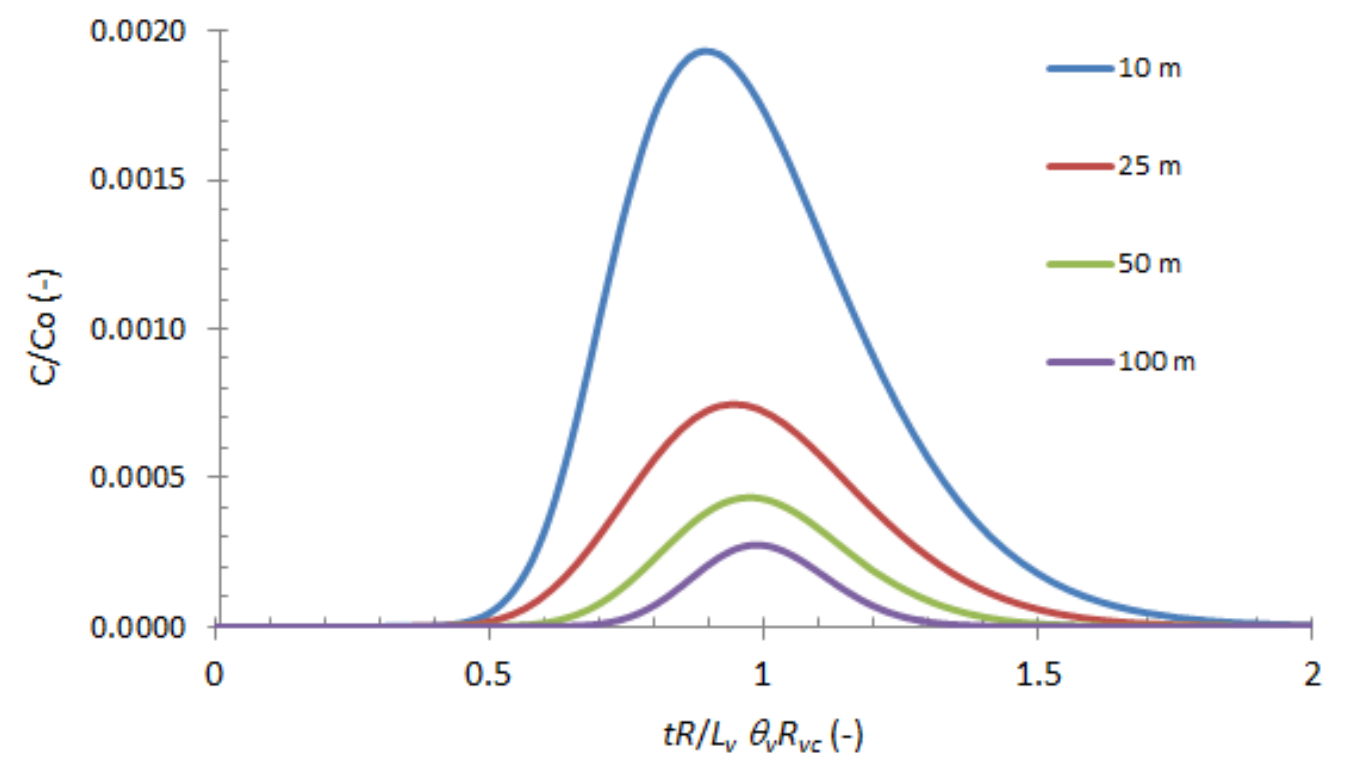

Figure 4.10. Normalized groundwater concentration vs. normalized time $\left(t R /\left(L_{v} \bar{\theta}_{v} R_{v c}\right)\right)$ for $n_{v}=0.1$, 0.2, 0.3, and 0.41. Simulations: sandy loam with $S A_{w d}=25 \mathrm{~m}^{2}, V_{w d}=1 \mathrm{~m}^{3}, D_{w d}=1$ day, and $L_{v}=25 \mathrm{~m}$. 


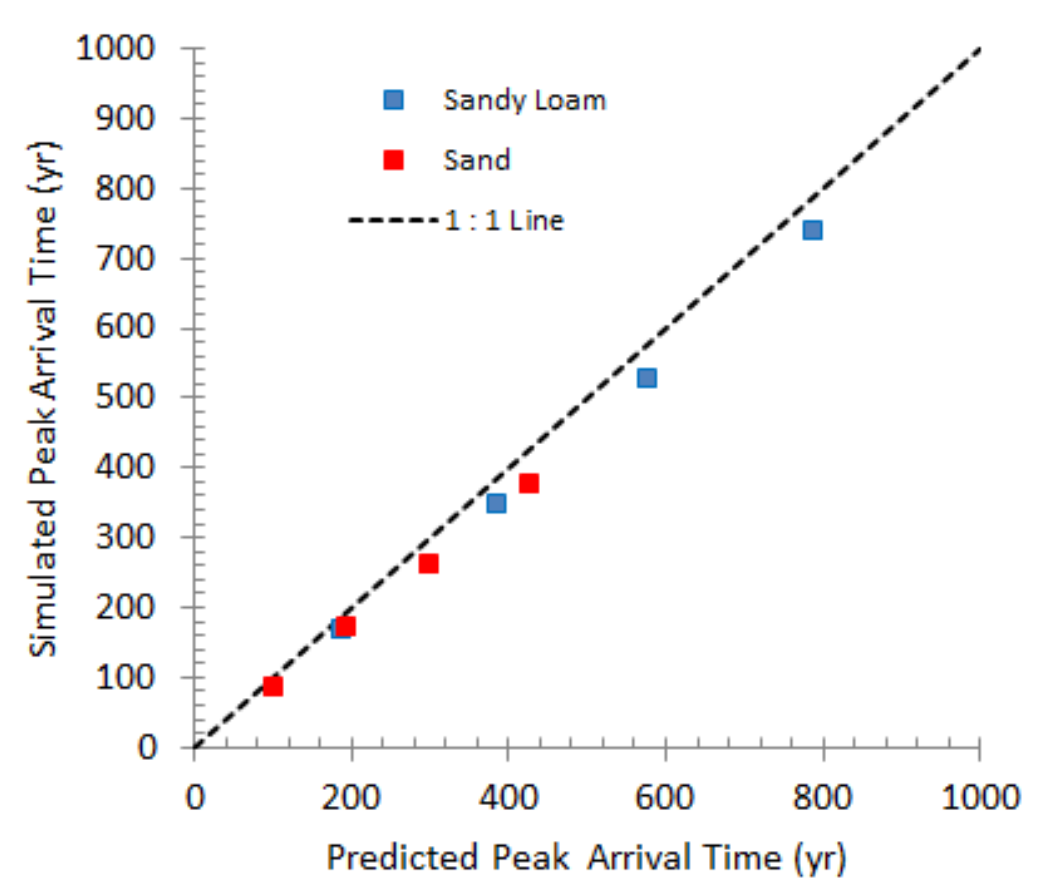

Figure 4.11. Relation between predicted and simulated peak arrival times of nonsorbing contaminants with $n_{v}=0.1,0.2,0.3$, and 0.41 for sandy loam and $n_{v}=0.1,0.2,0.3$, and 0.43 for sand. Simulations: sandy loam and sand with with $S A_{w d}=25 \mathrm{~m}^{2}, V_{w d}=1 \mathrm{~m}^{3}, D_{w d}=1$ day, and $L_{v}=25 \mathrm{~m}$.

\subsubsection{Impact of Contaminant Retardation}

Simulations with different $R_{c v}$ values allow for the testing of Eq. (4.2) for sorbing contaminant transport in Category I sites. In the example shown in Figure 4.12, $K_{d}$ values of $0,0.1$, and $0.2 \mathrm{~mL} / \mathrm{g}$, corresponding to $R_{v c}$ values of $1,2.42$, and 3.86, respectively, are used. Note that for this case, the larger nominal disposal volume is used. As expected, Figure 4.12 shows delayed arrival times for sorbed contaminants. The $C_{a}$ results versus normalized time (Figure 4.13) show $T_{c p}$ values close to 1 for the three considered $R_{c v}$ values, indicating that for sorbing contaminants at Category I sites, normalized arrival times such as Eq. (4.2) may be used for arrival predictions. A comparison of predicted peak $t_{c p}$ values using Eq. (4.1) and simulated $t_{c p}$ values is shown in Figure 4.14 for the sandy loam and equivalent sand simulations. Similar to what was shown for variations in $L_{v}, R$, and $n_{v}$ in the previous sections, the predicted and simulated values are again relatively close, with the differences the result of the addition of water to the surface during waste disposal. 


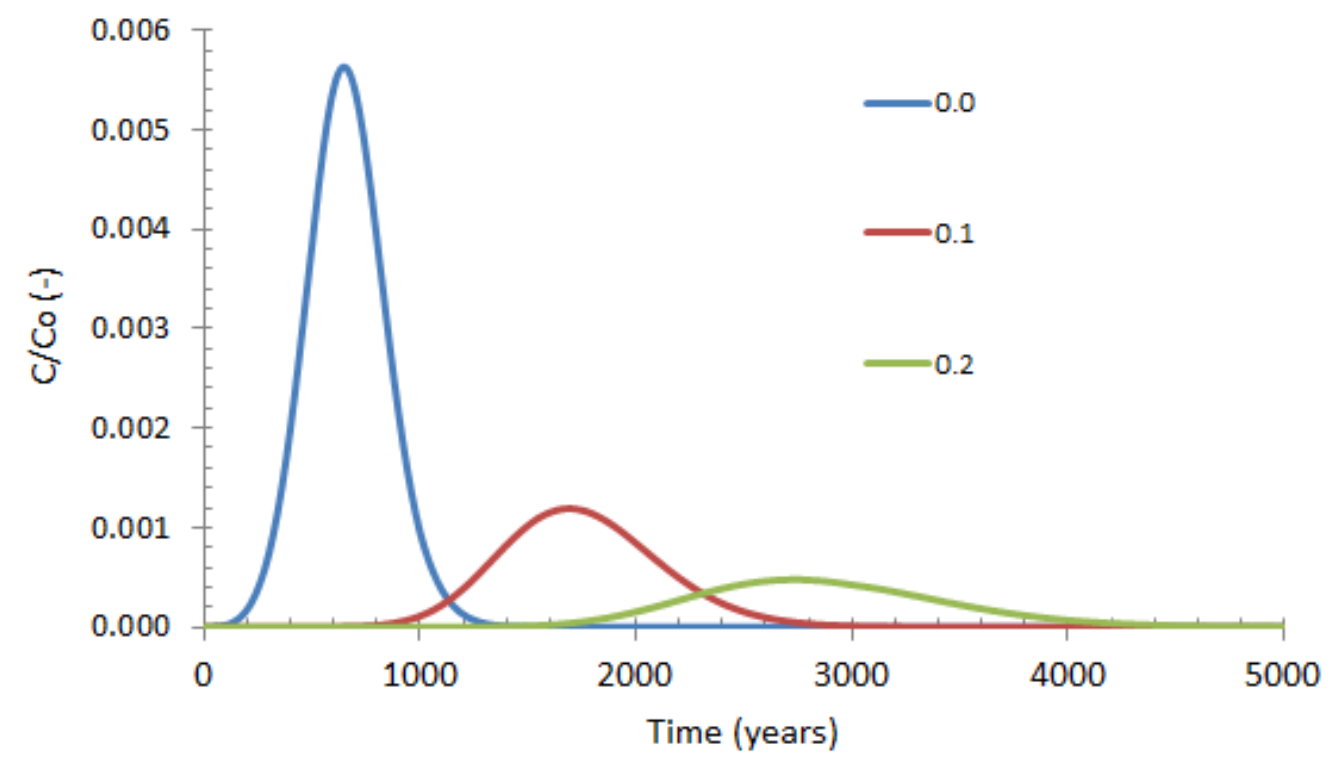

Figure 4.12. Normalized groundwater concentration over time for solutes with $K_{d}=0,0.1$, and 0.2 $\left(R_{c v}=1,2.42\right.$, and 3.86). Simulations: sandy loam with $S A_{w d}=25 \mathrm{~m}^{2}, V_{w d}=25 \mathrm{~m}^{3}, D_{w d}$ $=1$ day, and $L_{v}=25 \mathrm{~m}$.

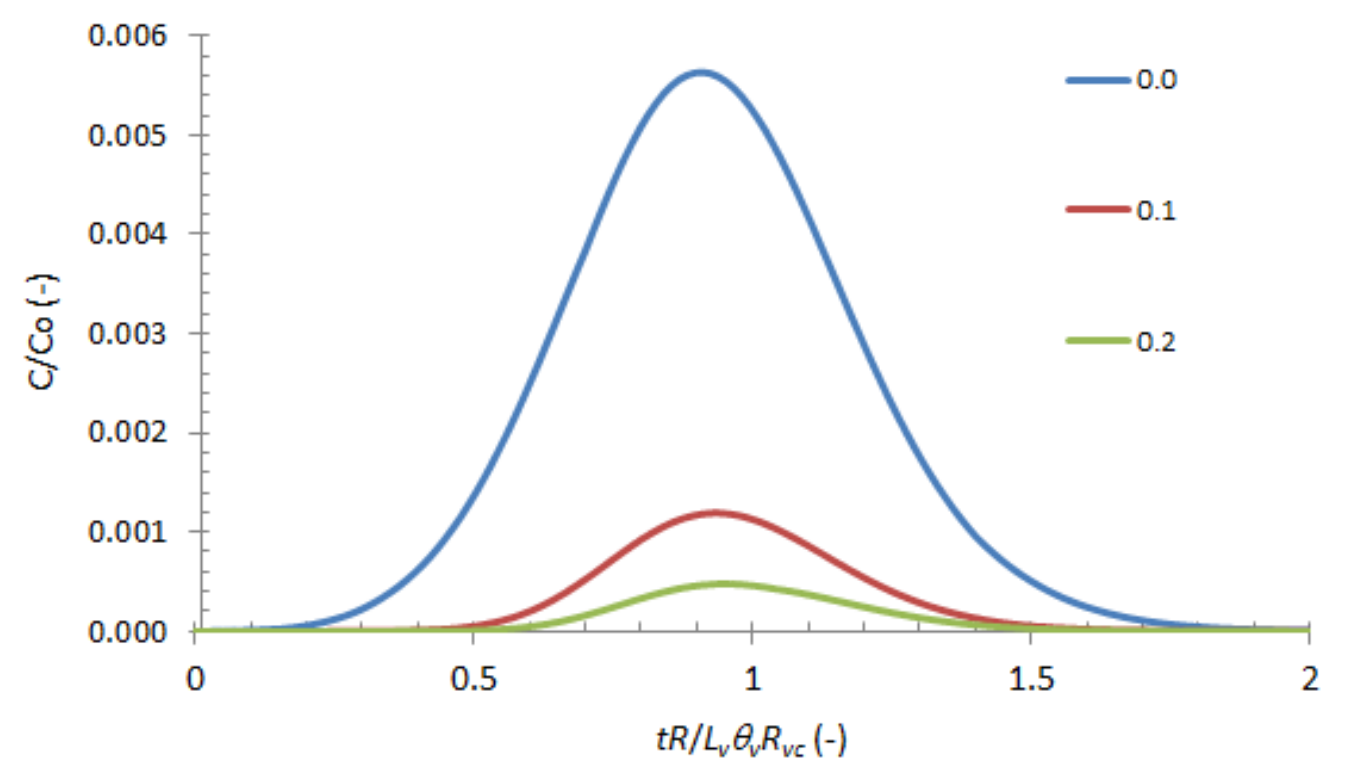

Figure 4.13. Normalized groundwater concentration vs. normalized time $\left(t R /\left(L_{v} \bar{\theta}_{v} R_{c v}\right)\right)$ for solutes with $K_{d}=0,0.1$, and $0.2\left(R_{v c}=1,2.42\right.$, and 3.86). Simulations: sandy loam with $S A_{w d}=$ $25 \mathrm{~m}^{2}, V_{w d}=25 \mathrm{~m}^{3}, D_{w d}=1$ day, and $L_{v}=25 \mathrm{~m}$. 


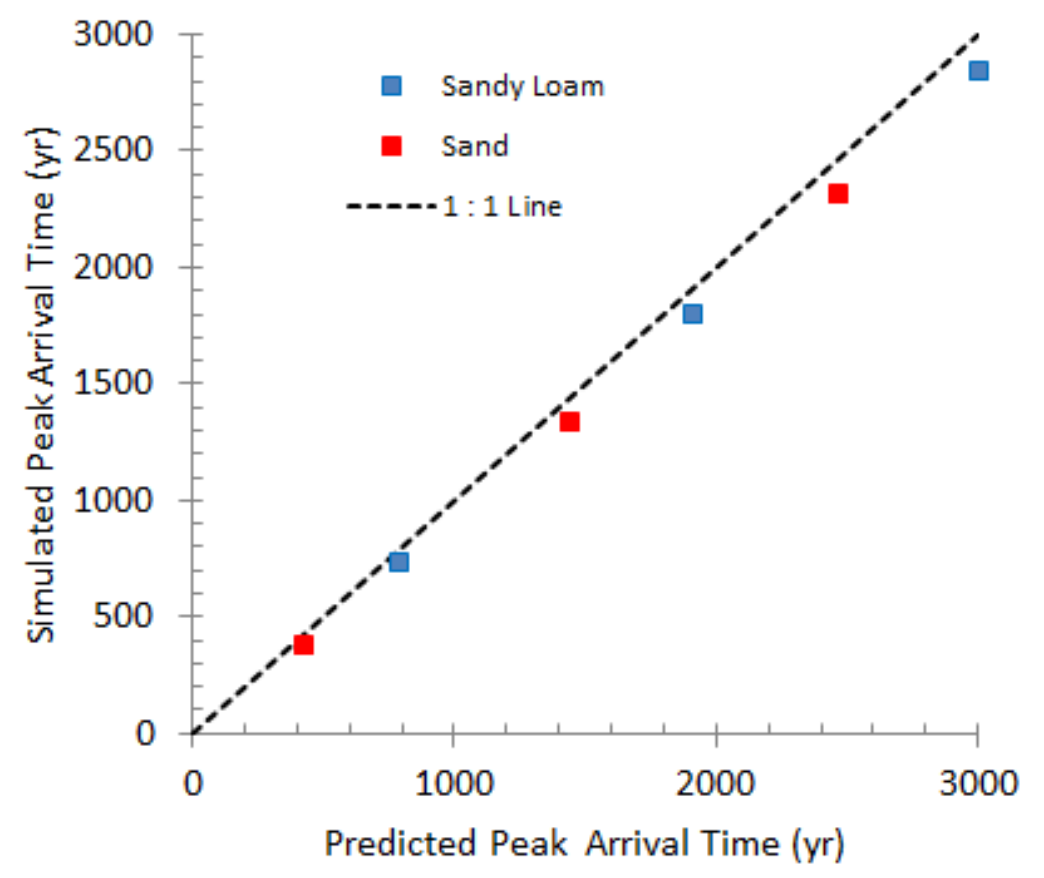

Figure 4.14. Relation between predicted and simulated peak arrival times for three solutes with $K_{d}=0.0$, 0.1 , and $0.2 \mathrm{~mL} / \mathrm{g}$. Simulations: sandy loam and sand with $S A_{w d}=25 \mathrm{~m}^{2}, V_{w d}=25 \mathrm{~m}^{3}$, $D_{w d}=1$ day, and $L_{v}=25 \mathrm{~m}$.

\subsubsection{Impact of Current Contaminant Distribution in Vadose Zone}

When a contaminant is located at a known position in the vadose zone, Eqs. (4.1) or (4.2) may be applied for peak travel time calculations under steady-state flow conditions at Category I sites. To demonstrate this, two examples are shown with known contaminant distributions in the vadose zone. No waste disposal is considered in these example simulations. In Figure 4.15, $C_{a}$ values are shown for configurations with a $5 \mathrm{~m}$ contaminated zone in the center of a vadose zone with $L_{v}=25 \mathrm{~m}$ and $R$ ranging from 3.5 to $100 \mathrm{~mm} / \mathrm{yr}$. The contaminant concentration in the layer is $1 / \mathrm{L}$, Denoting the top surface as $z=0 \mathrm{~m}$, the center of mass $(C M)$ is at $z=12.5 \mathrm{~m}$. Comparing Figure 4.15 with Figure 4.6, obtained for the same configuration but with disposed contaminated water at the top of the vadose zone, the peak arrival times occur in about half the time. This ratio is consistent with the distance of $C M$ to the water table $\left(=L_{v}-\mathrm{CM}=12.5 \mathrm{~m}\right)$ and the distance the contaminant has to move from the top to bottom after disposal $\left(=L_{v}=25 \mathrm{~m}\right)$. These results suggest that groundwater contaminant peak arrival times for such sites can be estimated by

$$
t_{c p}=\frac{\left(L_{v}-C M\right) \bar{\theta}_{v} R_{c v}}{R}
$$


To test this concept, $C_{a}$ is plotted in Figure 4.16 versus normalized time $\left(T_{c}\right)$, which, for systems with a contaminated zone with a $C M$ in the vadose zone, can be written as

$$
T_{c}=\frac{t R}{\left(L_{v}-C M\right) \bar{\theta}_{v} R_{c v}}
$$

Figure 4.16 clearly shows that the normalized contaminant peak arrival time, $T_{c p}$, is nearly 1 for all simulations. This result demonstrates that Eq. (4.4) can be used for these configurations.

To investigate the effects of the contaminated layer location, simulations are conducted for the same domain with 5-m thick contaminant layers at two different locations $(C M=2.5$ and $12.5 \mathrm{~m})$ for two $R$ values ( 25 and $50 \mathrm{~mm} / \mathrm{yr})$ in a vadose zone with $L_{v}=25 \mathrm{~m}$. Figure 4.17 shows groundwater concentrations as function of time for the four simulations. In Figure 4.18, concentrations are shown versus normalized time, as defined in Eq. (4.5). This figure clearly demonstrates that scaling using Eq. (4.5) is appropriate for Category I sites with different layer positions.

The analysis presented so far in this section applies to well-defined contaminated zones with a known $C M$ location. Information to estimate the position of such zones typically comes from site characterization. However, if such information is not available, the position of the $C M$ at a Category I site with constant recharge, $t_{C M}$ years after the waste disposal, can be estimated by

$$
C M=\frac{t_{C M} R}{\bar{\theta}_{v} R_{v c}}
$$

Eq. (4.6) is valid for vadose zone with relative homogeneous water content conditions. For layered systems, an estimate of the CM needs to consider the lengths of the individual layers $i$ and their average moisture contents, $\bar{\theta}_{v i}$. With that information, the travel time through each layer, $\Delta t_{i}$, can be computed as follows

$$
\Delta t_{i}=\frac{L_{v i} \bar{\theta}_{v i} R_{v c i}}{R}
$$

and cumulative travel time plots can be constructed as a function of vadose zone depths. An example of such a plot is shown in Figure 4.19 for a layered system defined in the caption. Cumulative travel time plots can be used to estimate $C M$ from $t_{C M}$ as indicated by the example in the plot. An additional feature of such plots is that it also provides an estimate for the travel time of the concentration peak from the current $C M$ location to groundwater, $t_{c p}$, which is equal to the total travel time from the top surface to the groundwater, $t_{t}$, minus $t_{C M}$ (Figure 4.19). 


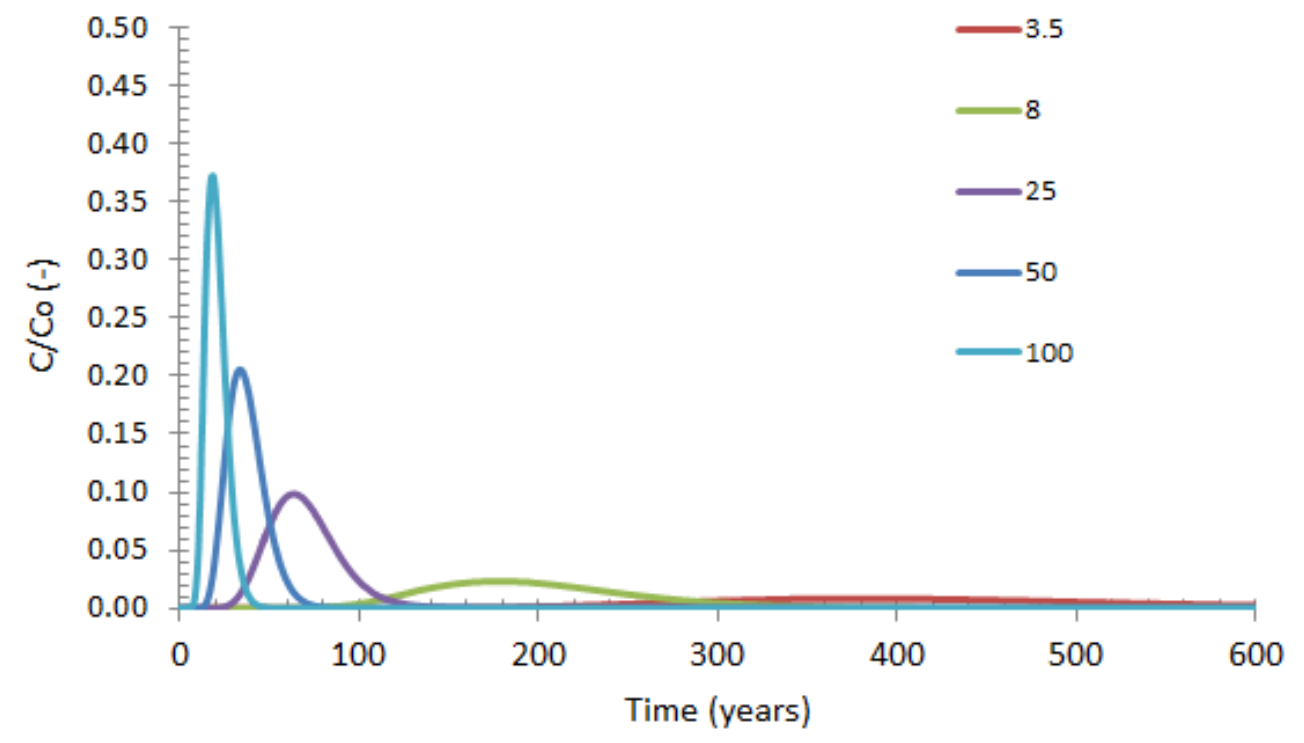

Figure 4.15. Normalized groundwater concentration over time for $R=3.5,8,25,50$, and $100 \mathrm{~mm} / \mathrm{yr}$ with the initial $C / C_{o}=1.0$ between $z=10$ and $15 \mathrm{~m}(C M$ is at $z=12.5 \mathrm{~m})$. Simulations: sandy loam with $S A_{w d}=25 \mathrm{~m}^{2}$ and $L_{v}=25 \mathrm{~m}$.

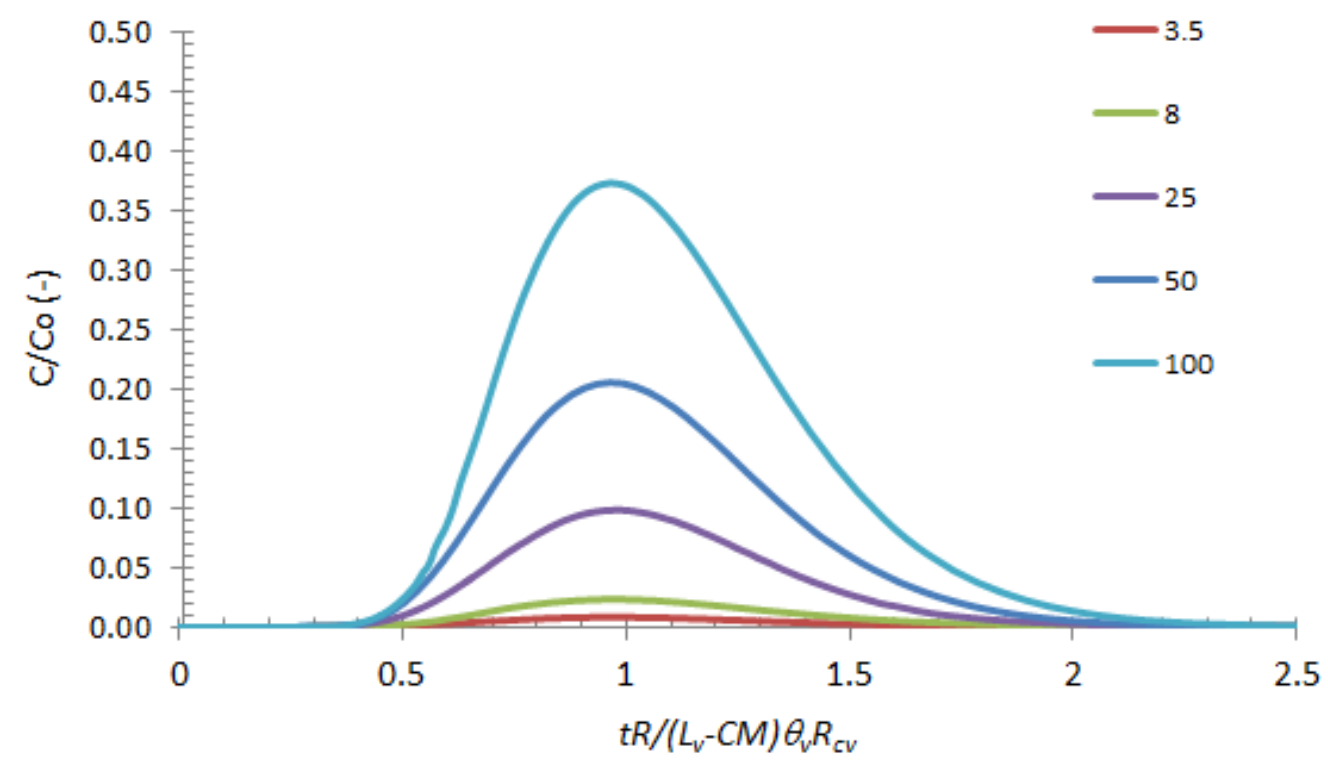

Figure 4.16. Normalized groundwater concentration vs. normalized time $\left(t R /\left(L_{v} \bar{\theta}_{v} R_{c v}\right)\right)$ for $R=3.5,8$, 25,50 , and $100 \mathrm{~mm} / \mathrm{yr}$ with the initial $C / C_{o}=1.0$ between $z=10$ and $15 \mathrm{~m}(C M$ is at $z=$ $12.5 \mathrm{~m})$. Simulations: sandy loam with $S A_{w d}=25 \mathrm{~m}^{2}$ and $L_{v}=25 \mathrm{~m}$. 


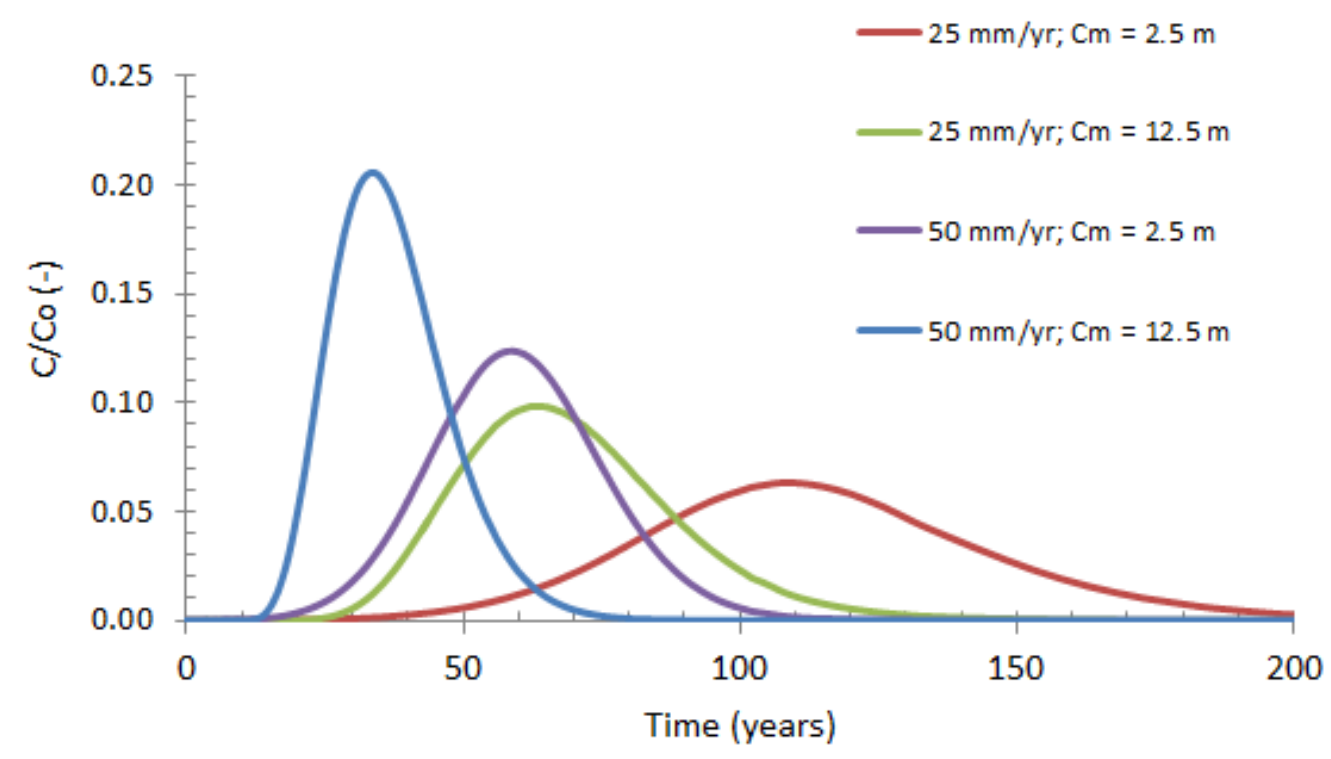

Figure 4.17. Normalized groundwater concentration versus time for two $5 \mathrm{~m}$ thick contaminated zones $(z$ $=0-5 \mathrm{~m}$ with $C M$ at $z=2.5 \mathrm{~m} ; z=10-15 \mathrm{~m}$ with $C M$ at $z=12.5 \mathrm{~m}$ ) where the initial $C / C_{o}=$ 1.0. The scaling is shown for $R=25$ and $50 \mathrm{~mm} / \mathrm{yr}$. Simulations: sandy loam with $S A_{w d}=$ $25 \mathrm{~m}^{2}$ and $L_{v}=25 \mathrm{~m}$.

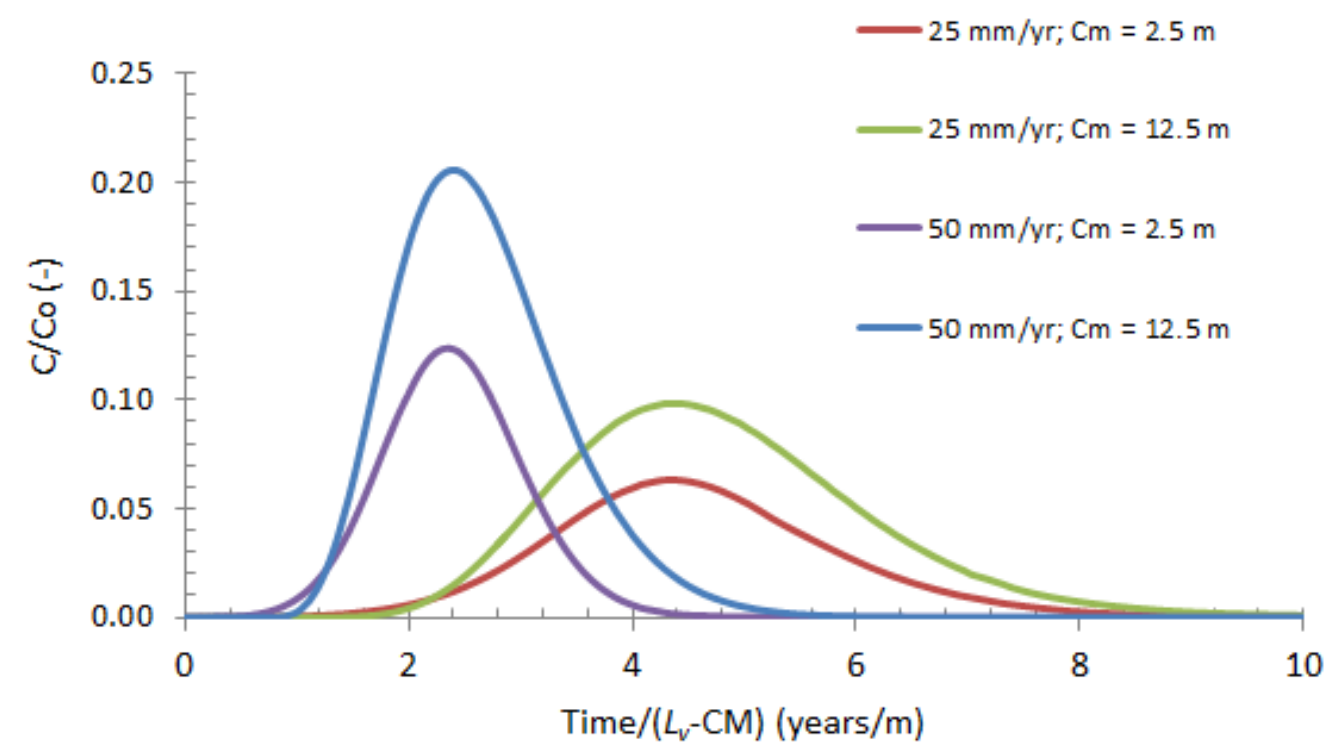

Figure 4.18. Normalized groundwater concentration over time/CM for two $5 \mathrm{~m}$ thick contaminated zones ( $z=0-5 \mathrm{~m}$ with $C M$ at $z=2.5 \mathrm{~m} ; z=10-15 \mathrm{~m}$ with $C M$ at $z=12.5 \mathrm{~m}$ ) where the initial $C / C_{o}$ $=1.0$. The scaling is shown for $R=25$ and $50 \mathrm{~mm} / \mathrm{yr}$. Simulations: sandy loam with $S A_{w d}$ $=25 \mathrm{~m}^{2}$ and $L_{v}=25 \mathrm{~m}$. 


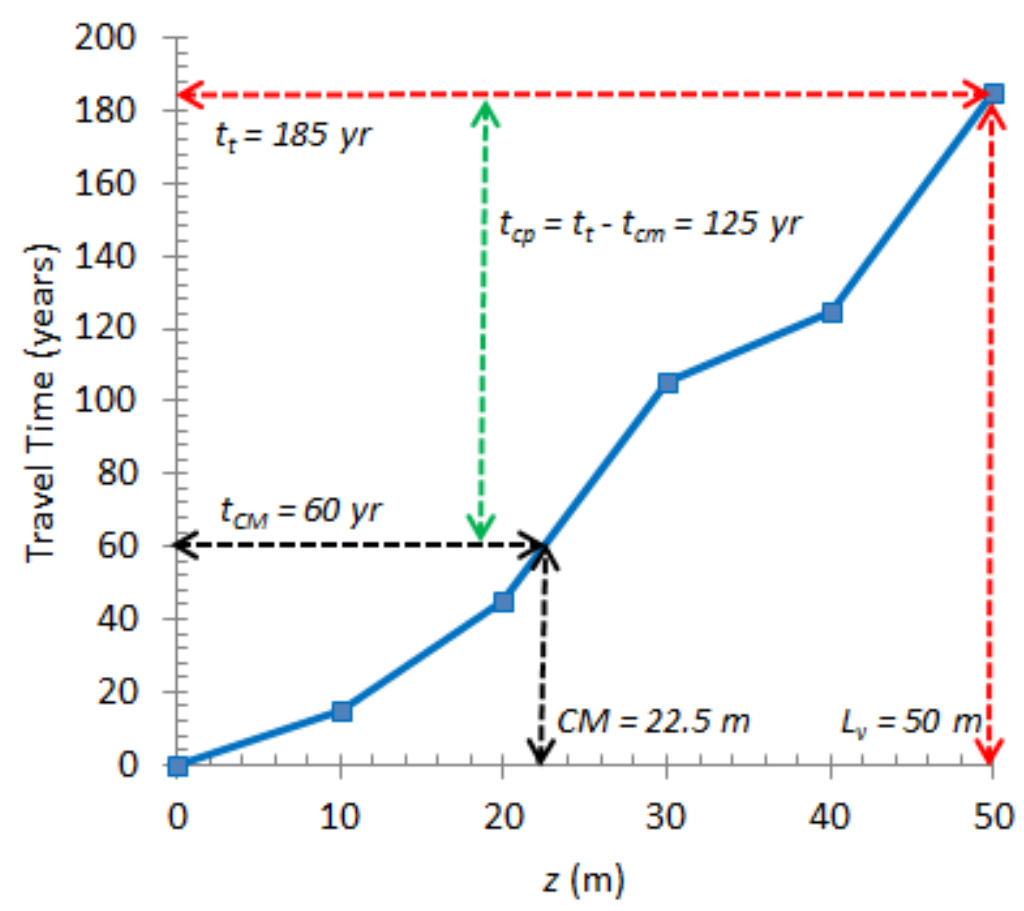

Figure 4.19. Peak arrival travel time from a waste disposal site to depth $z(\mathrm{~m})$ under steady-state, recharge-dominated conditions with $R=50 \mathrm{~mm} /$ year $(0.05 \mathrm{~m} /$ year $)$. The vadose zone contains five layers of $10 \mathrm{~m}$ each, with, starting at the top going downwards, $\bar{\theta}_{v}$ values of $0.075,0.15,0.3,0.1$, and 0.3 , respectively. The black dashed lines indicate an example calculation for $C M$ in the vadose zone at $t_{C M}=60$ years after waste disposal. The red dashed lines indicate the determination of the total travel time through the vadose zone $\left(t_{t}\right.$ $=185$ year). The contaminant peak arrival time, $t_{c p}$, (green dashed line) is predicted to occur $185-60=125$ years from the current time.

\subsubsection{Category I; Layered Subsurface}

The effect of layered systems on contaminant mass discharge was investigated for the same variables described in Section 4.1.1. for homogeneous systems. The results are all consistent with the application of Eqs. (2.10) and (2.11) for steady-state conditions at Category I sites and for that reason only results for variations in $L_{v}$ and $R$ are discussed in this section. In Figure 4.20 examples of computed groundwater concentrations, $C_{a}$, resulting from the disposal of a nonsorbing contaminant in sandy loam, are shown for four $L_{v}$ values with a $5 \mathrm{~m}$ silt layer in the center. The $C_{a}$ results indicate that compared to the homogeneous sandy loam simulations (Figure 4.1), the travel times have increased. The silt layer is wetter than the surrounding sandy loam and the additional water in the layered system causes the contaminant to have a delayed arrival at the water table. Under the imposed $R$ of $3.5 \mathrm{~mm} / \mathrm{yr}$, the approximate $\bar{\theta}_{v}$ of the silt layer is 0.25 , which is equivalent to average saturation of about 0.6. In Figure 4.21, the aquifer concentrations are plotted as a function of normalized time. The plots show that for all $L_{v}$ values, $T_{c p}$ is close to 1 , computed using simulated $\bar{\theta}_{v}$ values of $0.442,0.334,0.297$, and 0.278 for $L_{v}$ 
$=10,25,50$, and $100 \mathrm{~m}$, respectively. The deviation from $T_{c p}=1$ increases with a decrease in $L_{v}$ because the influence of the disposal volume is more significant in a smaller vadose zone. A comparison of predicted peak $t_{c p}$ values using Eq. (4.1) and simulated $t_{c p}$ values is shown in Figure 4.22 for a nonsorbing contaminant in sandy loam and sand with a $5 \mathrm{~m}$ silt layer in the center for four $L_{v}$ values.

Examples of the effects of recharge on contaminant transport in layered systems are shown in Figure 4.23-Figure 4.25. Computed groundwater concentrations, $C_{a}$, are shown for five $R$ values, ranging from $3.5 \mathrm{~mm} / \mathrm{yr}$ to $100 \mathrm{~mm} / \mathrm{yr}$. The $C_{a}$ results in Figure 4.23 indicate that the arrival times are larger for the layered cases than for the homogeneous sandy loam simulations (Figure 4.6). The $C_{a}$ results versus normalized time (Figure 4.24) show $T_{c p}$ values close to 1 for all $R$ values, indicating that even for the largest $R$ value of $100 \mathrm{~mm} / \mathrm{yr}$ where the silt layer has an average saturation 0.85 ( $\left.\bar{\theta}_{v}=0.36\right)$, the contaminant mass discharge falls in Category I. A comparison of predicted peak $T_{c p}$ values using Eq. (2.11) and simulated $T_{c p}$ values is shown in Figure 4.25 for the sandy loam and equivalent sand simulations. Consistent with the findings for homogeneous cases, the predicted and simulated values are fairly close, indicating the appropriateness of using a simple algebraic relation (Eq (2.11)) for estimating arrival times for Category I sites with steady-state recharge conditions.

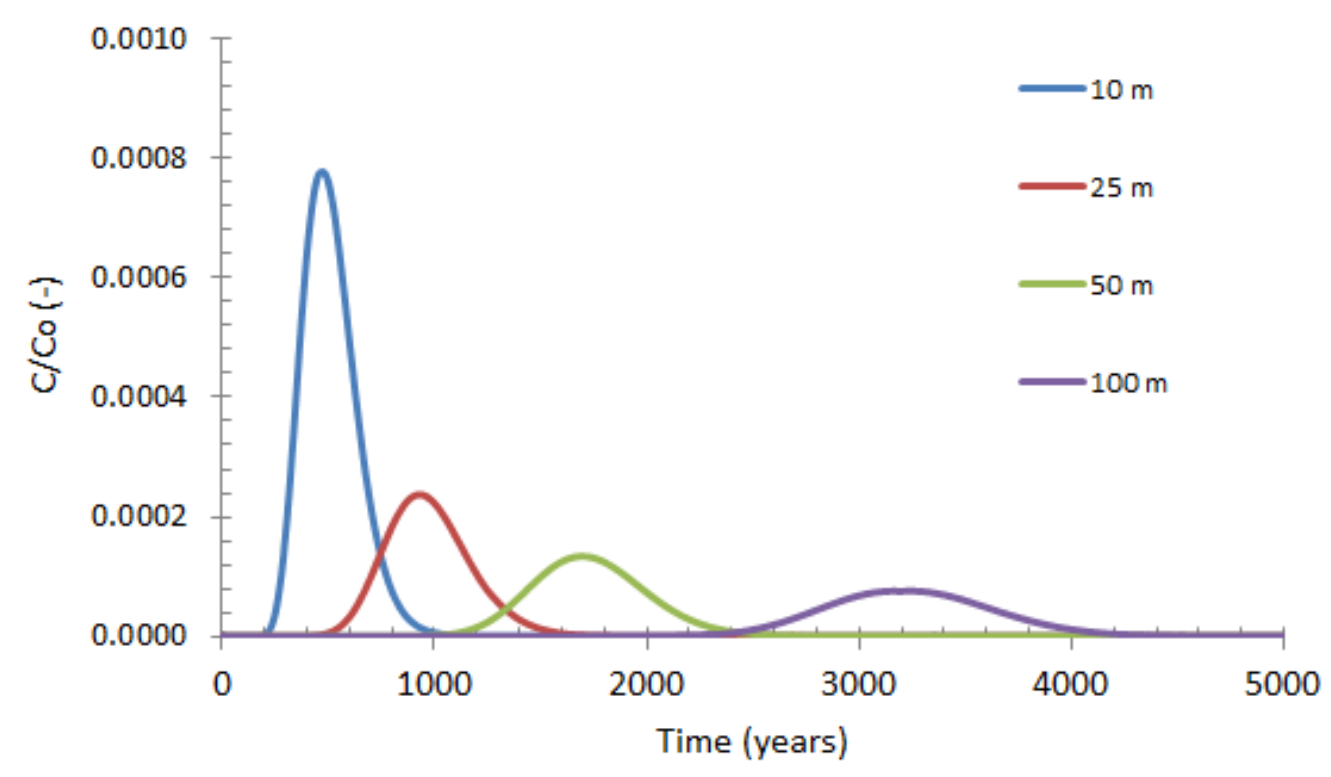

Figure 4.20. Normalized groundwater concentration over time for $L_{v}=10,25,50$, and $100 \mathrm{~m}$.

Simulations: sandy loam with $5 \mathrm{~m}$ silt zone in the center; $S A_{w d}=25 \mathrm{~m}^{2}, V_{w d}=1 \mathrm{~m}^{3}, D_{w d}$ $=1$ day, and $R=3.5 \mathrm{~mm} / \mathrm{yr}$. 


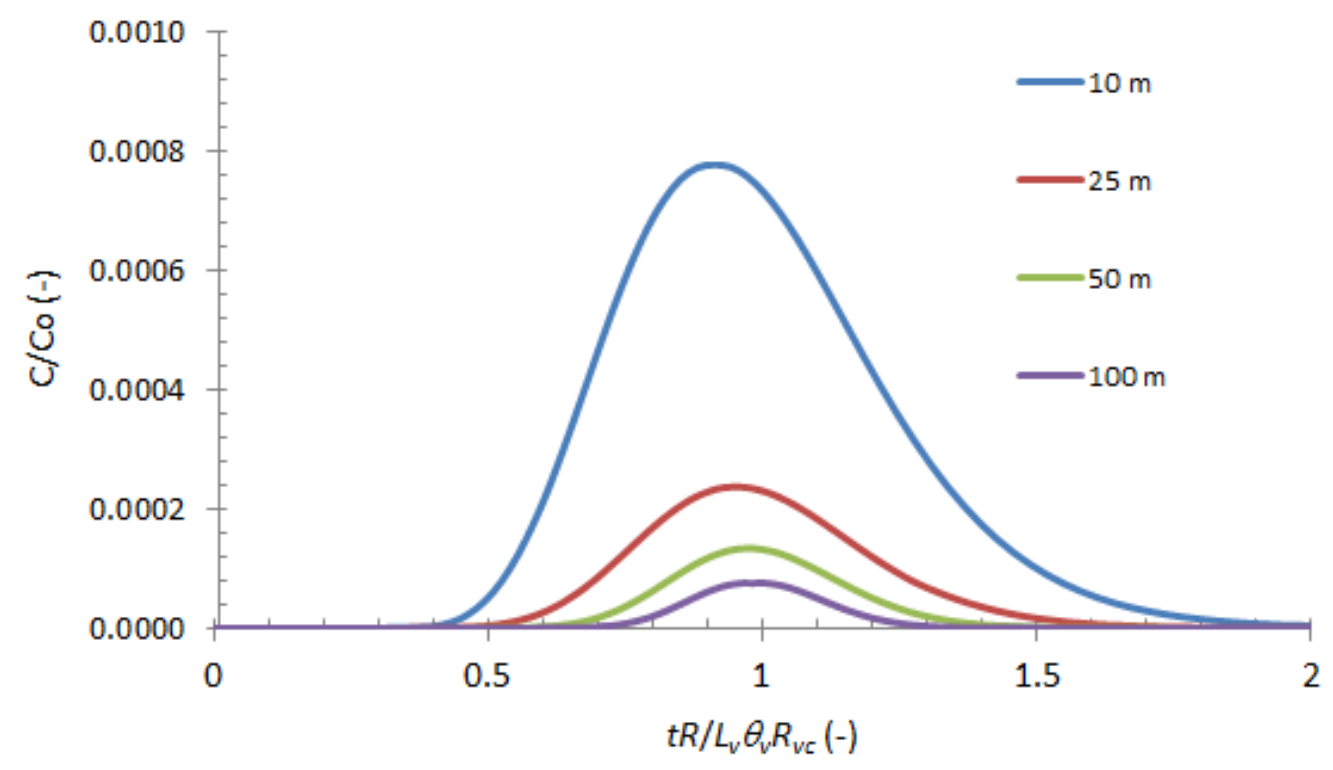

Figure 4.21. Normalized groundwater concentration vs. dimensionless time $\left(t R /\left(L_{v} \bar{\theta}_{v} R_{c v}\right)\right)$ for $L_{v}=$ $10,25,50$, and $100 \mathrm{~m}$. Simulations: sandy loam with $5 \mathrm{~m}$ silt zone in the center; $S A_{w d}=25$ $\mathrm{m}^{2}, V_{w d}=1 \mathrm{~m}^{3}, D_{w d}=1$ day, and $R=3.5 \mathrm{~mm} / \mathrm{yr}$.

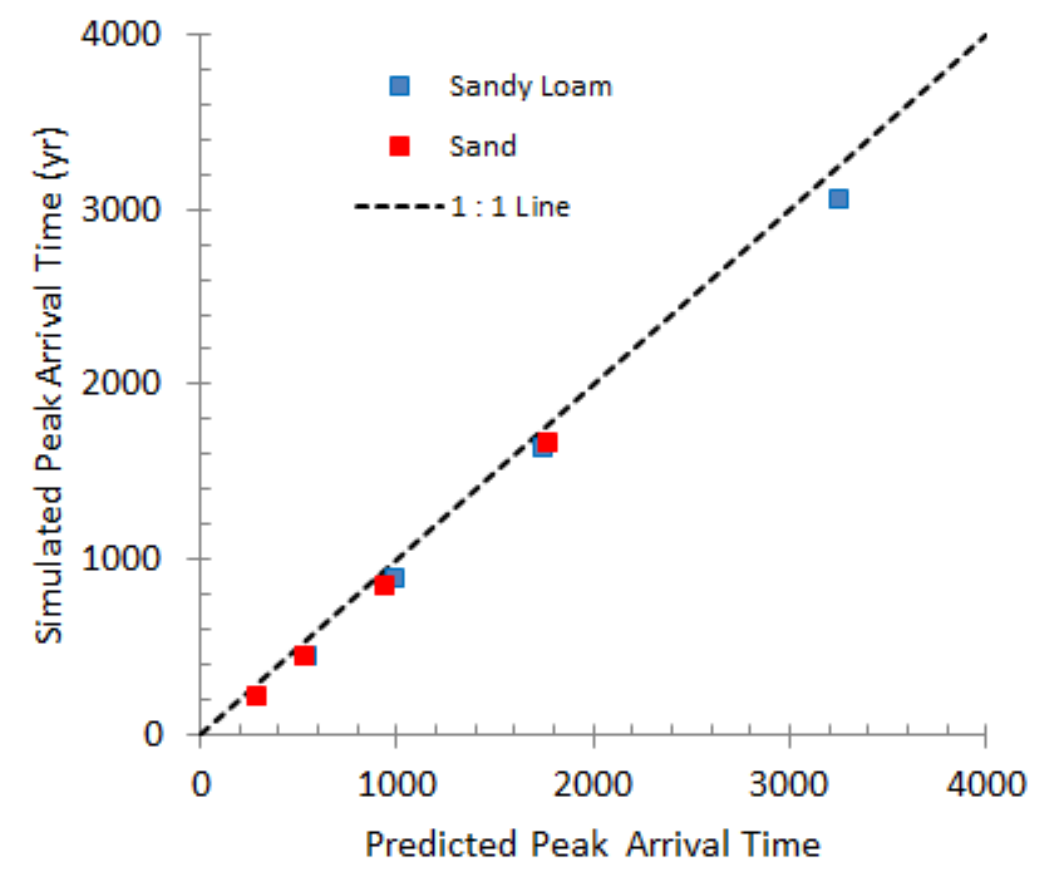

Figure 4.22. Relation between predicted and simulated peak arrival times of nonsorbing contaminants for $L_{v}=10,25,50$, and $100 \mathrm{~m}$. Simulations: sandy loam with $5 \mathrm{~m}$ silt zone in the center; $S A_{w d}=25 \mathrm{~m}^{2}, V_{w d}=1 \mathrm{~m}^{3}, D_{w d}=1$ day, and $R=3.5 \mathrm{~mm} / \mathrm{yr}$. 


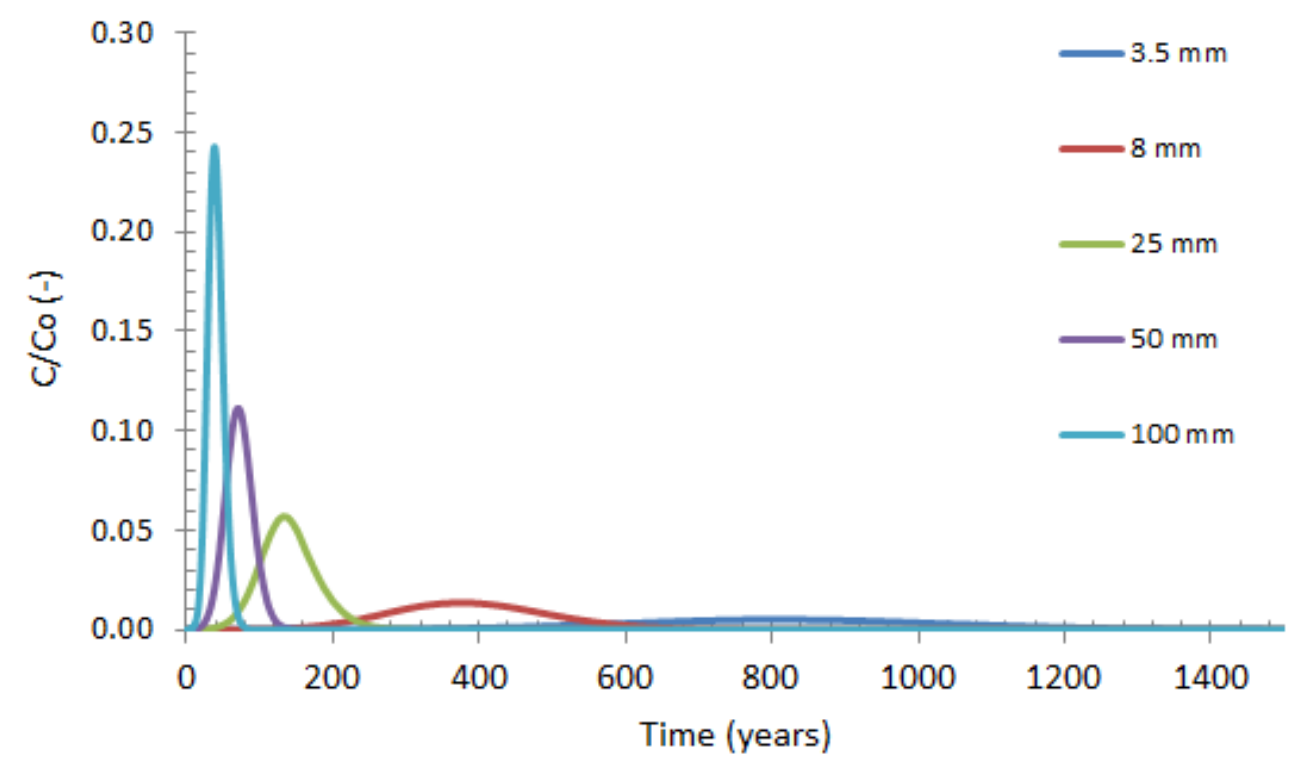

Figure 4.23. Normalized groundwater concentration over time for $R=3.5,8,25,50$, and $100 \mathrm{~mm} / \mathrm{yr}$. Simulations: sandy loam with a $5 \mathrm{~m}$ silt layer in the center. $S A_{w d}=25 \mathrm{~m}^{2}, V_{w d}=25 \mathrm{~m}^{3}$, $D_{w d}=1$ day, and $L_{v}=25 \mathrm{~m}$.

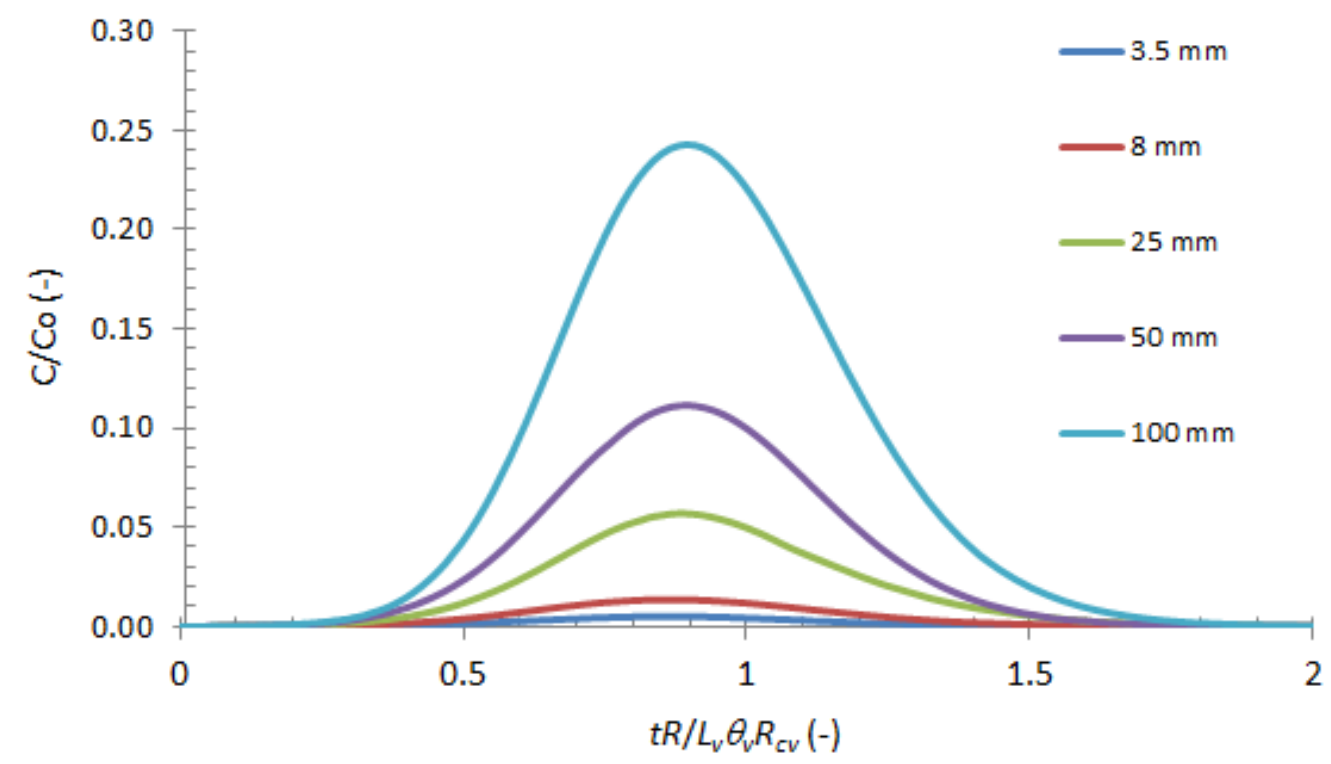

Figure 4.24. Normalized groundwater concentration vs. dimensionless time $\left(t R /\left(L_{v} \bar{\theta}_{v} R_{v c}\right)\right)$ for $R=$ $3.5,8,25,50$, and $100 \mathrm{~mm} / \mathrm{yr}$. Simulations: sandy loam with a $5 \mathrm{~m}$ silt layer in the center. $S A_{w d}=25 \mathrm{~m}^{2}, V_{w d}=25 \mathrm{~m}^{3}, D_{w d}=1$ day, and $L_{v}=25 \mathrm{~m}$. 


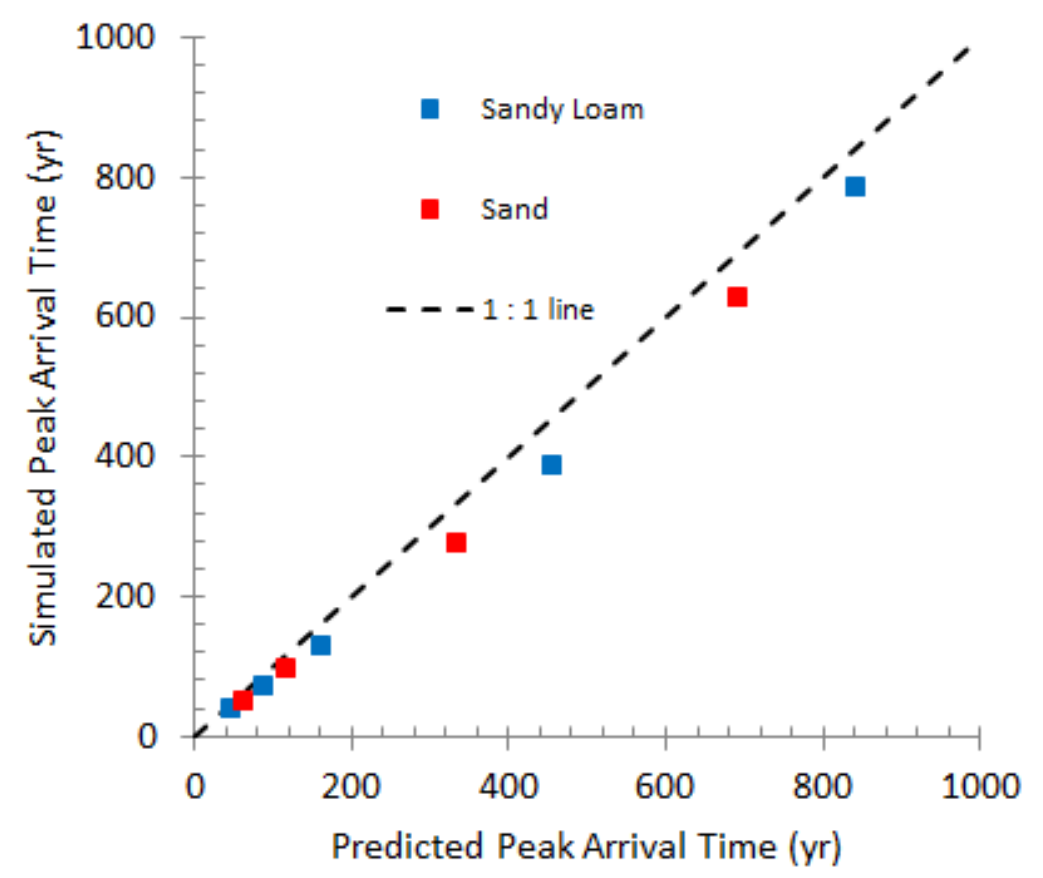

Figure 4.25. Relation between predicted and simulated peak arrival times of nonsorbing contaminants for $R=3.5,8,25,50$, and $100 \mathrm{~mm} / \mathrm{yr}$. Simulations: sandy loam and sand with $5 \mathrm{~m}$ silt layer in the center. $S A_{w d}=25 \mathrm{~m}^{2}, V_{w d}=25 \mathrm{~m}^{3}, D_{w d}=1$ day, and $L_{v}=25 \mathrm{~m}$.

\subsubsection{Category I: Contaminant Mixing}

In the analysis and examples shown so far in Section 4, the emphasis has been on the contaminant peak arrival time. It has been clearly demonstrated that this time can be predicted with simple algebraic equations (Eqs. (2.10) and (2.11)) using only a few averaged parameter values. The previous concentration plots indicate that some spreading occurs around the peak, as is typical for contaminant breakthrough behavior. The spreading in steady-state systems is the result of hydrodynamic dispersion, as explained in Section 2. In the simulations, a total variation diminishing scheme is used to compute mechanical dispersion to keep numerical mixing to a minimum. Molecular diffusion is computed using a Fick's type approach (Eq. (2.6)). The effects of molecular diffusion have been investigated in a sensitivity analysis for several configurations in which the diffusion coefficient in water $\left(D_{o}\right)$ was varied from 0.25 to 4 times the assumed contaminant $D_{o}$ of $2.5 \mathrm{e}-5 \mathrm{~cm}^{2} / \mathrm{s}$. An example of the results is shown in Figure 4.26, demonstrating a limited effect of diffusion on contaminant spreading. These results can be explained by realizing that the diffusive flux is directly related to the product of the tortuosity $(\tau)$ and $D_{o}: \tau D_{o}$. For unsaturated systems in sandy loam and sand, the $\tau$ value is typically less than 0.01 , making the diffusive process rather tortuous. The results shown in Figure 4.26 suggest that the observed spreading is likely the result of mechanical dispersion. Additional research is needed to quantify and improve the understanding of this mixing process related to mass discharge from a vadose zone into groundwater. 
To quantify the spreading behavior, all $C_{a}$ results for Category I sites (Appendix A) have been analyzed to obtain contaminant arrival and elution concentration times. The contaminant arrival time, $t_{c a}$, is defined as the time when $C_{a}$ is $1 \%$ of the peak concentration at the beginning of the period of mass discharge into the groundwater. The contaminant elution time, $t_{c e}$, is defined as the time when $C_{a}$ is $1 \%$ of the peak concentration at the end of the mass discharge period. Both times can be normalized using an expression similar to Eqs. (4.1) and (4.2) to yield $T_{c a}$ and $T_{c e}$, respectively. The expression can be used to analyze arrival and elution times. An example in Figure 4.27 shows how these quantities can be used to specify spreading around $T_{c p}$. The example figure indicates that the relative spreading for this example decreases with increasing $L_{v}$.

The results from all homogeneous and heterogeneous simulations were analyzed to compute $T_{c a}, T_{c p}$, and $T_{c e}$ values. The ranges in the normalized times are presented in Table 4.1 for different $L_{v}$ values. The specified ranges in the tables included sorbing and nonsorbing contaminants and apply to both homogeneous and heterogeneous systems. Although detailed knowledge of the relative narrow ranges has not been obtained, the presented numbers are of practical use for Category I waste sites.

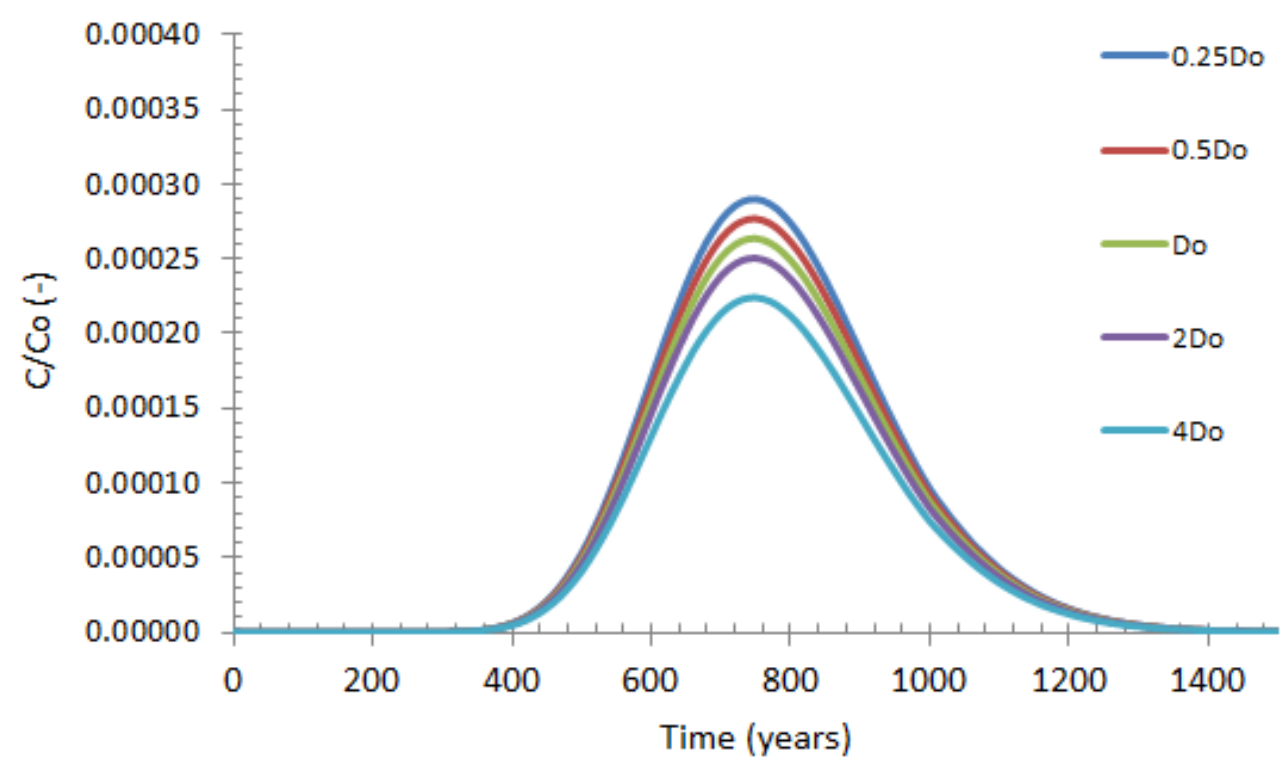

Figure 4.26. Normalized groundwater concentration over time for various diffusion coefficients $\left(D_{o}=\right.$ 2.5e-5 $\mathrm{cm}^{2} / \mathrm{s}$. Simulations: sandy loam with $S A_{w d}=25 \mathrm{~m}^{2}, V_{w d}=1 \mathrm{~m}^{3}, D_{w d}=1$ day, $R=$ $3.5 \mathrm{~mm} / \mathrm{yr}$, and $L_{v}=25 \mathrm{~m}$. 


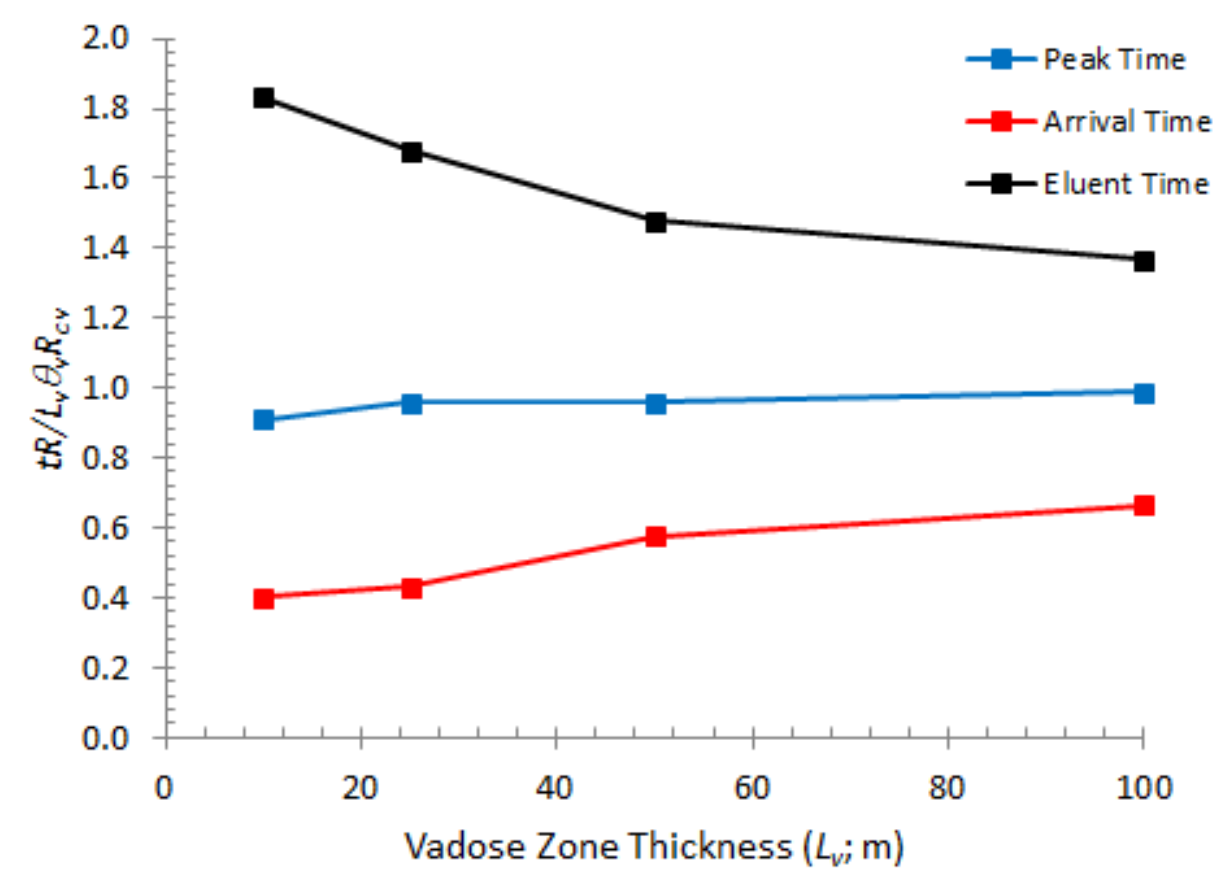

Figure 4.27. Normalized time $\left(t R /\left(L_{v} \bar{\theta}_{v} R_{v c}\right)\right)$ versus $L_{v}$ for contaminant arrival, peak, and elution times. Simulations: sandy loam with $S A_{w d}=25 \mathrm{~m}^{2}, V_{w d}=1 \mathrm{~m}^{3}, D_{w d}=1$ day, and $R=3.5$ $\mathrm{mm} / \mathrm{yr}$.

Table 4.1. Simulated ranges in $T_{c a}: T_{c p}$ and $T_{c e}: T_{c p}$ ratios for Category I disposal events. The reported ranges are for homogeneous and layered systems and for contaminants with $K_{d}$ ranging from $0-0.2 \mathrm{~mL} / \mathrm{g}$.

\begin{tabular}{ccc}
\hline & $\begin{array}{c}\text { Normalized } \\
\text { Contaminant Arrival } \\
\text { Time/Peak Arrival Time }\end{array}$ & $\begin{array}{c}\text { Normalized } \\
\text { Contaminant Elution } \\
\text { Time/Peak Arrival Time }\end{array}$ \\
\hline Vadose Zone Length $\left(L_{v} ; \mathbf{m}\right)$ & $\left(T_{c a}: T_{c p}\right)$ & $\left(T_{c e}: T_{c p}\right)$ \\
\hline 10 & Sandy Loam & $1.92-2.05$ \\
25 & $0.42-0.49$ & $1.72-1.79$ \\
50 & $0.45-0.52$ & $1.50-1.57$ \\
100 & $0.56-0.63$ & $1.34-1.42$ \\
\hline & $0.65-0.72$ & $1.90-2.09$ \\
25 & Sand & $1.75-1.82$ \\
50 & $0.39-0.48$ & $1.56-1.65$ \\
100 & $0.43-0.50$ & $1.37-1.44$ \\
\hline
\end{tabular}




\subsection{Waste Disposal Parameters}

In this section, waste disposal impacts of key parameters listed in Table 3.1 are discussed for Category I sites. The parameters include volume $\left(V_{w d}\right)$, duration $\left(D_{w d}\right)$, rate $\left(R_{w d}\right)$, contamination concentration $\left(C_{w d}\right)$, and surface area $\left(S A_{w d}\right)$. The disposed mass $\left(M_{w d}\right)$ is also considered to be the product of $V_{w d}$ and $C_{w d}$. In the examples, it was assumed that the retardation coefficients and porosities were the same in the vadose zone and groundwater $\left(R_{c a}=R_{c v}\right.$ and $\left.n_{a}=n_{v}\right)$, and that $L_{a}=5 \mathrm{~m}$.

\subsubsection{Waste Disposal Volume}

For a given $C_{w d}, V_{w d}$ determines $M_{w d}$ disposed at a site. For systems where contaminant transport is dominated by advective migration driven by recharge, the mass discharge into groundwater from the vadose zone is almost directly proportional to $V_{w d}$ and the resulting aquifer concentrations $\left(C_{a}\right)$ follow suit. This relationship is shown in Figure 4.28 and Figure 4.29.

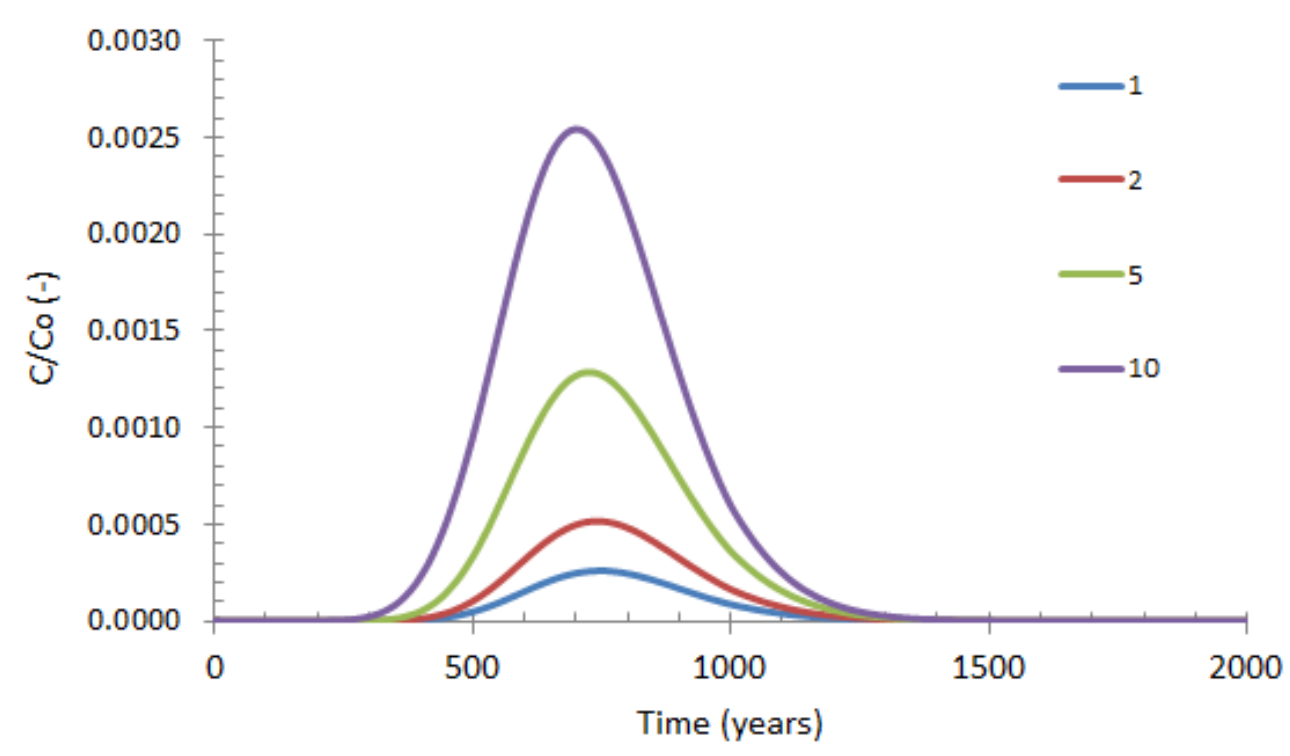

Figure 4.28. Normalized groundwater concentration over time for $V_{w d}=1,2,5$, and $10 \mathrm{~m}^{3}$.

Simulations: sandy loam with $S A_{w d}=25 \mathrm{~m}^{2}, D_{w d}=1$ day, $C_{w d}=1 / \mathrm{L}, R=3.5 \mathrm{~mm} / \mathrm{yr}$, and $L_{v}=25 \mathrm{~m}$. 


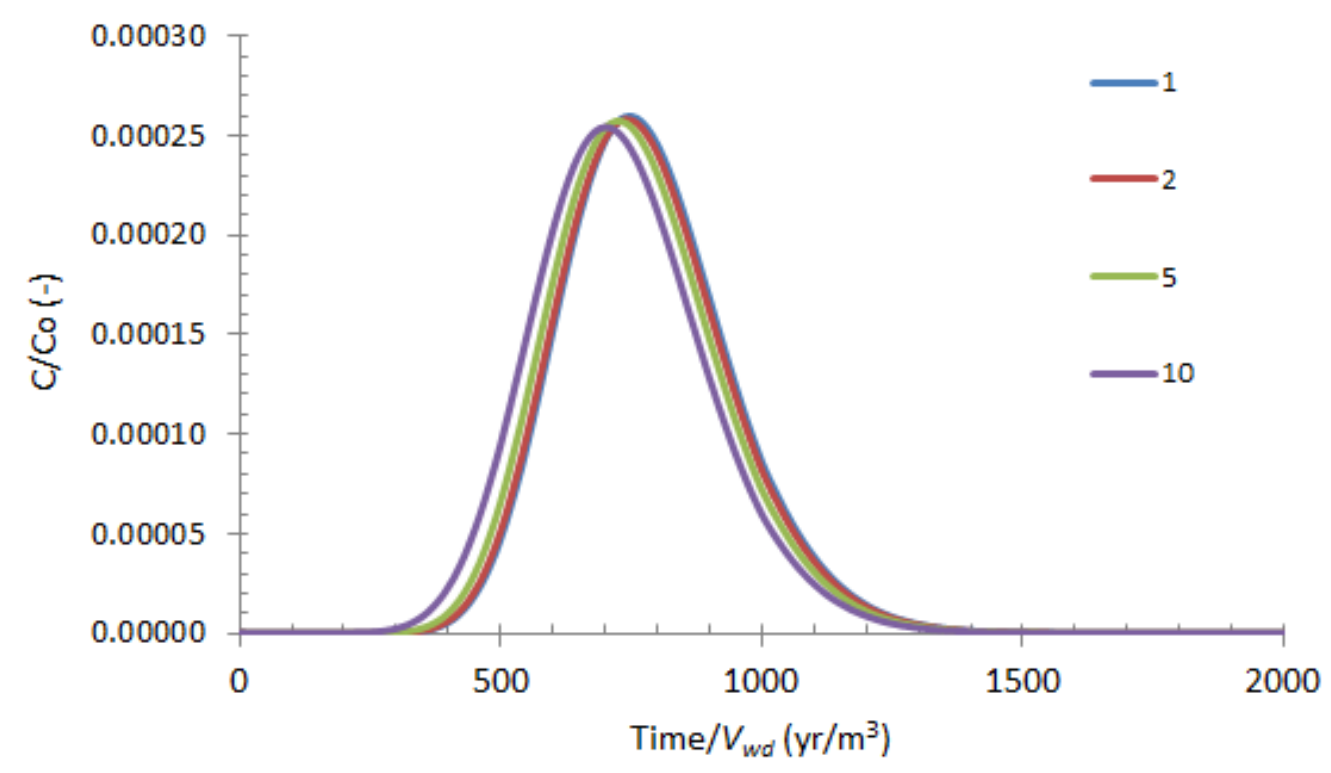

Figure 4.29. Normalized groundwater concentration over time/ $V_{w d}$ for $V_{w d}=1,2,5$, and $10 \mathrm{~m}^{3}$.

Simulations: sandy loam with $S A_{w d}=25 \mathrm{~m}^{2}, D_{w d}=1$ day, $C_{w d}=1 / \mathrm{L}, \mathrm{R}=3.5 \mathrm{~mm} / \mathrm{yr}$, and $L_{v}=25 \mathrm{~m}$.

\subsubsection{Waste Disposal Duration}

For a given total $V_{w d}$, the $D_{w d}$ does not change the $M_{w d}$ disposed at a site. The mass discharge into groundwater from the vadose zone is therefore only marginally affected by $D_{w d}$ as is shown in Figure 4.30. 


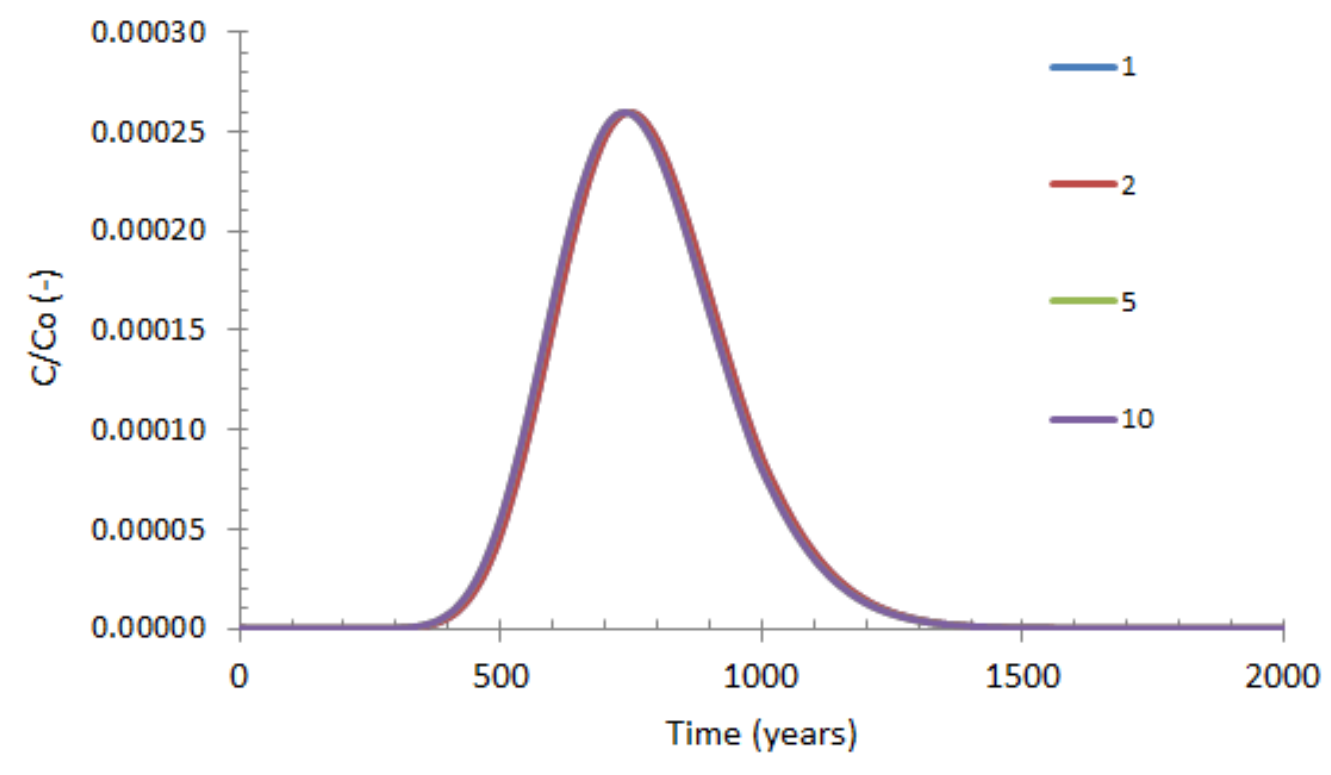

Figure 4.30. Normalized groundwater concentration over time for $D_{w d}=1,2,5$, and 10 days. Simulations: sandy loam with $S A_{w d}=25 \mathrm{~m}^{2}, V_{w d}=1 \mathrm{~m}^{3}, R=3.5 \mathrm{~mm} / \mathrm{yr}$, and $L_{v}=25 \mathrm{~m}$.

\subsubsection{Waste Concentration}

For a given $V_{w d}, C_{w d}$ determines $M_{w d}$ disposed at a site. For Category I systems, the mass discharge into groundwater from the vadose zone is almost directly proportional to $C_{w d}$ and the resulting aquifer concentrations are also directly proportional. When plotted as a normalized concentration, the resulting plots are similar. This relationship is shown in Figure 4.31. 


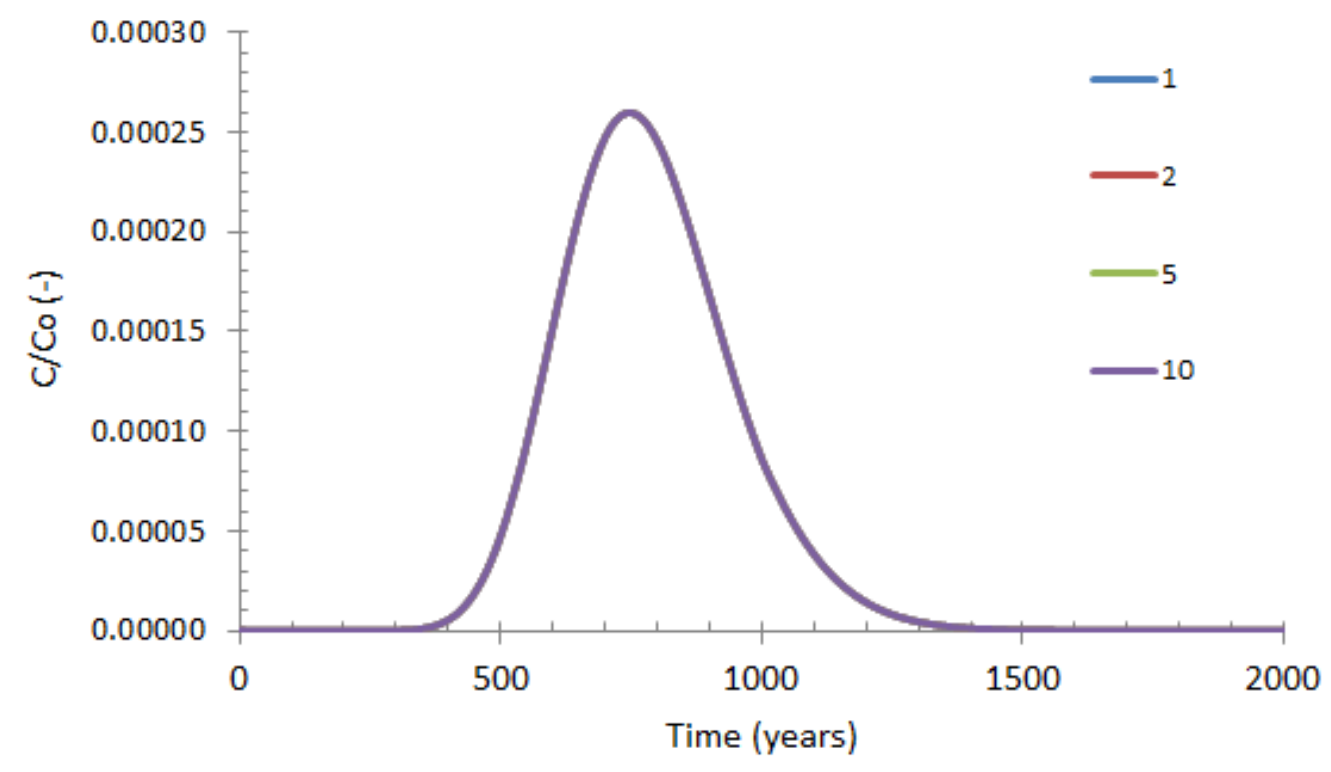

Figure 4.31. Normalized groundwater concentration over time for $C_{w d}=1,2,5$, and $101 / \mathrm{L}$.

Simulations: sandy loam with $S A_{w d}=25 \mathrm{~m}^{2}, V_{w d}=1 \mathrm{~m}^{3}, D_{w d}=1$ day, $R=3.5 \mathrm{~mm} / \mathrm{yr}$, and $L_{v}=25 \mathrm{~m}$.

\subsubsection{Waste Disposal Area}

For a given $V_{w d}$ and $C_{w d}$ at a Category I site, $S A_{w d}$ has a minimal effect on aquifer concentrations because the $M_{w d}$ does not change. Therefore, in recharge-dominated systems, the mass discharge into groundwater is very similar. This relationship is shown in Figure 4.32. 


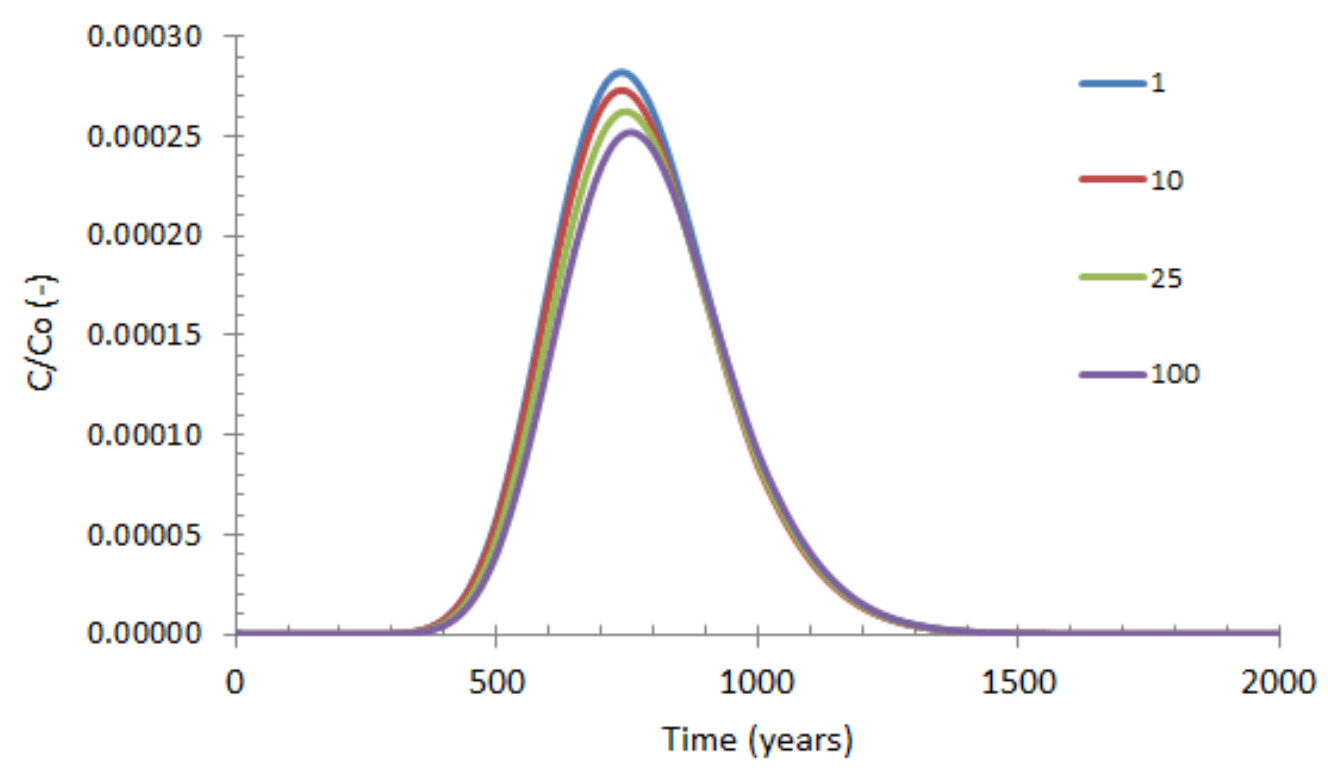

Figure 4.32. Normalized groundwater concentration over time for $S A_{w d}=1,10,25$ and $100 \mathrm{~m}^{2}$.

Simulations: sandy loam with $V_{w d}=1 \mathrm{~m}^{3}, D_{w d}=1$ day, $\mathrm{R}=3.5 \mathrm{~mm} / \mathrm{yr}$, and $L_{v}=25 \mathrm{~m}$.

\subsection{Transition from Category I to Category II}

The above analysis has focused on Category I sites, and results are characterized by a single, nearly symmetric peak of groundwater contamination that, in most cases, will occur at some time in the future. Alternatively, Category II sites are characterized by two peaks in groundwater concentration: the first peak is associated with an existing or near-term plume, and the second peak will occur in the future, similar to the peak at a Category I site. Even though groundwater concentrations below the source area are diminishing in the near term (i.e., the decline of the first peak), the contaminant mass discharge from the vadose zone will not reduce to zero and will rise again much later as part of the second contaminant breakthrough. This second peak results from contamination retained within the vadose zone that slowly migrates downwards due to surface recharge and gravity drainage. Not all sites can be defined as either a Category I or II site because volumes and/or disposal rates are too high to cause a Category I site but too low to create the characteristic double peak to qualify as a Category II site. The mass discharge of a transition site may lead to an asymmetric single peak, with a slower rise toward the peak concentration than the decline afterwards. Transition from a Category I to a Category II site may, for instance, be obtained by the increase of the disposed volume $\left(V_{w d}\right)$ as shown in Figure 4.33. For each of the plots, the disposed mass $\left(M_{w d}\right)$ is kept the same by keeping the product of $V_{w d}$ and $C_{w d}$ equal to 1 . The figure shows that a transition starts to occur at a $V_{w d}$ of $50 \mathrm{~m}^{3}$. The full simulation matrix (Appendix A) demonstrated that every Category I site can be transitioned to a Category II site by increasing the $V_{w d}$. However, the set of simulations were not sufficient to clearly identify an expression relating some of the key parameters in Table 3.1. For instance, for the same conditions shown in Figure 4.33, a Category II site is clearly obtained for $V_{w d}$ values of $25,100,500$, and $8,000 \mathrm{~m}^{3}$ for $L_{v}$ values of $10,25,50$, and 100 m. Examples for two $L_{v}$ values are shown in Figure 4.34. 


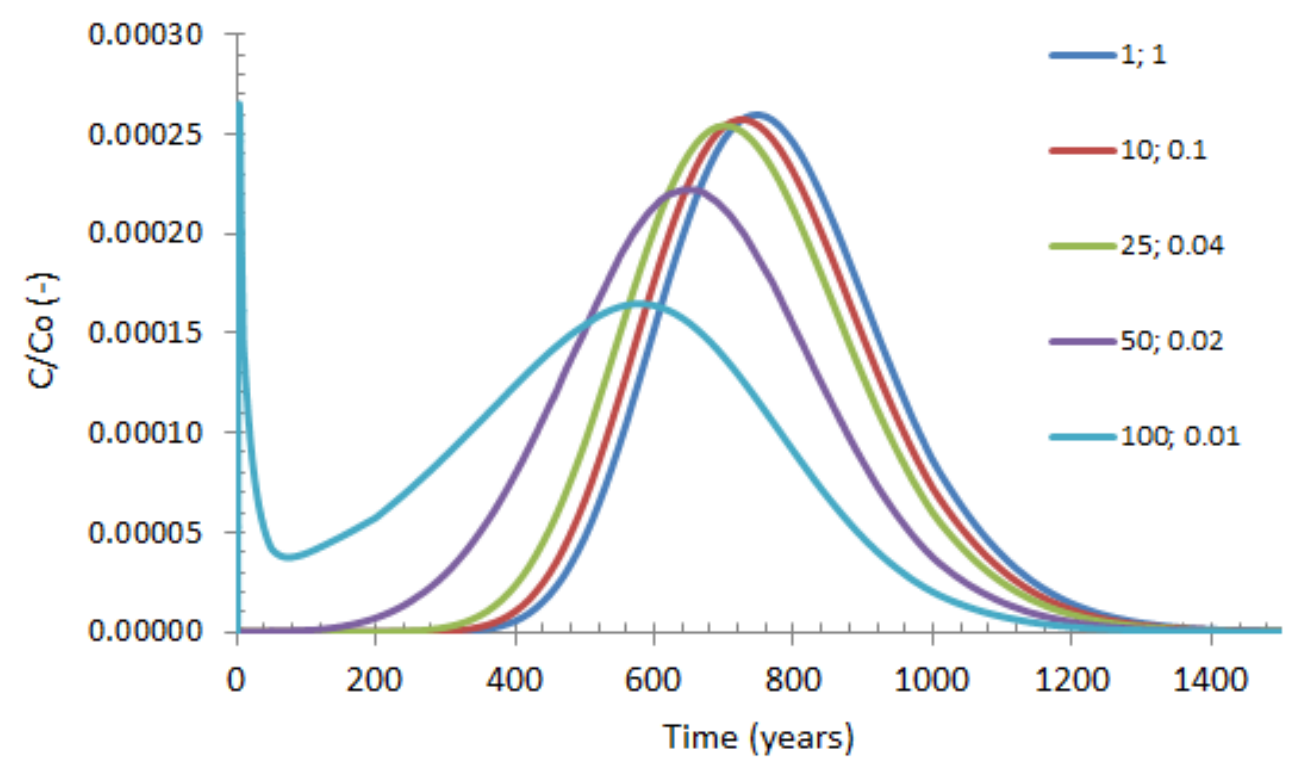

Figure 4.33. Normalized groundwater concentration over time for different waste disposal volumes with the same mass. The numbers in the legend denote $V_{w d}\left(\mathrm{~m}^{3}\right)$ and $C_{w d}(1 / \mathrm{L})$. The simulations are for sandy loam with $S A_{w d}=25 \mathrm{~m}^{2}, D_{w d}=1$ day, $\mathrm{R}=3.5 \mathrm{~mm} / \mathrm{yr}$, and $L_{v}=$ $25 \mathrm{~m}$.

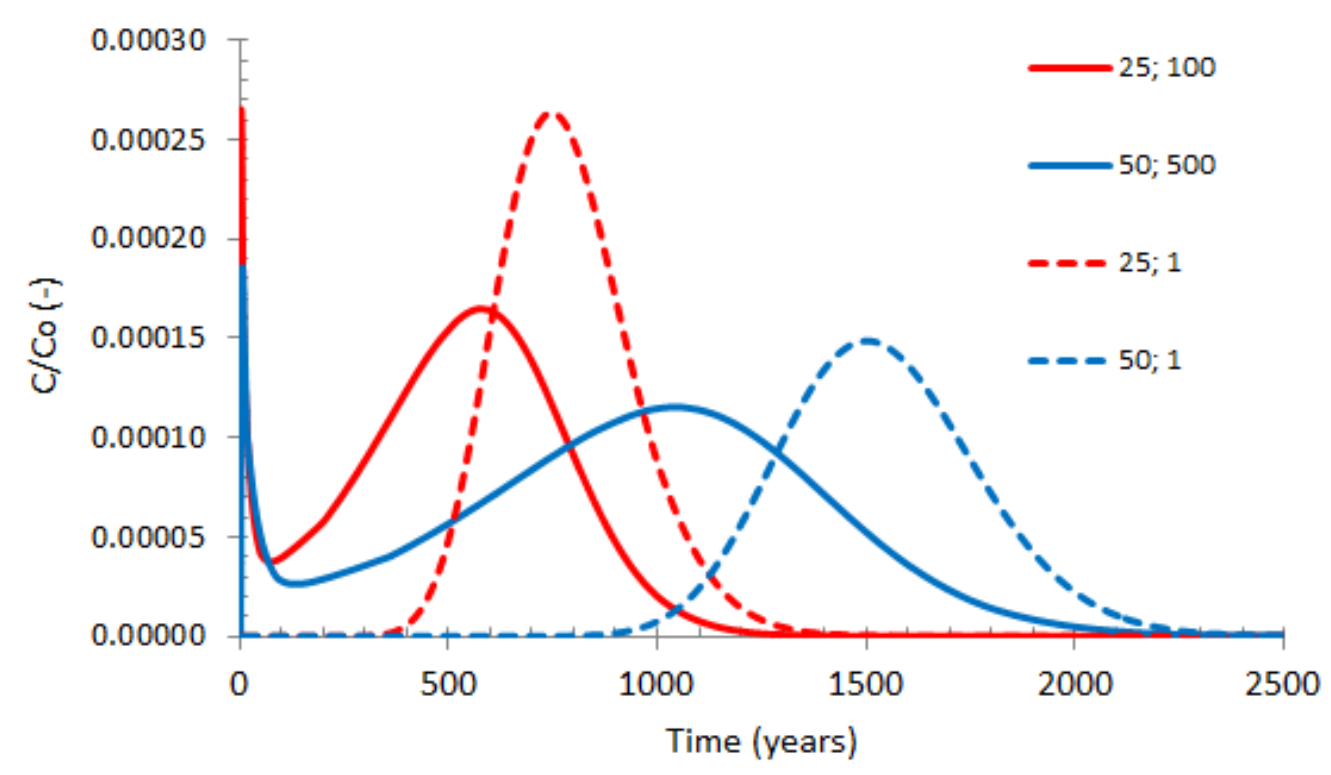

Figure 4.34. Comparison of Category I and II normalized groundwater concentrations over time for different waste scenarios with the same mass. The numbers in the legend denote $L_{v}$ and $V_{w d}$, respectively. Simulations: sandy loam with $S A_{w d}=25 \mathrm{~m}^{2}, R=3.5 \mathrm{~mm} / \mathrm{yr}$, and $D_{w d}=1 \mathrm{~m}^{3}$.

Another way to transfer from a Category I to a Category II site is by reducing the $D_{w d}$ of a given $V_{w d}$. As a result, the increased rate may, at some point, cause a direct impact on groundwater such that it would 
be classified as a Category II site. This transition is shown in Figure 4.35. However, this modification will only lead to a transition when the total volume is sufficient. For smaller volumes, even an extreme rate increase is not sufficient to create a direct groundwater impact. An interesting result is that the transition zone is relatively small in terms of $V_{w d}$ for all investigated $L_{v}$ values. An example of such a relation is shown in Figure 4.36. Although all curves show a gradual decline in peak arrival time, the rapid decline toward a Category II site is obvious for all $L_{v}$ values.

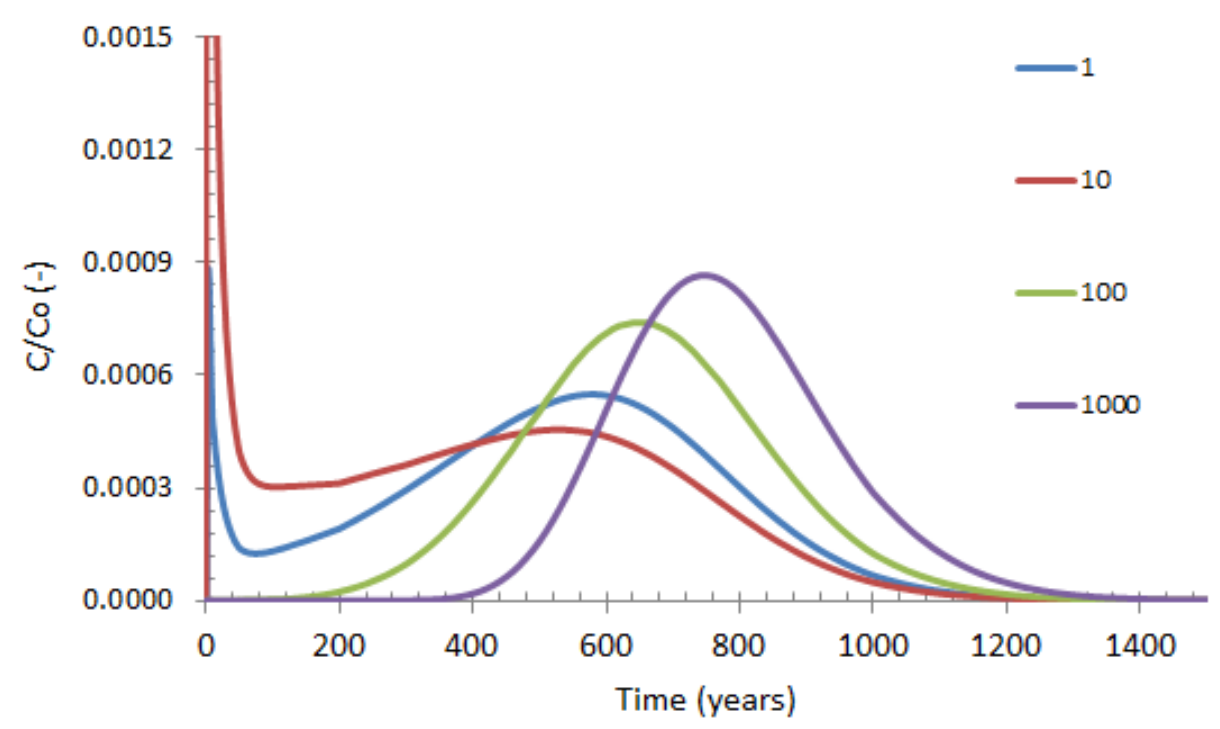

Figure 4.35. Normalized groundwater concentration over time for different waste disposal times with the same mass. The numbers in the legend denote the disposal time (in days). The simulations are for sandy loam with $S A_{w d}=25 \mathrm{~m}^{2}, V_{w d}=100 \mathrm{~m}^{3}, C_{w d}=1 / \mathrm{L},=3.5 \mathrm{~mm} / \mathrm{yr}$, and $L_{v}=$ $25 \mathrm{~m}$. 


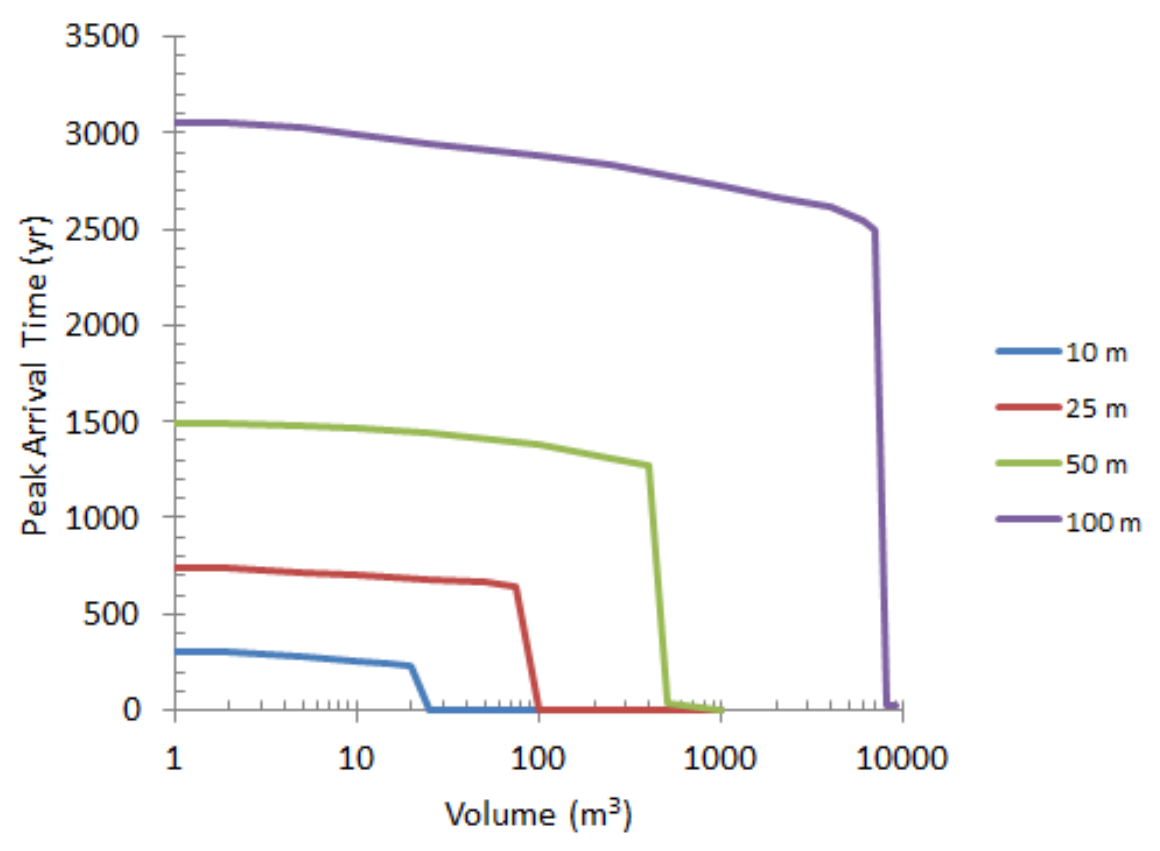

Figure 4.36. Peak contaminant arrival time as a function of $V_{w d}\left(\mathrm{~m}^{3}\right)$ for $L_{v}=10,25,50$, and $100 \mathrm{~m}$. Simulations: sandy loam with $S A_{w d}=25 \mathrm{~m}^{2}, D_{w d}=1$ day, and $R=3.5 \mathrm{~mm} / \mathrm{yr}$.

\subsection{Groundwater Parameters}

In this section, impacts of aquifer parameters (Table 3.1) on $C_{a}$ are discussed. The parameters include Darcy velocity $\left(q_{a}\right)$, contaminant mixing thickness $\left(L_{a}\right)$, porosity $\left(n_{a}\right)$, and the contaminant retardation coefficient $\left(R_{c s}\right)$. In the examples, it was assumed that the retardation coefficients and porosities are the same in the vadose zone and groundwater $\left(R_{c a}=R_{c v}\right.$ and $\left.n_{a}=n_{v}\right)$, and that $L_{a}=5 \mathrm{~m}$. The impacts of the groundwater parameters are determined by the mixing model, which uses the mass discharge data generated by the numerical model. When a mixing model is used, its simplicity leads to straightforward results, with near linearity in the response to a changing Darcy velocity (Figure 4.37), and contaminant mixing thickness in the aquifer (Figure 4.38). The impact of aquifer porosity on concentration (Figure 4.39) is negligible under most conditions. For instance, a reduction in porosity by a factor two means that the travel time through the contaminated aquifer reduces by the same factor.

Therefore, the mass discharge over this time period is halved. Because the reduced mass discharge is divided by a pore space half the size, the resulting water concentration is the same. Finally, Figure 4.40 shows that, for the same mass discharge into groundwater, concentrations for a sorbing contaminant are smaller than for a nonsorbing contaminant by a factor equal to the retardation coefficient. 


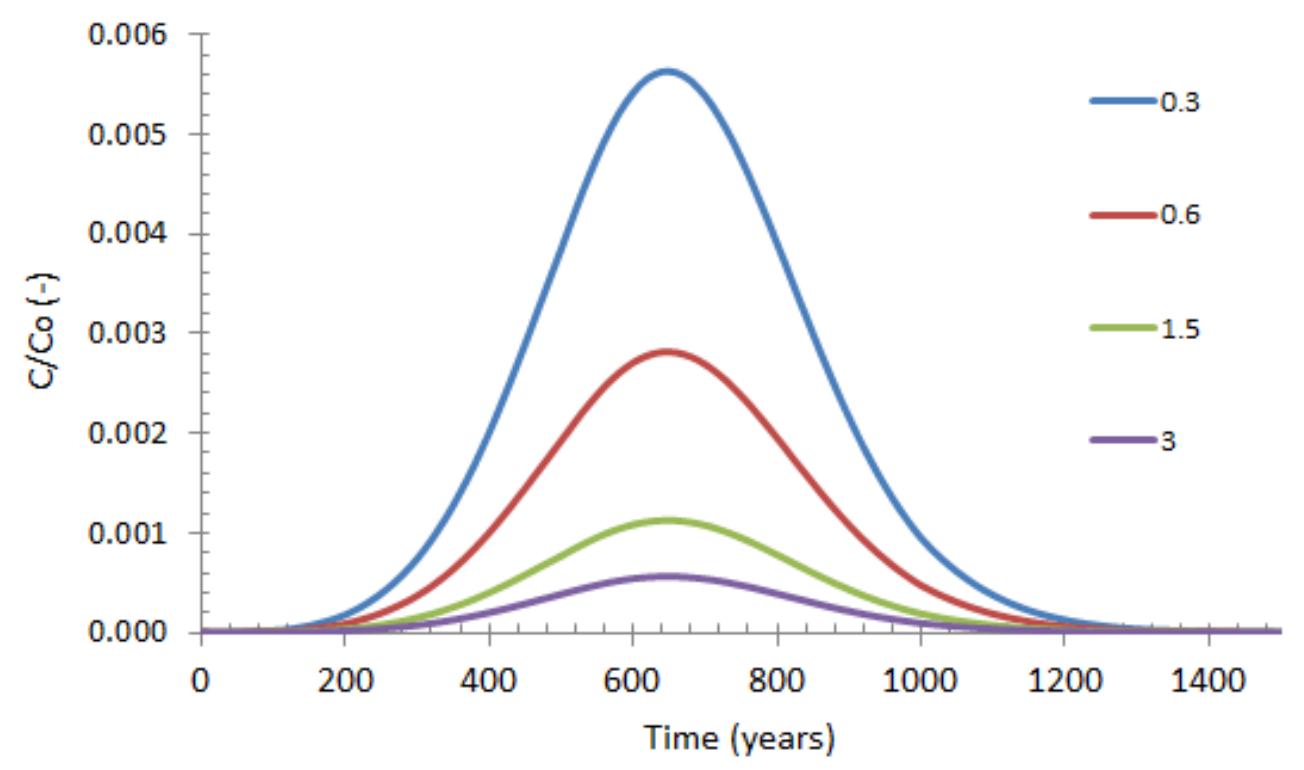

Figure 4.37. Normalized groundwater concentration over time for $q_{a}=0.3,0.6,1.5$ and $3.0 \mathrm{~m} / \mathrm{d}$.

Simulations: sandy loam with $S A_{w d}=25 \mathrm{~m}^{2}, V_{w d}=25 \mathrm{~m}^{3}, D_{w d}=1$ day, $R=3.5 \mathrm{~mm} / \mathrm{yr}$, $L_{a}=5 \mathrm{~m}$, and $L_{v}=25 \mathrm{~m}$.

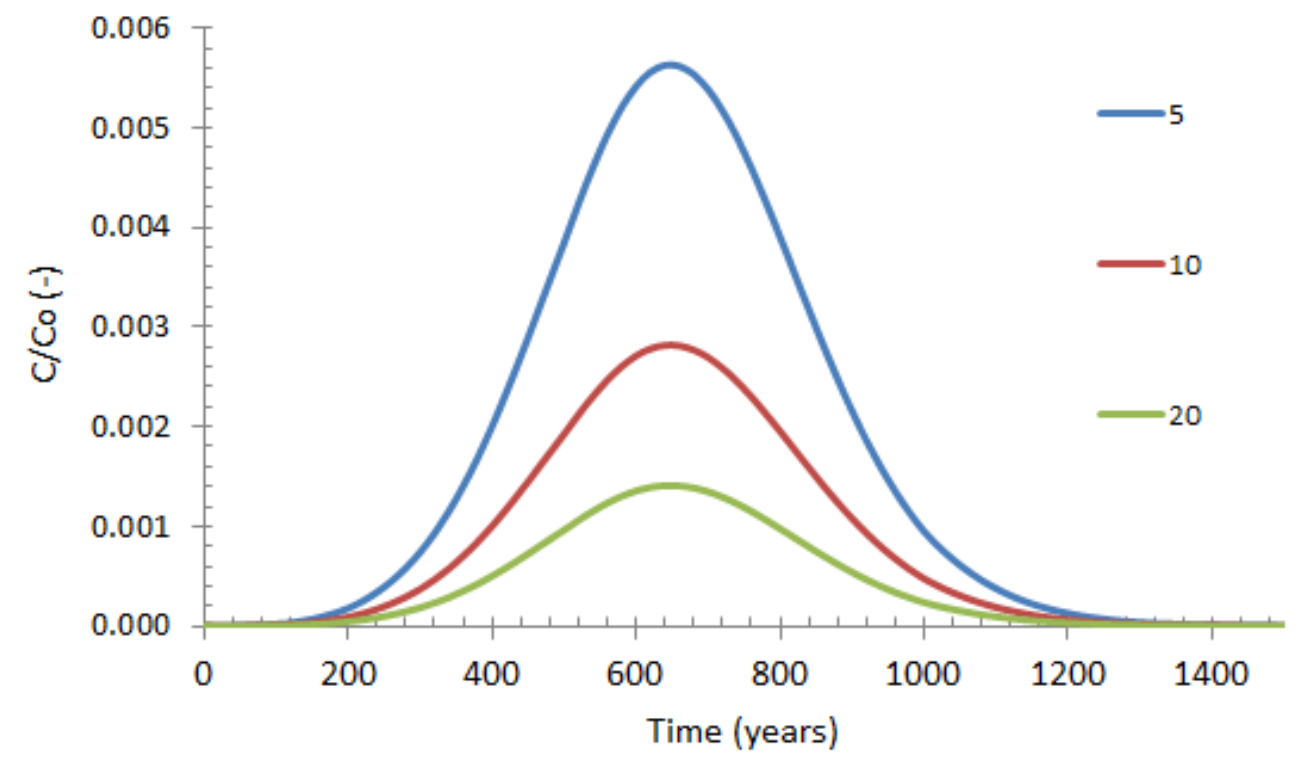

Figure 4.38. Normalized groundwater concentration over time for $L_{a}=5,10$, and $20 \mathrm{~m}$. Simulations: sandy loam with $S A_{w d}=25 \mathrm{~m}^{2}, V_{w d}=25 \mathrm{~m}^{3}, D_{w d}=1$ day, $R=3.5 \mathrm{~mm} / \mathrm{yr}, q_{a}=0.3 \mathrm{~m} / \mathrm{d}$, and $L_{v}=25 \mathrm{~m}$. 


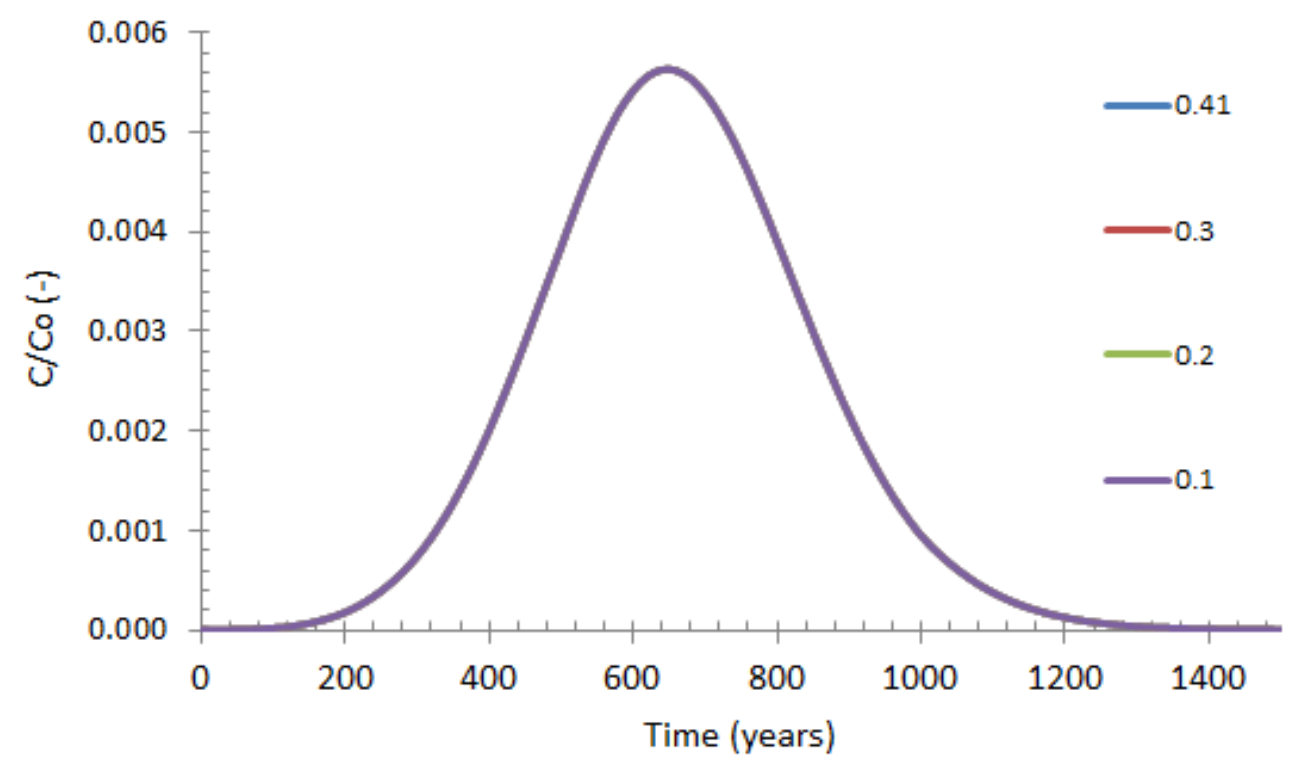

Figure 4.39. Normalized groundwater concentration over time for $n_{v}=0.1,0.2,0.3$, and 0.41 .

Simulations: sandy loam with $S A_{w d}=25 \mathrm{~m}^{2}, V_{w d}=25 \mathrm{~m}^{3}, D_{w d}=1$ day, $R=3.5 \mathrm{~mm} / \mathrm{yr}$, $q_{a}=0.3 \mathrm{~m} / \mathrm{d}, L_{a}=5 \mathrm{~m}$, and $L_{v}=25 \mathrm{~m}$.

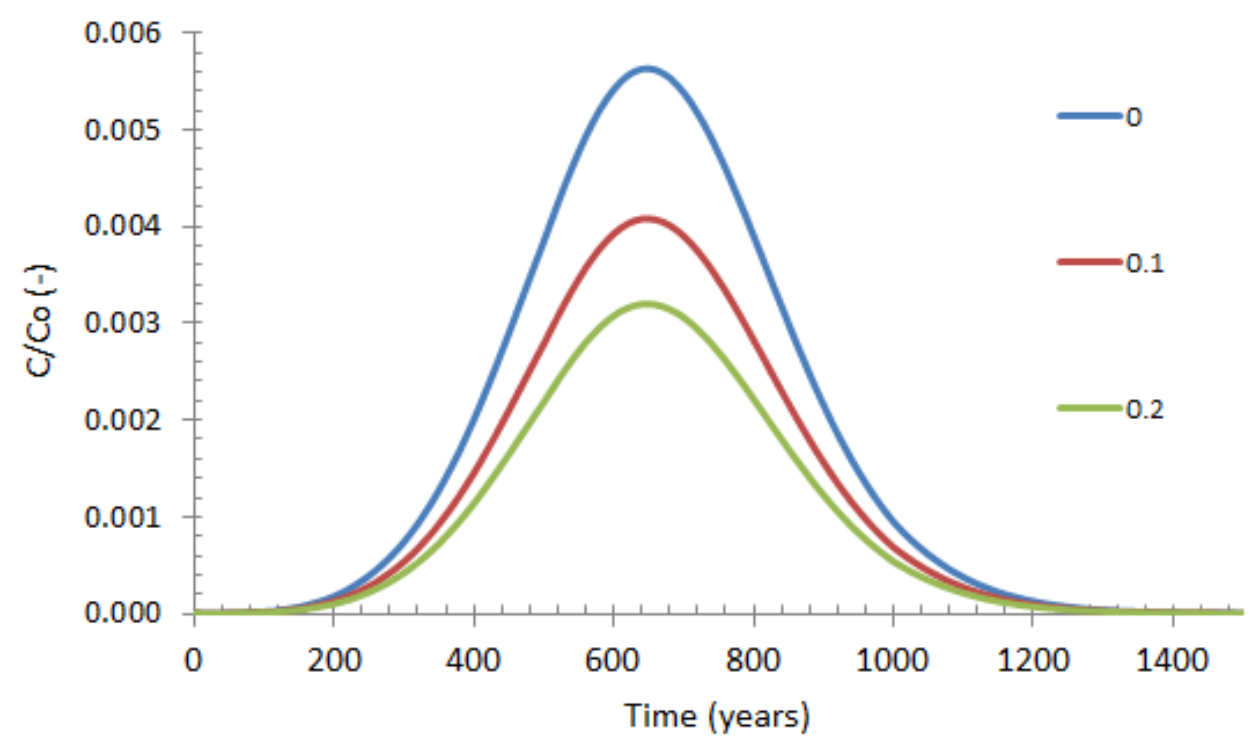

Figure 4.40. Normalized groundwater concentration over time for $K_{d}=0,0.1$, and $0.2\left(R_{a c}=1,1.38\right.$, and 1.76). Simulations: sandy loam with $S A_{w d}=25 \mathrm{~m}^{2}, V_{w d}=25 \mathrm{~m}^{3}, D_{w d}=1$ day, $R=$ $3.5 \mathrm{~mm} / \mathrm{yr}, q_{a}=0.3 \mathrm{~m} / \mathrm{d}, L_{a}=5 \mathrm{~m}$, and $L_{v}=25 \mathrm{~m}$. 



\subsection{Evaluation Procedure}

This section describes an approach to estimate transport of contaminants through the vadose zone and the resulting temporal profile of groundwater contaminant concentrations. The approach is summarized below. Subsequent sections provide additional discussion of each element.

1. Determine values of key vadose zone, waste disposal, and groundwater parameters.

2. Assess the current vertical distribution of contaminants in the vadose zone.

3. Assess the site in terms of short- and long-term impacts to groundwater.

4. Estimate contaminant travel times to groundwater.

5. Use the parameter-value estimates and impact to groundwater assessment to predict the future groundwater contaminant concentration profiles beneath the waste disposal site.

6. Evaluate uncertainty in the predictions.

\subsection{Parameter Value Estimation}

The first step in the evaluation is to estimate key vadose zone, waste disposal, and groundwater parameter values. These values are used later in the assessment to estimate contaminant travel times and groundwater concentrations. The vadose zone parameters include thickness $\left(L_{v}\right)$, recharge rate $(R)$, porosity $\left(n_{v}\right)$, water content $\left(\theta_{v}\right)$, and the contaminant retardation coefficient $\left(R_{c v}\right)$. The waste disposal parameters include volume $\left(V_{w d}\right)$, duration $\left(D_{w d}\right)$, rate $\left(R_{w d}\right)$ surface area $\left(S A_{\mathrm{wd}}\right)$, contaminant concentration $\left(C_{w d}\right)$, and total mass $\left(M_{w d}\right)$. For these parameters, two of the three parameters out of $V_{w d}, D_{w d}$, and $R_{w d}$ determine the $3^{\text {rd }}$ one. Similarly, either $M_{w d}$ or $C_{w d}$ can be obtained with knowledge of the other value and $V_{w d}$. The groundwater parameters needed to compute concentrations include contaminant mixing thickness in the aquifer $\left(L_{a}\right)$, Darcy velocity $\left(q_{a}\right)$, porosity $\left(n_{a}\right)$, and the retardation coefficient $\left(R_{c a}\right)$. In this approach, the assumption is that the monitoring screen length $(s)$ is equal to or smaller than $L_{a}$. The process for determining most of the listed parameters is straightforward. For a few parameters, such as porosity, water content, and retardation coefficients, some additional guidance is provided below.

The porosity and water content values needed in the assessment are average values over the whole vadose zone thickness or, in the case of a layered system, over each layer. Average porosity values $\left(\bar{n}_{v}\right.$ in the vadose zone and $\bar{n}_{a}$ in the aquier) can be obtained from core analyses, if available, or obtained for literature data sets (e.g., Carsel and Parrish, 1988). Average water content values $\left(\bar{\theta}_{v}\right)$ may be obtained 
by averaging neutron probe data or from other available field information (e.g., borehole sample data). Alternatively, a 1-D flow simulation may be conducted with the recharge rate as the top boundary condition and atmospheric pressure imposed at the bottom. Using generic sediment hydraulic properties from an applicable data base, simulated water contents are obtained as a function of elevation in the vadose zone. Integration of these water contents will then produce the $\bar{\theta}_{v}$ value needed for this analysis.

Values of retardation coefficients are obtained by evaluating physical/chemical interactions with sediments. Assuming a linear Freundlich relation, the average retardation coefficient in the whole vadose zone or for each layer is a function of $\bar{n}_{v}, \bar{\theta}_{v}$, and the partitioning coefficient $K_{d}$, is as follows:

$$
R_{c v}=1+\frac{\rho_{s}\left(1-\bar{n}_{v}\right) K_{d}}{\bar{\theta}_{v}}
$$

In the groundwater, the equivalent relation is:

$$
R_{c a}=1+\frac{\rho_{s}\left(1-\bar{n}_{a}\right) K_{d}}{\bar{n}_{a}}
$$

Values of $K_{d}$ are typically obtained from the literature or from site-specific batch or column leaching tests. In some cases, waste disposal chemistry may affect the retardation coefficients as discussed in Section 6.

\subsection{Contaminant Distribution Assessment}

The transport assessment in this document can be used to estimate travel times and resulting groundwater contaminant concentrations from the time of disposal. Alternatively, the current distribution of contaminants may be used as a starting point for evaluating future transport of contaminants through the vadose zone toward groundwater. The current distribution of contaminants needs to be estimated using either characterization data (e.g., borehole sample analysis of geophysical surveys), estimates of historical contaminant disposal and distribution, recharge-based simple algebraic expressions relating contaminant travel distance from the waste site to recharge rates and water contents (Section 4.1.1.5), or a combination of these methods. The current contaminant distribution can then be used to estimate transport distances from the center of contaminant mass in the vadose zone and from the current leading and trailing edges of the vadose zone contaminant distribution. In combination with information for average recharge rates and water contents, transport times can be computed from these locations using equations previously introduced and shown in Section 5.4.

The estimation of current contaminant distribution needs to include an assessment of transport and attenuation effects from biogeochemical reactions and/or physical/chemical interaction with sediments. For instance, neutralization of acidic or alkaline waste discharged to the vadose zone can dissolve sediment components with subsequent re-precipitation that can coat or bind some contaminants and render them functionally immobile (i.e., only released to the pore water with slow dissolution of lowsolubility precipitates that would occur over a very long timeframe) (e.g., Truex et al. 2014a; Szecsody et al. 2013). 


\subsection{Groundwater Impact Assessment}

The information obtained in Section 5.1 and Section 5.2 can be used to assess potential short-term impacts on groundwater. For a given vadose zone thickness, there is a disposal volume and rate above which contaminants will break through to the groundwater during, or shortly after, the disposal period. For most sites with historical disposal, this condition would be indicated by an existing groundwater contaminant plume. In this step of the assessment, data are compiled to classify the site as not having a short-term impact (Category I) or having a short-term impact, followed by an additional long-term impact (Category II). The contaminant discharge from Category I sites is predominantly transported to the groundwater due to advective processes driven by the recharge rate. Category II sites require some analyses to evaluate the portion of the contaminant mass that has or will be discharged in the short-term due to advective processes driven by the waste discharge. These Category II sites will also have contaminant mass that will be transported to the groundwater later on due to advective processes driven by the recharge rate. For some sites, the groundwater impacts are in between these two categories.

If a waste site can be classified as a Category II site, it is recommended that pseudo 3-D axisymmetric simulations, similar to those used in this document, be conducted. These types of simulations are needed to estimate the temporal profile of groundwater contaminant concentrations for a Category II site. The simulations can be performed with off-the-shelf groundwater flow and transport software. It is important to use the numerical procedures discussed in this document to produce results that are minimally affected by grid discretization and parameter value choices. However, the site may also elect to estimate the future Category II site groundwater impact using the algebraic equations for a Category I site as a bounding case. The Category II contaminant mass discharge will always occur sooner and have a lower peak concentration than what is calculated using the Category I equations. The equations relevant for a Category I site are provided in Section 5.4 and described in more detail in Section 2. This approach may provide sufficient information at some sites to support remedy decisions.

\subsection{Travel Time Predictions}

Estimates for contaminant transport parameters outlined in Section 5.1 can be used to determine contaminant arrival times in groundwater. For Category I sites, peak contaminant arrival times after disposal, for non-sorbing $\left(R_{v c}=1\right)$ and sorbing $\left(R_{v c}>1\right)$ contaminants, can be estimated by

$$
t_{p}=\frac{L_{v} \bar{\theta}_{v} R_{v c}}{R}
$$

The peak contaminant arrival time from a current vadose zone distribution, with a center of mass location, $C M$ (distance from top surface to the center of mass), can similarly be estimated using

$$
t_{p}=\frac{\left(L_{v}-C M\right) \bar{\theta}_{v} R_{v c}}{R}
$$

Mass discharge spreading in time may be estimated with values presented in Table 4.1. 
These calculations are also pertinent to the portion of the contaminant mass for Category II sites that will be transported to the groundwater by the recharge rate. The computed travel times for a Category I sites may be used as a bounding case for equivalent Category II sites (same geology and recharge conditions but with different waste disposal characteristics) because contaminant mass discharge to the groundwater for Category II always occurs sooner than at equivalent Category I sites.

\subsection{Prediction of Groundwater Concentrations}

This consolidated analysis builds on the information compiled in the previous steps to develop predicted groundwater contaminant concentration profiles. A mixing model can be applied to transform estimates of contaminant mass discharge from the vadose zone to groundwater contaminant concentration. This type of mixing approach is appropriate for local estimates of groundwater concentration within transmissive zones. Additional analysis would be needed to estimate how groundwater concentrations change during transport downgradient within the groundwater or to consider the impact of low-permeability zones within the aquifer beneath the waste disposal site. The mixing model takes into consideration parameters identified in Section 5.1, i.e., contaminant mixing thickness in the aquifer, Darcy velocity, porosity, and the retardation coefficient. The mixing model is fully described in Section 2.

\subsection{Uncertainty Evaluation}

Sensitivity analyses can be used to provide a range of estimated groundwater contaminant concentration profiles based on reasonable ranges for the transport and mixing calculation parameters. These sensitivity results can be used by decision makers to help interpret the results in terms of remedy decisions associated with these estimates. Additional information about variations in input parameters is provided in Section 4. 


\subsection{Remediation Decisions}

The preceding sections of this report provide a technical approach for estimating contaminant mass discharge from the vadose zone to the groundwater and the associated groundwater contaminant concentrations that would occur beneath the disposal site. As demonstrated by the supporting information for the approach, these estimates can be conducted for a variety of vadose zone conditions using the fundamental relationships included in the estimation method. Several factors may be important when applying the results of these estimates to remediation decisions.

1. Results need to be presented and explained in the context of the site-specific heterogeneities and other complexities.

2. In some cases, the results need to be described in the context of a Monitored Natural Attenuation (MNA) remedy for the coupled system of the vadose zone and groundwater.

3. The results may need to be interpreted in terms of the types of, and targets for, mitigation approaches in the vadose zone that would reduce the temporal profile of contaminant concentrations in groundwater.

4. Appropriate monitoring approaches to verify the estimated contaminant transport and associated predictions of groundwater contaminant concentrations may be needed.

The following sections discuss these factors and relevant actions to support remedy decisions.

\subsection{Context of the Site-Specific Heterogeneities and Other Complexities}

All waste disposal sites will have some level of heterogeneous conditions in the vadose zone. In addition, waste disposal fluids, infrastructure, or methods may add complexity to how contaminants were added to the subsurface. Use of the estimates from the vadose zone transport evaluation presented herein will need to account for any uncertainties in the estimates related to site-specific heterogeneities and other complexities. The sections below provide a discussion of several categories of system complexity and how they can be addressed. Note also that Section 2 presents scenarios relevant to some types of heterogeneities and complexities.

\subsubsection{Non-Uniform Disposal Conditions at a Single Site}

A site-specific numerical model may be needed to assess impacts to groundwater at sites with highly variable discharges that occur over a long period of time such that there are multiple release characteristics of the disposal. In these cases, the waste discharge may not be represented by the analyses in this document that are more relevant to single-release events or a discrete series of single-release events (note: the document analyses can includes single-release events of relatively long duration). 


\subsubsection{Clusters of Waste Disposal Sites with Different Type and Timing of Disposal Fluids}

Multiple waste disposal sites located in close proximity with different types of contaminants disposed at various times might lead to complex subsurface flow and transport behavior combining short-term and long-term effects as described in this document. Evaluation of subsurface contaminant transport below a particular waste disposal site within the cluster should include the consideration of disposal at the adjacent sites. To capture the complexity of such sites, analysis of vadose zone contaminant transport and impacts to groundwater may need to be addressed with 3-D numerical models. An example of a 3-D approach for multiple waste sites has been presented by Truex et al. (2015).

\subsubsection{Large Uncontaminated Water Discharges in the Vicinity of the Waste Disposal Site}

Large-scale discharges of uncontaminated water near waste disposal sites might affect the water contents, and thus the transport behavior, below the waste disposal site under consideration. The effects of additional water from adjacent sites depend on the time of the disposal. If water contents are enhanced below the site due to lateral water movement effects before waste disposal, contaminant transport toward the water table may be slower compared to transport at an unaffected site. However, if fluids from adjacent sites move beneath the site of interest during or after waste disposal, the migrating water might accelerate vertical and lateral transport. In cases where adjacent sites might affect water contents, a numerical analysis similar to that conducted in Truex et al. (2015) is appropriate to capture the potentially complex behavior of flow and transport emanating from multiple sites.

\subsubsection{Large-Scale Layered Sequences of Sediments with Contrasting Hydraulic Properties}

Contrasting hydraulic properties present in the subsurface might lead to very high water contents in lower-permeability layers and, in more extreme cases, to the development of perched water during or after waste disposal. If the disposal volume and rates are such that these layers remain unsaturated, the analysis presented in this document for Category I sites can still be used. If the conditions are such that, due to disposal volumes and hydraulic conductivity limitations, layers become saturated during (or shortly after) disposal, lateral flow will occur below waste sites and lateral contaminant spreading will occur. Numerical simulations incorporating hydraulic properties of low-permeability layers are typically needed for such sites to evaluate contaminant distribution during disposal and until the system relaxes to recharge control. Once the system relaxes to recharge control, the analyses presented in this document are appropriate (i.e., low-permeability layers will no longer affect transport).

\subsubsection{Numerous Small-Scale Lenses of Sediments with Contrasting Hydraulic Properties}

The effects described in 6.1.4 are typically enhanced in systems with numerous small-scale lenses. The likelihood that one or more of these lenses will become fully saturated during disposal (and until the system relaxes to recharge control) and limit vertical flow increases when more layers are present and disposal volumes are large. A careful analysis using stratigraphic and hydraulic property information is needed to evaluate the effects of large-volume waste disposal for these highly heterogeneous sites in 
terms of the contaminant distribution due to disposal. Once the system relaxes to recharge control, the analyses presented in this document are appropriate (i.e., low-permeability lenses will no longer affect transport).

\subsubsection{Tilted Layers or Lenses of Sediments that Promote Lateral Flow during Aqueous Disposal}

Tilted layers can enhance lateral transport during disposal until conditions relax to recharge control. For given waste site characteristics (volume, rate, etc.) the vertical flow and transport rates will decrease due to lateral migration. However, the contaminant will spread over potentially larger areas, affecting larger vadose zone volumes. Due to this enhanced spreading, the contaminant will be diluted and groundwater concentration may decrease. Once the system relaxes to recharge control, the analyses presented in this document are appropriate (i.e., tilted layers will no longer affect transport).

\subsubsection{Perched Water Systems}

Perched water systems are a special case where a subsurface feature is present that requires a saturated water hydraulic head above the feature before the water flux through the feature is equal to the water flux from above the feature. This situation and associated analysis of water fluxes for perched water systems are described in detail by Truex et al (2013) and Oostrom et al. (2013).

\subsubsection{Presence of Features that Can Promote Localized Accelerated Vertical Transport (e.g., Clastic Dikes)}

Locally accelerated vertical transport as a result of clastic dikes can promote early-time localized contaminant movement toward the groundwater. The effect of clastic dikes is likely limited to sites with large volumes disposed at high rates. Under these conditions, a Category II site might develop. Once the system relaxes to recharge control, the analyses presented in this document are appropriate (i.e., clastic dikes will no longer affect transport).

\subsubsection{Acidic or Alkaline Waste Fluids}

Acidic or basic conditions in a disposed aqueous waste fluid can induce reactions with the vadose zone sediments that impact the phase and transport behavior of contaminants. Thus, an analysis to determine the appropriate transport parameters in the context of the disposed fluid properties is needed. Information to support this analysis, with emphasis on uranium contamination, is provided by Truex et al. (2014a) and Szecsody et al. (2013).

\subsubsection{High lonic Strength Waste Fluids}

High ionic strength in a disposed aqueous waste fluid can affect the adsorption behavior of ionic contaminants. Thus, an analysis to determine the appropriate transport parameters in the context of the disposed fluid properties is needed. Information to support this analysis, with emphasis on uranium contamination, is provided by Truex et al. (2014a) and Szecsody et al. (2013). 


\subsubsection{Dense or Viscous Waste Fluids}

Advective fluid flow is strongly affected by fluid density and viscosity. Mass flux is proportional to fluid density and inversely proportional to the viscosity. It is expected that vadose zone transport will be enhanced by dense fluids but lessened by more viscous fluids. Over time, the effects of dense and viscous fluids will dissipate due to mixing with the resident vadose zone water. If density and viscosity data are available, they should be taken into consideration in the evaluation and numerical simulators that have the capability to simulate the behavior of variable density and viscosity aqueous phase fluids may be needed.

\subsubsection{Nonaqueous-Phase Liquid Waste Fluids}

Nonaqueous-phase liquids (NAPLs) are mostly immiscible with water. The assessment presented in this report does not account for the evaluation of immiscible fluids. Due to the multiphase flow and transport behavior when NAPLs are involved, an analysis based on simple algebraic equation for single phase flow, cannot be applied. In general, multifluid flow simulators are needed to improve the understanding of groundwater impacts at NAPL sites.

\subsection{MNA Evaluation}

As demonstrated and discussed in Sections 2, 3, and 4, contaminant concentrations are attenuated in the vadose zone because of unsaturated-flow processes and transport processes, and further attenuation in concentration occurs during mixing with the groundwater. Thus, describing the transport of contaminants through the vadose zone in terms of an MNA evaluation can be of benefit and provide a means for structuring a coupled evaluation of the vadose zone and groundwater. For MNA of inorganic contaminants in groundwater, the U.S. Environmental Protection Agency (EPA) technical protocol for MNA of inorganic contaminants in groundwater (EPA 2007a, 2007b, 2010, hereafter referred to as the "EPA Protocol") describes use of a tiered evaluation approach for MNA in the groundwater. This same tiered approach can be applied with respect to vadose zone contaminant transport in describing the factors that quantify this transport as a contaminant source to the groundwater. Quantifying this source is important as part of evaluating the capacity and sustainability of attenuation within the aquifer in the context of meeting the RAOs for the site. The tiered analysis in the vadose zone provides a means of determining whether natural attenuation is effective for source control as part of the groundwater remediation approach.

In quantifying the magnitude of a vadose zone source with respect to its impact on groundwater, vadose zone pore-water contaminant concentrations are not directly important; instead, the overall mass discharge of contaminants to the groundwater over time is most important (e.g., the mass flux through a defined cross-sectional area). The contaminant mass discharge from the vadose zone in combination with the flow and transport characteristics of the aquifer determines the concentrations within the resulting groundwater contaminant plume. Thus, the role of natural attenuation in the vadose zone is in limiting the contaminant mass discharge to the groundwater.

As with groundwater contamination, natural attenuation may be sufficient as the sole vadose zone remedy or can be quantified for inclusion as part of a remedy along with other measures. By using a tiered approach, as described in the EPA Protocol for groundwater, an MNA-style approach to evaluation of contaminant transport through the vadose zone can provide useful information to support remedy 
decisions. Contaminants in the vadose zone for an aqueous waste disposal site typically originate from a surface or near-surface waste release and then must move through the vadose zone to become a contaminant source to the groundwater. Thus, the fate and transport of contaminants in the vadose zone affect the character of this source and the development/evolution of groundwater plumes. Natural attenuation in the vadose zone is a mechanism of source control relative to the groundwater and could be considered sufficient to mitigate risk (e.g., a no-action alternative), or MNA may be all or part of a remedy addressing the released waste material.

For groundwater contamination, the EPA Protocol uses three progressive evaluation tiers and a final implementation tier to assess MNA as a remedy for inorganic and radionuclide contamination (Table 6.1). A parallel approach can be applied for the vadose zone as part of evaluating the vadose zone contaminant source flux component of MNA or other groundwater remedies (Table 6.2). This approach builds from the information presented by Truex and Carroll (2013) using the contaminant transport information presented above in Sections 2, 3, and 4. The first three tiers of the transport and attenuation assessment for inorganic contaminants in the vadose zone are discussed below. The performance monitoring aspect of Tier IV is covered in Section 6.4. Section 6.3 provides information that may be useful for assessing enhanced attenuation in the vadose zone as an extension of the tiered attenuation assessment for conditions where natural attenuation is not solely sufficient to meet RAOs.

Table 6.1. Summary of the EPA Protocol tiered MNA assessment for groundwater plumes (after Truex and Carroll 2013).

\begin{tabular}{|c|c|c|}
\hline Tier & Objective & Assessment \\
\hline $\mathrm{I}$ & $\begin{array}{l}\text { Demonstrate active contaminant } \\
\text { removal from groundwater. }\end{array}$ & Is the plume expanding, static, or contracting? \\
\hline II & $\begin{array}{l}\text { Determine mechanism and rate of } \\
\text { attenuation. }\end{array}$ & $\begin{array}{l}\text { Is the attenuation rate sufficient for attaining cleanup in } \\
\text { reasonable time frame? }\end{array}$ \\
\hline III & $\begin{array}{l}\text { Determine system capacity and } \\
\text { stability of attenuation. }\end{array}$ & $\begin{array}{l}\text { Is the attenuation capacity sufficient and sustainable to } \\
\text { attenuate contaminant mass to below regulatory } \\
\text { objectives? }\end{array}$ \\
\hline IV & $\begin{array}{l}\text { Design performance monitoring } \\
\text { program and identify alternative } \\
\text { remedies. }\end{array}$ & $\begin{array}{l}\text { Can monitoring be implemented to verify performance } \\
\text { and identify condition changes that may lead to } \\
\text { failure? }\end{array}$ \\
\hline
\end{tabular}


Table 6.2. Summary of the tiered transport and attenuation assessment for inorganic contaminants in the vadose zone.

\begin{tabular}{|c|c|c|}
\hline Tier & Objective & Assessment \\
\hline I & $\begin{array}{l}\text { Demonstrate that conditions are } \\
\text { suitable for recharge to be } \\
\text { considered a primary driving force } \\
\text { for contaminant transport. }\end{array}$ & $\begin{array}{l}\text { Is the current water inflow at the surface equal to or } \\
\text { less than the recharge rate (e.g., there are currently no } \\
\text { significant water discharges other than precipitation)? }\end{array}$ \\
\hline II & $\begin{array}{l}\text { Determine and quantify the factors } \\
\text { attenuating the contaminant } \\
\text { transport rate. }\end{array}$ & $\begin{array}{l}\text { Will a large percentage of the contaminant mass in the } \\
\text { vadose zone be transported toward the groundwater at } \\
\text { a rate controlled by the recharge rate and/or be } \\
\text { transported slowly due to adsorption, solubility- } \\
\text { controlled interactions, or transformations that reduce } \\
\text { contaminant concentrations (e.g., radioactive decay or } \\
\text { degradation reactions [e.g., denitrification])? }\end{array}$ \\
\hline III & $\begin{array}{l}\text { Determine temporal profile of } \\
\text { contaminant mass discharge to the } \\
\text { groundwater and resulting } \\
\text { groundwater contaminant } \\
\text { concentration profile. }\end{array}$ & $\begin{array}{l}\text { Is the contaminant mass discharge to the groundwater } \\
\text { low enough to } 1 \text { ) reach or maintain groundwater } \\
\text { contaminant concentrations below regulatory } \\
\text { objectives, or } 2 \text { ) be addressed by a groundwater } \\
\text { remedy in a reasonable time? }\end{array}$ \\
\hline IV & $\begin{array}{l}\text { Design performance monitoring } \\
\text { program and identify alternative } \\
\text { remedies. }\end{array}$ & $\begin{array}{l}\text { Can monitoring be implemented to verify performance } \\
\text { and identify condition changes that may lead to failure } \\
\text { and the need for an alternative (contingency) remedy? }\end{array}$ \\
\hline
\end{tabular}

\subsubsection{Tier I: Demonstrate that Conditions Are Suitable for Recharge to Be Considered a Primary Driving Force for Contaminant Transport}

The EPA Protocol Tier I evaluation for groundwater plumes uses evidence that natural attenuation is occurring to identify sites for which MNA may be appropriate. As described in Sections 2, 3, and 4, a key distinguishing factor for contaminant mass discharge behavior in the vadose zone is the extent to which the recharge rate controls the water advection through the vadose zone. In most cases, recharge will be or become the primary driving force for water advection. Exceptions may be where there is a continued waste or water discharge at the site in addition to rainfall. In addition, the water advection at sites that received a large volume of water in relation to the vadose zone thickness may be controlled by this water discharge for some length of time after the discharge is terminated. The information in Sections 2, 3, and 4 can help distinguish these conditions as described by Category I and Category II sites. If a groundwater contaminant plume is present, the temporal profile of contaminant concentrations may also provide insight about whether a large volume water release is still controlling the short-term water advection through the vadose zone.

If evidence indicates that recharge is a primary driving force for contaminant transport (e.g., Category I sites), then attenuation of contaminant transport in the vadose zone is likely and a continued assessment based on Tier II is appropriate. If other water sources are present or the site is still under a condition with contaminant mass discharge from the vadose zone to the groundwater controlled by a large volume water release (e.g., Category II sites), consideration of these conditions using the information in Sections 2, 3, and 4 and/or a site-specific analysis such as described by Truex et al. (2015) and Oostrom et al. (2015) are recommended prior to considering continuation with a Tier II assessment. 


\section{Tier I Summary:}

- Direct evidence showing the lack of current and future water sources other than precipitation.

- Initial assessment of leak size and vadose zone thickness with respect to the importance of leak volume to current and future contaminant mass discharge into the groundwater at the site. Sites with a low importance of the leak volume (e.g., Category I sites) can proceed directly to Tier II. Sites where the leak volume may significantly affect current or future contaminant mass discharge may need to use a more complex, site-specific analysis to quantify this affect prior to proceeding to Tier II (see Sections 2, 3, and 4).

\subsubsection{Tier II: Determine and Quantify the Factors Attenuating the Contaminant Transport Rate}

The EPA Protocol Tier II evaluation for groundwater plumes requires determining the mechanisms and rates of attenuation. For the vadose zone, there are two major components to attenuation: 1) advective and dispersive factors that affect water and contaminant flux to the groundwater and 2) transport phenomena such as sorption, solubility control, and decay/degradation that slow contaminant movement relative to water movement. Figure 6.1 illustrates the type of mechanisms that may need to be considered for natural attenuation in the vadose zone. Note that Figure 6.1 includes waste fluid properties and chemistry because, typically, wastes are directly released to the vadose zone and attenuation may be impacted by the nature of the waste material (e.g., Szecsody et al. 2013; Truex et al. 2014a). The Tier II assessment focuses on the second component of attenuation factors. Advection and dispersive processes are addressed in Tier III.

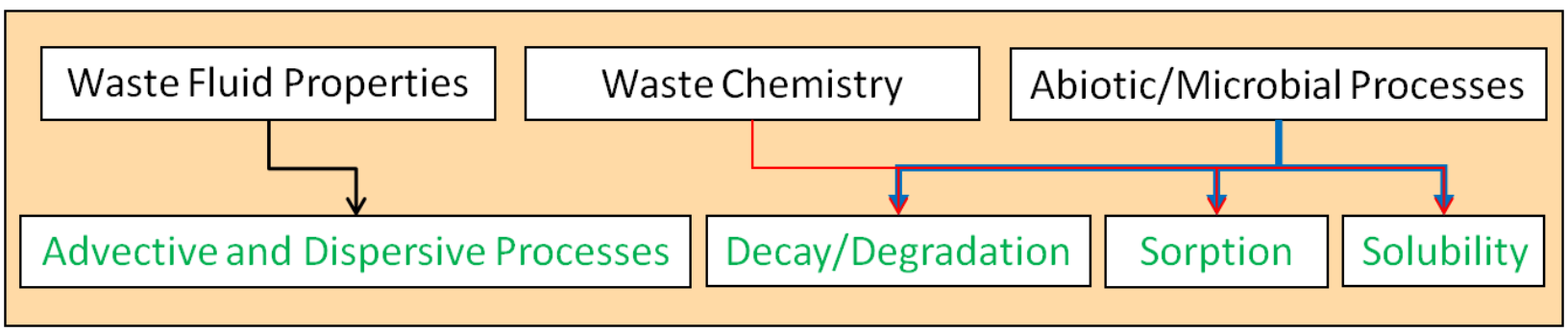

Figure 6.1. Attenuation mechanisms (green font) for inorganic contaminants in the vadose zone and factors that can impact attenuation (black font).

Several approaches can be applied to identify and describe transport parameters for a vadose zone site. Literature information may be sufficient to bound the range of parameter values for analysis of transport and would be sufficient to define the radioactive decay rate. Site-specific tests can be applied to investigate partitioning and solubility control through sequential extractions, pore-water chemistry evaluations, batch $\mathrm{K}_{\mathrm{d}}$ experiments, and soil-column leaching tests. These tests can be applied to define the portion of the contaminant inventory that is mobile and to estimate appropriate transport parameters. In some cases, there may be multiple transport parameters for different species of the same contaminant or within different portions of the vadose zone associated with different geochemical conditions (e.g., ionic strength). Degradation/transformation tests may be appropriate for contaminants such as nitrate or for contaminants such as iodine where transformation between species with differing transport properties may be important. Typically, redox changes may not be considered a long-term phenomenon for changing contaminant mobility, but may be appropriate in some cases for redox-sensitive contaminants 
(e.g., chromium or uranium). In the vadose zone, transport processes can vary with distance from the disposal location and time. For instance, Szecsody et al (2013) and Truex et al. (2014a) describe changes that occur in uranium transport when the uranium is disposed in combination with an acidic or an alkaline aqueous waste.

\section{Tier II Summary:}

- Collect data from sediment core samples or literature information that show partitioning of contaminants from the pore water to sediment-associated phases has occurred or is likely to occur.

- Quantify sorption, solubility control, and degradation/decay, taking into account changes with depth, waste disposal chemistry and abiotic/microbial processes:

- Conduct sediment and pore-water chemistry analyses.

- Perform sequential extraction analyses and contaminant partitioning or leaching experiments.

- Evaluate biogeochemical evolution with time and depth from initial waste release as appropriate.

- Evaluate the impact of waste fluid properties as appropriate.

\subsubsection{Tier III: Determine Temporal Profile of Contaminant Mass Discharge to the Groundwater and Resulting Groundwater Contaminant Concentration Profile}

The EPA Protocol Tier III evaluation for groundwater plumes focuses on two elements of natural attenuation that are important in demonstrating that MNA can meet remediation goals. First, natural attenuation effectiveness is assessed based on the capacity of an aquifer system to attenuate contaminants. The aquifer system within the zone identified for treatment (e.g., before reaching a compliance location) must be able to attenuate the amount of contaminants that are present and reach targeted concentration goals. Second, natural attenuation longevity in the aquifer is assessed. Because contaminants are left in place, it is necessary to demonstrate that the mechanisms that decrease concentrations below the identified goals will be able to maintain acceptable concentrations in the groundwater over time, under the range of hydraulic and geochemical conditions that are expected. That is, the attenuation mechanisms in the groundwater must be stable and sustainable. For the vadose zone, the capacity for and longevity of attenuation in the vadose zone controls the resulting contaminant mass discharge to the groundwater. In terms of evaluating the contaminant mass discharge in the context of a groundwater plume, the temporal profile of the discharge is also important.

Using the information obtained from Tier II evaluation, the temporal profile of contaminant mass discharge can be estimated using the approaches described herein (e.g., Sections 2, 3, and 4) or through other fate and transport analyses. Sensitivity in parameter values and potential for changes over time in conditions can be included to support interpretation of the results.

\section{Tier III Summary:}

- Compile appropriate parameters to use in the site-specific fate and transport analysis.

- Estimate the temporal profile of groundwater contaminant concentration. 
- Consider changes over time that may impact the temporal profile of groundwater contaminant concentration:

- changes in recharge rate;

- changes in pore-water chemistry that impact attenuation;

- changes in groundwater elevation or flow rate;

- changes induced by vadose zone actions (e.g., application of a surface infiltration barrier).

\subsection{Evaluating Mitigation Approaches}

When quantifying vadose zone transport and the resulting predicted concentration in groundwater beneath the waste disposal site, it may become apparent that remediation to decrease the discharge of vadose zone contaminants into the groundwater is useful as part of a coupled strategy with groundwater remediation. While a transport assessment specific to vadose zone remedy evaluation would likely be needed to finalize selection of a vadose zone remedy, the evaluation approach herein can provide some useful information.

One type of evaluation with respect to remediation would be to evaluate the effect of the recharge rate on the predicted concentrations. If it is possible to impose a recharge rate in the analysis that will meet the groundwater concentration goals, then a surface barrier and/or desiccation may be a viable vadose zone remediation strategy.

Scenarios with increased retardation of contaminants or decreasing the portion of the contaminant mass and concentration available for transport can also be investigated. In this way, targets for the magnitude of change in retardation or reduction in the functionally mobile contaminant mass (e.g., reducing mobile contaminant mass by sequestering some of the contaminants with low-solubility precipitates) can be identified. If these types of changes are predicted to meet the groundwater concentration goals, then technologies to achieve these changes can be evaluated (e.g., Dresel et al. 2011; Denham and Looney 2007; Szecsody et al. 2010a,b, 2012, 2015; Zhong et al. 2014; Truex et al. 2014b,c; Thornton et al. 2007)

\subsection{Monitoring Approaches}

For MNA in groundwater, the fourth tier of the EPA Protocol for groundwater plumes specifies designing a monitoring program using a network of wells to verify that the groundwater plume remains static or shrinks and that attenuation mechanisms are being sustained. This overall approach for groundwater is also relevant to the vadose zone in that it points to the need for verifying attenuation capacity and longevity, although the specific monitoring approach for groundwater using monitoring wells and groundwater chemistry assessment is not directly applicable in the vadose zone.

Monitoring is inherently difficult in the vadose zone because the aqueous phase involved in inorganic contaminant transport cannot be readily monitored by extracted samples and a limited number of sensors and geophysical techniques are applicable. Bunn et al. (2012) provide some insight into potential monitoring approaches for the vadose zone. The evaluation approach herein provides estimates for contaminant transport along with the associated conditions (e.g., parameter values) that can be verified as 
part of a vadose zone monitoring program and be applied in conjunction with groundwater monitoring. Recommended elements of a monitoring approach are provided below.

- Periodic neutron logging - These data are needed initially to support the transport analysis and then can be used afterward to verify moisture content distributions are behaving as expected.

- Contaminant distribution in the vadose zone - These data could be obtained with boreholes or geophysics (e.g., for contaminants that provide a change in pore-water electrical conductivity or other measureable property) and are needed initially to support the transport analysis and then can be used afterward to verify continuation of expected conditions and, in some cases, to observe the contaminant migration rate. Estimates for the center of contaminant mass and the leading edge of contamination can be useful to verify expected conditions.

- Verification of recharge or recharge changes - These data are important as initial input to the transport analysis and then afterward to gather additional data to verify the range of recharge values and to evaluate any recharge changes over time.

- Groundwater monitoring for short-term impacts - While vadose zone sources would tend to result in groundwater responses with a relatively low rate of change, monitoring should be frequent enough to verify expectations based on the predicted rate of change in the groundwater concentrations. 


\subsection{Conclusions}

An approach for evaluating transport and attenuation of inorganic contaminants in the vadose zone for aqueous waste disposal sites was developed for use in supporting remedy decisions associated with vadose zone contamination. Several aspects of this approach and associated technical foundations offer new perspectives for evaluation of vadose zone contamination, as listed below.

- Contaminant transport behavior can be categorized (i.e., Category I or Category II from Section 2) based on a set of site and waste disposal parameters, with use of groundwater plume data to corroborate the selection of a category. There are distinct characteristics of the temporal profile of groundwater contamination for each category.

- Category I sites are characterized by contaminant discharge from the vadose zone to the groundwater resulting in a single peak of groundwater contamination that, in most cases, will occur in the future. Thus, remedy decisions for Category I sites will need to consider whether the contaminant discharge from the vadose zone will cause a plume of concern and, if remediation is needed, whether a near-term vadose zone remedy or a later, longer-term groundwater remedy would be more effective.

- Category II sites are characterized by contaminant discharge from the vadose zone to the groundwater resulting in two peaks of groundwater contamination-one associated with an existing/near-term plume and one that will occur in the future, similar to a Category I site. Remedy decisions for Category II sites must consider that, even though groundwater concentrations in the source area are diminishing in the near term (i.e., the decline of the first peak), the contaminant mass discharge from the vadose zone will not decline to zero and will rise again much later as part of the second peak. Thus, near-term remedy decision must consider the nature and extent of the existing or near-term plume and how a combined vadose zone/groundwater remedy or a groundwater-only remedy can be applied to reach RAOs. In addition, when making Category II site remedy decisions a site will need to consider the continuing vadose zone source that will occur and, potentially, will be of a higher magnitude than the current source.

- Under some conditions a site may show a transitional behavior between Category I and Category II. This type of site is characterized as having near-term contaminant discharge from the vadose zone that remains somewhat steady over a period of time and then increases to a single peak later in time that is similar to what would be expected for a Category I site. Remedy decisions for a transition site would have the same type of considerations as described for Category II sites.

- For Category I sites, algebraic equations can be used to estimate the arrival time of the peak groundwater contaminant concentration beneath the vadose zone source and its concentration relative to the disposed concentration. Tabulated values for the duration of the contaminant mass discharge from the vadose zone to the groundwater (between the initial arrival and final elution of $1 \%$ of the peak concentration value) can be used to further estimate the characteristics of the vadose zone source area.

- For Category I sites, the equations provided herein may provide a sufficient estimate to guide remediation decisions, especially if sensitivity analyses are used to provide a reasonable range of estimated values. 
- For Category II sites and sites that are a transitional combination of Category I and Category II, the computed contaminant concentration profiles using the Category I equations are a bounding case where the computed values will always be for longer arrival times and higher peak concentrations than will occur for the second peak of a Category II site and for the main peak of a site that is a transitional combination of Category I and Category II.

- While nuances of site properties and waste disposal details will affect contaminant transport in the vadose zone, the technical basis for the evaluation approach presented herein suggests that reasonable estimates of vadose zone transport can be made. That is, transport of contaminants in the vadose zone is predictable under most conditions that are relevant to predicting the future contaminant mass discharge into groundwater from an aqueous disposal. In addition, a relatively small set of site and waste disposal parameters are needed to make estimates that will represent the bulk behavior of contaminant mass discharge into the groundwater. 


\subsection{References}

Bunn AL, DM Wellman, RA Deeb, EL Hawley, MJ Truex, M Peterson, MD Freshley, EM Pierce, J McCord, MH Young, TJ Gilmore, R Miller, AL Miracle, D Kaback, C Eddy-Dilek, J Rossabi, MH Lee, RP Bush, P Beam, GM Chamberlain, J Marble, L Whitehurst, KD Gerdes, and Y Collazo. 2012. Scientific Opportunities for Monitoring at Environmental Remediation Sites (SOMERS): Integrated Systems-Based Approaches to Monitoring. PNNL-21379, Pacific Northwest National Laboratory, Richland, Washington.

Carroll KC, M Oostrom, MJ Truex, VJ Rohay, ML Brusseau. 2012. "Assessing performance and closure for soil vapor extraction: Integrating vapor discharge and impact to groundwater quality." Journal of Contaminant Hydrology 128:71-82.

Carsel RF and RS Parrish. 1988. "Developing joint probability distributions of soil water retention characteristics." Water Resources Research 24:755-769.

Denham, ME and BB Looney. 2007. "Gas: A Neglected Phase in Remediation of Metals and Radionuclides.” Environmental Science \& Technology 41(12):4193-4198.

Dresel, PE, DM Wellman, KJ Cantrell, and MJ Truex. 2011. "Review: Technical and Policy Challenges in Deep Vadose Zone Remediation of Metals and Radionuclides." Environ. Sci. Technol. 45(10):42074216.

EPA (U.S. Environmental Protection Agency). 2007a. Monitored Natural Attenuation of Inorganic Contaminants in Ground Water - Volume 1, Technical Basis for Assessment. EPA/600/R-07/139, Washington, D.C.

EPA (U.S. Environmental Protection Agency). 2007b. Monitored Natural Attenuation of Inorganic Contaminants in Ground Water - Volume 2, Assessment for Non-Radionuclides Including Arsenic, Cadmium, Chromium, Copper, Lead, Nickel, Nitrate, Perchlorate, and Selenium. EPA/600/R-07/140, Washington, D.C.

EPA (U.S. Environmental Protection Agency). 2010. Monitored Natural Attenuation of Inorganic Contaminants in Ground Water - Volume 3,Assessment for Radionuclides Including Tritium, Radon, Strontium, Technetium, Uranium, Iodine, Radium, Thorium, Cesium, and Plutonium-Americium. EPA/600/R-10/093, Washington, D.C.

Mualem Y. 1976. "A new model predicting the hydraulic conductivity.” Geoderma 65:81-92.

Millington RJ and JP Quirk. 1959. "Permeability of porous media.” Nature 183:387-388.

Nimmo JR. 2005. "Unsaturated Zone Flow Processes.” In: Anderson MG and J Bear (eds), Encyclopedia of Hydrological Sciences: Part 13 Groundwater Volume 4, pp. 2299-2322. Wiley, Chichester, UK. 
Oostrom, M, MJ Truex, GV Last, CE Strickland, and GD Tartakovsky. 2015. "Evaluation of Deep Vadose Zone Contaminant Flux into Groundwater: Approach and Case Study." Submitted to Vadose Zone Journal.

Oostrom M, MJ Truex, KC Carroll, and GB Chronister. 2013. "Perched-water analysis related to deep vadose zone contaminant transport and impact to groundwater." Journal of Hydrology 505:228-239. doi:/10.1016/j.jhydrol.2013.10.001.

Oostrom M, MJ Truex, GD Tartakovsky, and TW Wietsma. 2010. "Three-dimensional simulation of volatile organic compound mass flux from the vadose zone to groundwater." Groundwater Monitoring and Remediation. doi: 10.1111/j1745-6592.2010.001285.x.

Summers K, S Gherini, and C Chen. 1980. Methodology to Evaluate the Potential for Groundwater Contamination from Geothermal Fluid Releases. EPA-600/7-8/117, U.S. Environmental Protection Agency/Industrial Environmental Research Laboratory, Cincinnati, Ohio.

Szecsody JE, MJ Truex, N Qafoku, DM Wellman, T Resch, and L Zhong. 2013. "Influence of acidic and alkaline waste solution properties on uranium migration in subsurface sediments." J. Contam Hydrol., 151:155-175. dx.doi.org/10.1016/j.jconhyd.2013.05.009.

Szecsody JE, MJ Truex, L Zhong, TC Johnson, NP Qafoku, MD Williams, JW Greenwood, EL Wallin, JD Bargar, and DK Faurie. 2012. "Geochemical and Geophysical Changes During $\mathrm{NH}_{3}$ Gas Treatment of Vadose Zone Sediments for Uranium Remediation." Vadose Zone J., 11(4). doi:

10.2136/vzj2011.0158.

Szecsody JE, MJ Truex, L Zhong, NP Qafoku, MD Williams, JP McKinley, CT Resch, JL Phillips, D Faurie, and J Bargar. 2010a. Remediation of Uranium in the Hanford Vadose Zone Using Ammonia Gas: FY10 Laboratory-Scale Experiments. PNNL-20004, Pacific Northwest National Laboratory, Richland, Washington.

Szecsody JE, MJ Truex, L Zhong, MD Williams, and CT Resch. 2010b. Remediation of Uranium in the Hanford Vadose Zone Using Gas-Transported Reactants: Laboratory-Scale Experiments. PNNL-18879, Pacific Northwest National Laboratory, Richland, Washington.

Szecsody JE, L Zhong, MJ Truex, and N Qafoku. 2015. "Remediation of Technetium in Vadose Zone Sediments Using Ammonia and Hydrogen Sulfide Gases.” Vadose Zone Journal.

doi:10.2136/vzj2014.09.0134

Thornton, EC, TJ Gilmore, KB Olsen, JT Giblin, and JM Phelan. 2007. "Treatment of a ChromateContaminated Soil Site by In Situ Gaseous Reduction." Ground Water Monitoring \& Remediation 27(1):56-64.

Truex MJ and KC Carroll. 2013. Remedy Evaluation Framework for Inorganic, Non-Volatile Contaminants in the Deep Vadose Zone. PNNL-21815, Pacific Northwest National Laboratory, Richland, WA. 
Truex MJ, M Oostrom, KC Carroll, and GB Chronister. 2013. Perched-Water Evaluation for the Deep Vadose Zone Beneath the B, BX, and BY Tank Farms Area of the Hanford Site. PNNL-22499, Pacific Northwest National Laboratory, Richland, Washington.

Truex MJ, M Oostrom, GV Last, CE Strickland, and G Tartakovsky. 2015. Evaluating Contaminant Flux from the Vadose Zone to the Groundwater in the Hanford Central Plateau: SX Tank Farms Case Study. PNNL-23737, Pacific Northwest National Laboratory, Richland, Washington.

Truex MJ, JE Szecsody, N Qafoku, and JR Serne. 2014a. Conceptual Model of Uranium in the Vadose Zone for Acidic and Alkaline Wastes Discharged at the Hanford Site Central Plateau. PNNL-23666, Pacific Northwest National Laboratory, Richland, Washington.

Truex MJ, JE Szecsody, L Zhong, JN Thomle, and TC Johnson. 2014b. Scale-Up Information for GasPhase Ammonia Treatment of Uranium in the Vadose Zone at the Hanford Site Central Plateau. PNNL23699, Pacific Northwest National Laboratory, Richland, Washington.

Truex MJ, JE Szecsody, L Zhong, and N Qafoku. 2014c. Gas-Phase Treatment of Technetium in the Vadose Zone at the Hanford Site Central Plateau. PNNL-23665, Pacific Northwest National Laboratory, Richland, Washington.

van Genuchten MT. 1980. "A Closed Form Equation for Predicting the Hydraulic Conductivity of Unsaturated Soils.” Soil Science Society of America Journal 44(5):892-898.

White MD and M Oostrom. 2006. STOMP: Subsurface Transport Over Multiple Phases, Version 4.0, User's Guide. PNNL-15782, Pacific Northwest National Laboratory, Richland, Washington.

Zhong L, JE Szecsody, MJ Truex, and MD Williams. 2014. “Ammonia Gas Transport and Reactions in Unsaturated Sediments: Implications for Use as an Amendment to Immobilize Inorganic Contaminants." J. Hazardous Materials 289:118-129. doi. 10.1016/j.jhazmat.2015.02.025. 



\section{Appendix A}

\section{Detailed Simulation Matrices}





\section{Appendix A}

\section{Detailed Simulation Matrices}

Table A.1. Overview of sandy loam simulations. Unless otherwise noted, $C_{w d}=1 / \mathrm{L}$ and $n_{v}=0.41$. For each simulation, three solutes are considered with $K_{d}=0.0,0.1$, and $0.2 \mathrm{~mL} / \mathrm{g}$.

\begin{tabular}{|c|c|c|c|c|}
\hline$V_{w d}\left(\mathrm{~m}^{3}\right)$ & $S A_{w d}\left(\mathrm{~m}^{2}\right)$ & $L_{v}(\mathrm{~m})$ & $D_{w d}$ (days) & \# of simulations \\
\hline \multicolumn{5}{|c|}{$R=3.5 \mathrm{~mm} /$ year } \\
\hline $1,2,5,10$ & $1,10,25,100$ & $10,25,50,100$ & $1,10,100$ & $192(4 \times 4 \times 4 \times 3)$ \\
\hline \multicolumn{5}{|c|}{$R=8 \mathrm{~mm} /$ year } \\
\hline $1,10,25$ & 25 & $10,25,50,100$ & 1 & 12 \\
\hline \multicolumn{5}{|c|}{$R=25 \mathrm{~mm} /$ year } \\
\hline 1,10 & 25 & $10,25,50,100$ & 1 & 8 \\
\hline \multicolumn{5}{|c|}{$R=50 \mathrm{~mm} /$ year } \\
\hline 1,10 & 25 & $10,25,50,100$ & 1 & 8 \\
\hline \multicolumn{5}{|c|}{$R=100 \mathrm{~mm} /$ year } \\
\hline 1,10 & 25 & $10,25,50,100$ & 1 & 8 \\
\hline
\end{tabular}

II. $R=3.5 \mathrm{~mm} /$ year - Category transition simulations

\begin{tabular}{ccccc}
\hline$V_{w d}\left(\mathrm{~m}^{3}\right)$ & $S A_{w d}\left(\mathrm{~m}^{2}\right)$ & $L_{v}(\mathrm{~m})$ & $D_{w d}$ (days) & \# of simulations \\
\hline $7.5,15$ & 25 & 10 & 1 & 3 \\
$15,20,25,30,50$ & 25 & 25 & 1 & 5 \\
$25,100,250,500$, & 25 & 50 & 1 & 5 \\
750 & & & & 5 \\
$100,1000,5000$, & 25 & 100 & 1 & \\
7000,8000 & & & & \\
\hline
\end{tabular}

III. $R=3.5 \mathrm{~mm} /$ year - Porosity simulations

\begin{tabular}{cccccc}
\hline$V_{w d}\left(\mathrm{~m}^{3}\right)$ & $S A_{w d}\left(\mathrm{~m}^{2}\right)$ & $L_{v}(\mathrm{~m})$ & $D_{w d}($ days $)$ & $n_{v}$ & \# of simulations \\
\hline 1,25 & 25 & $10,25,50,100$ & 1 & $0.1,0.2,0.3$, & 24 \\
\hline
\end{tabular}

$I V . R=3.5 \mathrm{~mm} /$ year - Diffusion Coefficient simulations. $D_{o}=2.5 \mathrm{e}-5 \mathrm{~cm}^{2} / \mathrm{s}$

\begin{tabular}{cccccc}
\hline$V_{w d}\left(\mathrm{~m}^{3}\right)$ & $S A_{w d}\left(\mathrm{~m}^{2}\right)$ & $L_{v}(\mathrm{~m})$ & $D_{w d}(\mathrm{days})$ & $D_{o}\left(\mathrm{e}-5 \mathrm{~cm}^{2} / \mathrm{s}\right)$ & \# of simulations \\
\hline 1,25 & 25 & 25 & 1 & $0.625,1.25,2.5$, & 10 \\
& & & & 5.0, and 10.0 & \\
\hline
\end{tabular}




\begin{tabular}{cccc}
\multicolumn{4}{c}{$V$. Contaminant distribution simulations } \\
\hline $\begin{array}{c}\text { Contaminated } \\
\text { zone location }(m \\
\text { from top })\end{array}$ & $R(\mathrm{~mm} /$ year $)$ & $\begin{array}{c}\text { \# of } \\
\text { simulations }\end{array}$ \\
\hline 10 & $2.5-7.5$ & 3.5 & 1 \\
25 & $10-15$ & $3.5,8,25,50,100$ & 5 \\
25 & $2.5-7.5$ & 3.5 & 1 \\
50 & $22.5-27.5$ & 25,50 & 2 \\
100 & $47.5-52.5$ & 3.5 & 5 \\
\hline
\end{tabular}

VI. Effects of $V_{w d}, L_{v}$, and $R$ (layered system). $D_{w d}=1$ day and $S A_{w d}=25 \mathrm{~m}^{2}$.

\begin{tabular}{ccccc}
\hline$V_{w d}\left(\mathrm{~m}^{3}\right)$ & $L_{v}(\mathrm{~m})$ & $R(\mathrm{~mm} /$ year $)$ & $\begin{array}{c}\text { Silt layer location }(\mathrm{m} \\
\text { from top })\end{array}$ & \# of simulations \\
\hline 1,25 & 10 & 3.5 & $2.5-7.5$ & 4 \\
1,25 & 25 & $3.5,8,25,50,100$ & $10-15$ & 20 \\
& & & $7.5-17.5$ & \\
1,25 & 50 & 3.5 & $22.5-27.5$ & 4 \\
& & & $20-30$ & 4 \\
1,25 & \multirow{2}{*}{100} & 3.5 & $47.5-52.5$ & $45-55$ \\
\end{tabular}


Table A.2. Overview of sand simulations. Unless otherwise noted, $C_{w d}=1 / \mathrm{L}$ and $n_{v}=0.43$. For each simulation, three solutes are considered with $K_{d}=0.0,0.1$, and $0.2 \mathrm{~mL} / \mathrm{g}$.

I. Effects of $V_{w d}, S A_{w d}, L_{v}, D_{w d}$ and $R$ (homogeneous system)

\begin{tabular}{|c|c|c|c|c|}
\hline$V_{w d}\left(\mathrm{~m}^{3}\right)$ & $S A_{w d}\left(\mathrm{~m}^{2}\right)$ & $L_{v}(\mathrm{~m})$ & $D_{w d}$ (days) & \# of simulations \\
\hline \multicolumn{5}{|c|}{$R=3.5 \mathrm{~mm} /$ year } \\
\hline $1,2,5,10$ & $1,10,25,100$ & $10,25,50,100$ & $1,10,100$ & $192(4 \times 4 \times 4 \times 3)$ \\
\hline \multicolumn{5}{|c|}{$R=8 \mathrm{~mm} /$ year } \\
\hline $1,10,25$ & 25 & $10,25,50,100$ & 1 & 12 \\
\hline \multicolumn{5}{|c|}{$R=25 \mathrm{~mm} /$ year } \\
\hline 1,10 & 25 & $10,25,50,100$ & 1 & 8 \\
\hline \multicolumn{5}{|c|}{$R=50 \mathrm{~mm} /$ year } \\
\hline 1,10 & 25 & $10,25,50,100$ & 1 & 8 \\
\hline \multicolumn{5}{|c|}{$R=100 \mathrm{~mm} /$ year } \\
\hline 1,10 & 25 & $10,25,50,100$ & 1 & 8 \\
\hline
\end{tabular}

II. $R=3.5 \mathrm{~mm} /$ year - Category transition simulations

\begin{tabular}{ccccc}
\hline$V_{w d}\left(\mathrm{~m}^{3}\right)$ & $S A_{w d}\left(\mathrm{~m}^{2}\right)$ & $L_{v}(\mathrm{~m})$ & $D_{w d}$ (days) & \# of simulations \\
\hline 7.5 & 25 & 10 & 1 & 1 \\
$15,20,25$ & 25 & 25 & 1 & 3 \\
$25,50,75$ & 25 & 50 & 1 & 3 \\
$25,50,100,150,200$ & 25 & 100 & 1 & 5 \\
\hline
\end{tabular}

III. $R=3.5 \mathrm{~mm} /$ year - Porosity simulations

\begin{tabular}{cccccc}
\hline$V_{w d}\left(\mathrm{~m}^{3}\right)$ & $S A_{w d}\left(\mathrm{~m}^{2}\right)$ & $L_{v}(\mathrm{~m})$ & $D_{w d}($ days $)$ & $n_{v}$ & \# of simulations \\
\hline 1,25 & 25 & $10,25,50,100$ & 1 & $0.1,0.2,0.3$ & 24 \\
\hline
\end{tabular}

$I V . R=3.5 \mathrm{~mm} /$ year - Diffusion Coefficient simulations. $D_{o}=2.5 \mathrm{e}-5 \mathrm{~cm}^{2} / \mathrm{s}$

\begin{tabular}{cccccc}
\hline$V_{w d}\left(\mathrm{~m}^{3}\right)$ & $S A_{w d}\left(\mathrm{~m}^{2}\right)$ & $L_{v}(\mathrm{~m})$ & $D_{w d}$ (days) & $D_{o}\left(\mathrm{e}-5 \mathrm{~cm}^{2} / \mathrm{s}\right)$ & \# of simulations \\
\hline 1,10 & 25 & 25 & 1 & $0.625,1.25,2.5$, & 10 \\
& & & & $5.0,10.0$ & \\
\hline
\end{tabular}




\begin{tabular}{cccc}
\multicolumn{4}{c}{$V$. Contaminant distribution simulations } \\
\hline $\begin{array}{c}\text { Contaminated } \\
\text { zone location }(m \\
\text { from top })\end{array}$ & $R(\mathrm{~mm} /$ year $)$ & $\begin{array}{c}\text { \# of } \\
\text { simulations }\end{array}$ \\
\hline 10 & $2.5-7.5$ & 3.5 & 1 \\
25 & $10-15$ & $3.5,8,25,50,100$ & 5 \\
25 & $2.5-7.5$ & 3.5 & 1 \\
50 & $22.5-27.5$ & 25,50 & 2 \\
100 & $47.5-52.5$ & 3.5 & 5 \\
\hline
\end{tabular}

VI. Effects of $V_{w d}, L_{v}$, and $R$ (layered system). $D_{w d}=1$ day and $S A_{w d}=25 \mathrm{~m}^{2}$.

\begin{tabular}{ccccc}
\hline$V_{w d}\left(\mathrm{~m}^{3}\right)$ & $L_{v}(\mathrm{~m})$ & $R(\mathrm{~mm} / \mathrm{year})$ & $\begin{array}{c}\text { Silt layer location }(\mathrm{m} \\
\text { from top })\end{array}$ & \# of simulations \\
\hline 1,5 & 10 & 3.5 & $2.5-7.5$ & 4 \\
1,10 & 25 & $3.5,8,25,50,100$ & $10-15$ & 20 \\
& & & $7.5-17.5$ & \\
1,10 & 50 & 3.5 & $22.5-27.5$ & 4 \\
& & & $20-30$ & 4 \\
1,10 & \multirow{2}{*}{100} & 3.5 & $47.5-52.5$ & $45-55$ \\
\end{tabular}


PNNL-24731

RPT-DVZ-AFRI-033

\section{Distribution}

U.S. Department of Energy Richland Operations Office

John Morse
Pacific Northwest National Laboratory

MJ Truex

(PDF)

M Oostrom

(PDF)

DM Wellman

(PDF)

MH Lee

(PDF)

Distr.1 


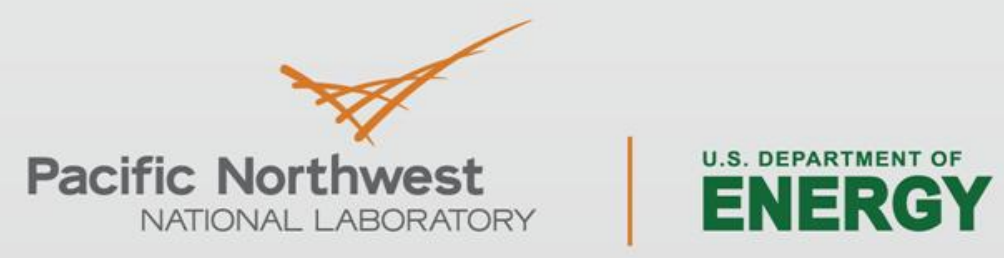

Proudly Operated by Battelle Since 1965

902 Battelle Boulevard

P.O. Box 999

Richland, WA 99352

1-888-375-PNNL (7665)

www.pnnl.gov 